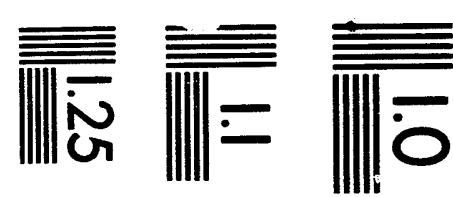

$$
\begin{aligned}
& \text { ||| } \\
& \text { 需市 }
\end{aligned}
$$



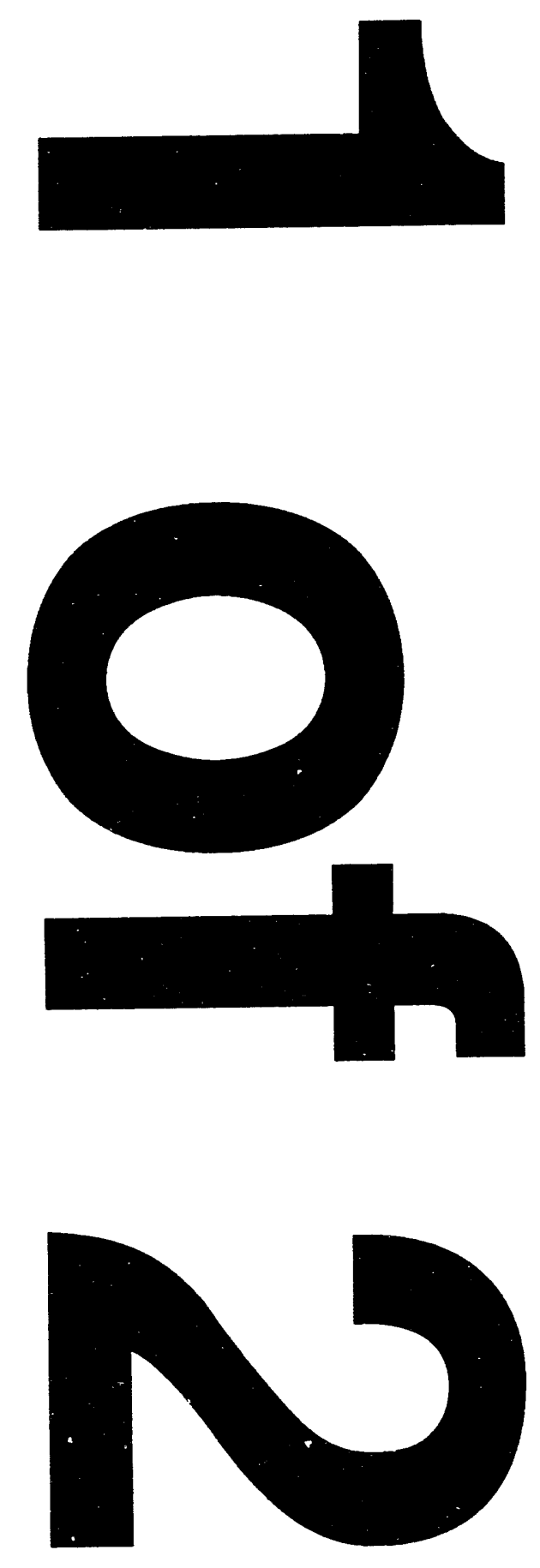


\title{
Interstitially Stabilized Phases in the Zirconium-Nickel system
}

\author{
by Richard Mackay
}

\section{thesis submitted to Iowa State University}

\author{
Ames Laboratory, U. S. DOE \\ Iowa State University \\ Ames, Iowa 50011
}

Date Transmitted: July 1993

\author{
Prepared for the U. S. Department of Energy \\ Under contract no. W-7405-eng-82.
}

\section{DISCLAIMER}

\begin{abstract}
This report was prepared as an account of work sponsored by an agency of the United States Government. Neither the United States Government nor any agency thereof, nor any of their employees, makes any warranty, express or implied, or assumes any legal liability or responsibility for the accuracy, completeness, or usefulness of any information, apparatus, product, or process disclosed, or represents that its use would not infringe privately owned rights. Reference herein to any specific commercial product, process, or service by trade name, trademark, manufacturer, or otherwise does not necessarily constitute or imply its endorsement, recommendation, or favoring by the United States Government or any agency thereof. The views and opinions of authors expressed herein do not necessarily state or reflect those of the United States Government or any agency thereof.
\end{abstract}


Interstitially stabilized phases in the zirconium - nickel system

by

Richard Alan Mackay

An Abstract of

A Dissertation Submitted to the

Graduate Faculty in Partial Fulfillment of the

Requirements for the Degree of

DOCTOR OF PHILOSOPHY

Approved:

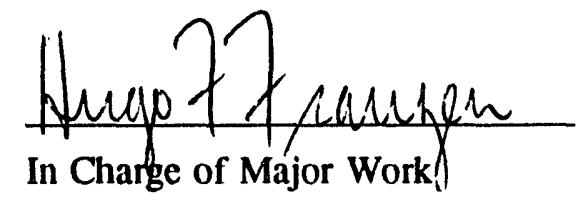

Eor the Major Department

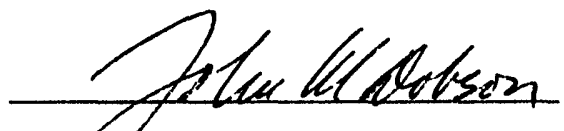

For tho Graduate College

lowa State University

Ames, Iowa

1993 
Interstitially stabilized phases in the

zirconium - nickel system

Richard Alan Mackay

\section{Under the supervision of Hugo F. Franzen \\ From the Department of Chemistry \\ Iowa State University}

A study of the effect of the addition of nonmetal interstitial atoms to zirconium - nickel compounds has led to the discovery of several new phases and the elucidation of general features of the bonding within these phases. In addition to the new phases discovered, a single crystal X-ray study was carried out for the previously reported compound $\mathrm{Zr}_{3} \mathrm{NiO}(\mathrm{Cmcm}, \mathrm{a}=3.353 \AA, b=11.013 \AA$, $c=8.755 \AA)$.

$\mathrm{Zr}_{4} \mathrm{Ni}_{2} \mathrm{O}$ is a high temperature phase, forming in samples annealed at $1250^{\circ} \mathrm{C}$. It crystallizes with the filled $\mathrm{Ti}_{2} \mathrm{Ni}$ type structure ( $\left.\mathrm{Fd} \overline{3} \mathrm{~m}, \mathrm{a}=12.1970 \AA\right)$. Band calculations of the extended Hückel type led to the prediction and then confirmation of additional phases in more electron rich systems. Other phases studied by single crystal $\mathrm{X}$-ray diffraction are $\mathrm{Zr}_{6} \mathrm{Ni}_{4} \mathrm{Ti}_{2} \mathrm{O}_{0.6}(\mathrm{a}=12.0299 \AA), \mathrm{Nb}_{6} \mathrm{Ni}_{6} \mathrm{O}$ $(a=11.2117 \AA)$, and $\mathrm{Nb}_{6} \mathrm{Ni}_{4} \mathrm{Ta}_{2} \mathrm{O}_{2}(a=11.5813 \AA)$. Phases identified by powder diffraction film data are $\mathrm{Nb}_{4} \mathrm{Ni}_{2} \mathrm{O}(\mathrm{a}=11.5933 \AA), \mathrm{Zr}_{4} \mathrm{Cu}_{2} \mathrm{O}(\mathrm{a}=12.2659 \AA)$, and $\mathrm{Zr}_{6} \mathrm{Co}_{4} \mathrm{Ti}_{2} \mathrm{O}(\mathrm{a}=11.8649 \AA)$. The band calculations do not explain the differences of oxygen ordering observed within these phases, but they do point out several features of general bonding characteristics.

New zirconium kappa phases, in space group $\mathrm{P}_{3} / \mathrm{mmc}$, have been found. These new phases are $\mathrm{Zr}_{9} \mathrm{Mo}_{4} \mathrm{SO}_{\mathrm{x}}(\mathrm{a}=8.685 \AA, \mathrm{c}=8.571 \AA), \mathrm{Zr}_{9} \mathrm{~W}_{4} \mathrm{SO}_{\mathrm{x}}(\mathrm{a}=8.671 \AA, \mathrm{c}=8.607 \AA)$, and $\mathrm{Zr}_{9} \mathrm{~W}_{4}(\mathrm{~S}, \mathrm{Ni}) \mathrm{O}_{3}$ $(\mathrm{a}=8.688 \AA, \mathrm{c}=8.558 \AA)$. Kappa phases show the ability of filling both trigonal prismatic and octahedral sites simultaneously. Sulfur and nickel also demonstrate the ability to substitute on the same site. 
A new structure type was discovered with the compound $\mathrm{Zr}_{6} \mathrm{Ni}_{6} \mathrm{TiSiO}_{1.8}$. This structure consists of a metal framework of zirconium and nickel, with titanium and silicon filling icosahedral sites. The structure can be viewed as a distortion of the kappa phase $(\mathrm{P} \overline{3} \mathrm{~m} 1, a=8.2778 \AA$, $c=7.441 \AA)$.

A common feature in all of these interstitially stabilized phases is the coordination of oxygen in zirconium octahedra. There are no nickel - oxygen interactions. In $\mathrm{Zr}_{3} \mathrm{NiO}$ the octahedra share vertices and edges. In all of the new phases they share faces. The face sharing octahedra form large rings, forming two - dimensional networks in the kappa phases and $\mathrm{Zr}_{6} \mathrm{Ni}_{6} \mathrm{TiSiO}_{1.8}$, and a three - dimensional network in the $\mathrm{Ti}_{2} \mathrm{Ni}$ type structures. Icosahedral units fill the spaces between the octahedral networks. 
Interstitially stabilized phases in the zirconium - nickel system

by

Richard Alan Mackay

A Dissertation Submitted to the

Graduate Faculty in Partial Fulfiliment of the

Requirements for the Degree of

DOCTOR OF PHILOSOPHY

$\begin{aligned} \text { Department: } & \text { Chemistry } \\ \text { Major: } & \text { Inorganic Chemistry }\end{aligned}$

Approved:

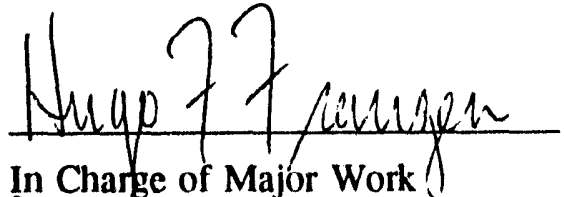

In Charge of Major Work?

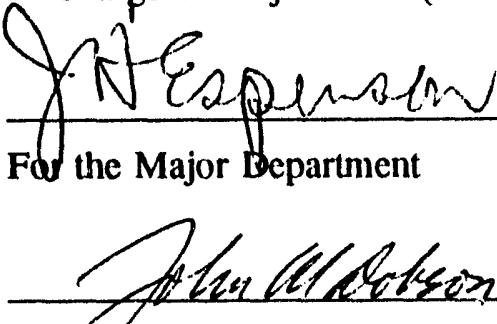

For the Graduate College

Iowa State University

Ames, lowa 
TABLE OF CONTENTS

INTRODUCTION

EXPERIMENTAL TECHNIQUES

Synthesis $\quad 12$

$\begin{array}{ll}\text { Characterization } & 17\end{array}$

$\begin{array}{lr}\text { Calculations } & 18\end{array}$

SINGLE CRYSTAL X-RAY STUDY OF $\mathrm{Zr}_{3} \mathrm{NiO}$

Introduction $\quad 20$

Experimental Details $\quad$. 20

Results and Discussion $\quad 21$

NEW OXIDES OF THE FILLED Ti ${ }_{2} \mathrm{Ni}$ TYPE STRUCTURE

Introduction $\quad 29$

Experimental Details 38

Results $\quad 39$

Band Calculations $\quad 50$

$\begin{array}{ll}\text { Discussion } & 62\end{array}$

NEW ZIRCONIUM KAPPA PHASES

Introduction $\quad 71$

Experimental Details $\quad 79$

$\begin{array}{ll}\text { Results and Discussion } & 79\end{array}$

$\mathrm{Zr}_{6} \mathrm{Ni}_{6} \mathrm{TiSiO}_{\mathrm{x}}$ : A NEW STRUCTURE TYPE WITH A MIXED

EARLY-LATE TRANSITION METAL FRAMEWORK

$\begin{array}{ll}\text { Introduction } & 87\end{array}$

Experimental Details $\quad 88$

$\begin{array}{lr}\text { Results } & 90\end{array}$

$\begin{array}{lr}\text { Discussion } & 101\end{array}$

IDEAS FOR FUTURE RESEARCH 105

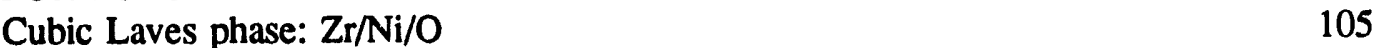

Hexagonal Laves phase: $\mathrm{Zr} / \mathrm{Ti} / \mathrm{Ni} \quad 106$

New phase in $\mathrm{Zr} / \mathrm{W} / \mathrm{Ni} / \mathrm{O}$ system $\quad 109$

New phase in $\mathrm{Zr} / \mathrm{Ni} / \mathrm{S}$ system 109

Vaporization study of $\mathrm{Nb}_{4} \mathrm{Ni}_{2} \mathrm{O} \quad 111$

REFERENCES CITED $\quad 112$

$\begin{array}{ll}\text { ACKNOWLEDGEMENTS } & 118\end{array}$

APPENDIX: OBSERVED AND CALCULATED STRUCTURE FACTOR AMPLITUDES 119 


\section{INTRODUCTION}

The investigation of metal rich sulfides of the early transition metals has led to the discovery of several new compounds and has necessitated new explanations in the theory of bonding in extended solids. To illustrate this point, a report published in 1964 stated the compound $\mathrm{Ti}_{2} \mathrm{~S}$ would be thermodynamically unstable with respect to disproportionation to the elements or to TiS and $\mathrm{Ti}$, and hence would not form [1]. The thermodynamic calculations were based on the Kapustinskii equation [3] for an ionic model of bonding. Shortly afterwards, the crystal structure of $\mathrm{Ti}_{2} \mathrm{~S}$ was solved [2]. The structure of $\mathrm{Ti}_{2} \mathrm{~S}$ is very different from an ionic compound where Coulombic interactions between the metal and nonmetal provide the significant stabilizing force. The high coordination of titanium and the short titanium-titanium distances are evidence of the strong metalmetal interactions involved in this metal-rich sulfide and these interactions are not accounted for by considering only Coulombic interactions. The ability to calculate properties and predict the chemistry in this class of metal rich compounds depends on the ability to determine the effect of the presence of extensive metal-metal bonding, a factor not included in the ionic model. While the ability to predict new compounds and structures still lies in the future, the discovery of so many new materials with extensive regions of metal-metal bonding has motivated chemists to explain the electronic and structural features in these compounds. Before proceeding further, the term metal-rich should be defined more clearly. For any compound $\mathrm{M}_{\mathrm{x}} \mathrm{X}_{\mathrm{y}}$, where $\mathrm{M}$ is a metal atom and $\mathrm{X}$ is a nonmetal atom, one can quickly determine if $x>y$, however, this criterion tells nothing about the extent of metal-metal bonding or coordination environment of the metal. As it is the strength of this metal-metal bonding that is essential for the formation of these phases, a better criterion is the condition $\Sigma \mathrm{n}(\mathrm{M}-\mathrm{M}) / \Sigma \mathrm{n}(\mathrm{M}-\mathrm{X})>1$, where $\mathrm{n}$ is the Pauling bond order [4], as determined by the equation $d(n)=d(1)-0.6 \log n$. Because of the empirical nature of this equation the individual bond orders calculated mean little by themselves, but the bond orders scale as indications of bond 
strengths, and the comparison of the sum of all the metal-metal interactions with the sum of all the metal-nonmetal interactions does yield a meaningful definition of metal-rich compounds. With this in mind, the new oxygen stabilized phases found in this research are viewed as oxidized intermetallics rather than reduced metal oxides.

A number of metal-rich compounds have been discovered in this lab alone. Considering just the binary sulfides of the Group 4 and Group 5 elements, they include $\mathrm{Ti}_{2} \mathrm{~S}$ [2], $\mathrm{Ti}_{8} \mathrm{~S}_{3}[5], \mathrm{Zr}_{2} \mathrm{~S}[6]$, $\mathrm{Zr}_{21} \mathrm{~S}_{8}[6], \mathrm{Zr}_{9} \mathrm{~S}_{2}$ [7], $\mathrm{Hf}_{2} \mathrm{~S}$ [8], $\mathrm{Nb}_{21} \mathrm{~S}_{8}$ [9], $\mathrm{Nb}_{14} \mathrm{~S}_{5}$ [10], $\mathrm{Ta}_{2} \mathrm{~S}$ [11], $\alpha-\mathrm{Ta}_{6} \mathrm{~S}$ [12], $\beta-\mathrm{Ta}_{6} \mathrm{~S}[13$ ]. Other groups in other laboratories have contributed to this work, synthesizing additional new compounds, such as a low temperature binary phase, $\mathrm{Ta}_{3} \mathrm{~S}_{2}[14]$, and carrying out theoretical band energy calculations [15]. The results are immensely interesting and surprising. For example, for a given stoichiometry, $\mathrm{M}_{2} \mathrm{~S}$, the phases $\mathrm{Ti}_{2} \mathrm{~S}, \mathrm{Zr}_{2} \mathrm{~S}, \mathrm{Hf}_{2} \mathrm{~S}, \mathrm{Ta}_{2} \mathrm{~S}$ exist. Within Group 4, the titanium and zirconium phases have the same structure, roughly based on bcc units in the metal framework. Dihafnium sulfide has a unique hexagonal structure, with close packed layers in the order $\mathrm{ABACBC}$ for Hf-S-Hf-Hf-S-Hf layers. In Group 5, the structure of the tantalum phase is different from either of those in Group 4, being built of chains of interpenetrating icosahedra. No phases of this stoichiometry form at all for vanadium or niobium. All of the phases are characterized by high sulfur coordination, often with capped trigonal prismatic coordination, and with sulfur occuring as a substituent on metal sites in bcc fragments. The tantalum sulfides have distinctive icosahedral chains. The zirconium and niobium phases are built up of bcc units. The compounds formed by the elements grouped together within a column of the Periodic Table are distinguished as much by their differences as by their similarities, if not more so. Naturally, it is these differences that are of interest to the chemist.

Exploiting the differences between the tantalum sulfides and the niobium sulfides, X.Yao discovered several new ternary metal rich compounds in the $\mathrm{Ta} / \mathrm{Nb} / \mathrm{S}$ system [16-19]. These 
compounds form only in the termary system and form structures stabilized entropically by a mixing of tantalum and niobium on the metal sites. The results of band calculations on two of these phases indicate also the importance of the relative strength of the metal-metal and the metal-nonmetal bonds in determining the ordering of niobium and tantalum on the mixed metal sites [19]. This result has been generalized to include several mixed-metal phosphides and sulfides [20]. Similarly, an investigation of mixed-metal sulfides of mixed Group 4 and Group 5 metals has yielded exciting results. A new structure $\mathrm{Hf}_{10} \mathrm{Ta}_{3} \mathrm{~S}_{3}$ is related to the gamma brass structure, with sulfur filling large channels. Other phases, such as $\mathrm{Zr}_{9} \mathrm{Ta}_{4} \mathrm{~S}_{4-\mathrm{x}}$, are new examples of kappa phases, with metal frameworks made up of early transition metals [21]. In a like manner, there are investigations on the mixing of sulfur and selenium in metal rich systems. That is to say, $\mathrm{Ta}_{2} \mathrm{~S}$ and $\mathrm{Ta}_{2} \mathrm{Se}$ have different structures, so the temary $\mathrm{Ta} / \mathrm{S} / \mathrm{Se}$ system is not necessarily expected to contain large solid solubility regions, and the ternary system may include interesting new phases [22].

The formation of these metal-rich compounds has always involved the early transition metals. The specific examples cited so far have been from Groups 4 and 5 . Binary metal-rich compounds are not known to form for the later transition metals [23]. The ability of the early transition metals to fill vacant d-orbitals in forming metal-nonmetal bonds through interactions with the nonmetal, and maintain significant metal-metal bonding seems a necessary condition for the formation of these compounds. As the late transition metals have few vacant orbitals they do not meet this condition and binary metal rich sulfides of late transition metals do not form.

The question arises of what might happen in temary compounds with mixed early transition metal-late transition metal frameworks. Although initially begun as an effort to place iron group metals in the sulfur - lined channels of the $\mathrm{Ta}_{2} \mathrm{~S}$ structure, the discovery of $\mathrm{M}_{2} \mathrm{Ta}_{9} \mathrm{~S}_{6}$ (where $\mathrm{M}=$ $\mathrm{Fe}, \mathrm{Co}, \mathrm{Ni})$ suggested new possibilities in structures and properties of metal rich compounds $[24,25]$. Significantly, the structure contains only M-Ta, Ta-Ta, and Ta-S interactions, but no M-S 
interactions. The structure consists of a hexagonal metal network, with large channels lined by sulfur atoms, a feature similar to $\mathrm{Ta}_{2} \mathrm{~S}$. A theoretical band structure calculation suggests that filling the sulfur-lined channels of $\mathrm{M}_{2} \mathrm{Ta}_{9} \mathrm{~S}_{6}$ with metal atoms might be energetically favorable [26]. This suggestion neglects the inference that these channels are not void regions at all; they contain nonbonding, lone pair orbitals of sulfur. The sulfur atoms are separated by van der Waals' contacts within the channels. Presumably that is why the addition of the metal $\mathrm{M}$ atoms to $\mathrm{Ta}_{2} \mathrm{~S}$ caused a rearrangement of the structure, rather than a filling of the channels. Additional new ternary phases include $\mathrm{Nb}_{9} \mathrm{Ni}_{2-\mathrm{x}} \mathrm{S}_{3+\mathrm{x}}[27]$ and $\mathrm{M}_{2} \mathrm{Ta}_{11} \mathrm{Se}_{8}$ (where $\mathrm{M}=\mathrm{Fe}, \mathrm{Co}, \mathrm{Ni}$ ) [28]. These results in the ternary systems of mixed early and late transition metals again confirm the differences that exist in chemical behaviour between niobium and tantalum, as was found in the binary sulfides.

The research project described in this dissertation began as an investigation of the temary system of mixed early-late transition metal compounds involving zirconium rather than niobium or tantalum as the early transition metal. Based on the known binary phases of metal-rich sulfides, and the observed differences between the Group 4 and Group 5 compounds, as well as the novel features in the temary phases, there was no way of predicting what phases might form, but it was highly probable new phases would form.

This research has in fact led to the discovery of several new phases: The results, however, have taken a somewhat different path than the work previously described. Several new phases have been discovered, but rather than new sulfides, these phases are all new oxides. The presence of oxygen, adventitious or not, is a well documented problem in the synthesis of solid state compounds. Modern instrumentation has increased the solid-state scientists' capability of detecting the presence of small impurity atoms in samples. For example, the intensity of X-ray diffraction depends on the amount of electron density within the unit cell of the crystal, and the geometrical distribution of the electron density. Light elements such as oxygen have less electron density than transition elements 
and are less easily observed by single crystal X-ray diffraction techniques. The increased intensity in X-ray beams available with a rotating anode as the X-ray source enables sufficient collection of even the weak data points to satisfactorily refine the light atom positions in the structure. This has been an important factor in the success of this research. Neutron diffraction, although not a common procedure, is now a standard procedure, and is in a number of cases inherently better for locating light atoms since it does not depend on electron density. In addition, elemental analysis of bulk samples, such as by Energy Dispersive X-ray Spectroscopy or EDS, can help identify the presence of impurity atoms.

Techniques have also been improved so as to eliminate, or reduce, the likelihood of oxygen contamination in solid state reactions. Whether the oxygen comes from surface oxides on the starting material, or from residual gaseous oxygen in the reaction chamber, or from reaction with the container, the end result is the same - an oxide phase forms. Each source of oxygen must be eliminated to form oxygen free samples. The presence of surface oxides can be reduced by using foils, with less surface than powders, which are etched or cleaned before using. This use has the disadvantage of providing less surface area for reaction with the desired reactants. This is of no consequence in arc-melting, tust is important for diffusion-limited reactions. Alternately, buik metals can be converted to the hydride, and subsequently dehydrided. Sample containers can also be a source of oxygen. Samples heated in fused silica ampoules, $\mathrm{SiO}_{2}$, are susceptible to reaction directly with the container, which contains oxygen, as well as with oxygen in the form of water, absorbed within the walls of the glass, which degasses at temperatures above $1000^{\circ} \mathrm{C}$. Of course, if the sample melts it may react with the container whether the container is silica, alumina, zirconia or any other refractory material. A common technique now in use is to carry out reactions in inert metal containers. These containers can be sealed under an inert gas, and subsequently sealed in an evacuated silica tube. Another technique, used exclusively in this research, is the use of tungsten 
crucibles and heating of the samples under a dynamic vacuum in an induction furnace. The Knudsen cell design of the tungsten crucibles actually creates a condition within the cell that is more reducing than the residual atmosphere that can be achieved by pumping [30]. Tungsten oxides are volatile anc pumped out. As noted by previous workers in the zirconium sulfide system, reaction with the crucible can result in the formation of $\mathrm{W}_{2} \mathrm{Zr}$ [29].

The effectiveness of these techniques for the careful exclusion of oxygen is evident in the number of new compounds which have been discovered, and which would not form in the presence of oxygen. The early transition metals have a high affinity towards oxygen, and the formation of oxides is often thermodynamically favorable to the formation of oxygen - free compounds. Thus, although the metal - rich sulfides are often quite stable with respect to oxidation under ambient conditions, they do not form in the presence of oxygen. The exclusion of oxygen has been so effective it has perhaps led chemists to believe the interesting phases do not contain oxygen. The results of this research certainly show the interesting aspects of oxygen - stabilized phases, that is, phases which form only in the presence of small amounts of oxygen. Subtleties in the structural chemistry of these oxygen - stabilized phases are more clearly understood with the single crystal Xray diffraction studies carried out and the improved ability to detect the light elements by X-ray crystallography.

At first glance, there is not an obvious connection between the sulfides described earlier, and the oxides studied in this research. Indeed, the differences between the sulfides and the oxides in the metal rich compounds are readily apparent. First, sulfur is larger than oxygen. That is to say, sulfur occupies larger crystallographic sites, and can be more highly coordinated. Second. oxygen is more electronegative than sulfur, the energy levels of oxygen $2 p$ orbitals lie at lower energies than do those of sulfur 3p. The bonding overlaps will be different in oxides than in sulfides, and the nature of the bonding will be different. The sulfur in binary metal - rich sulfides has been described 
as having directional, delocalized bonds [31]. Oxygen orbital overlaps are more localized. The results of these differences are twofold. First, because of the size difference, oxygen can often occupy small vacant so-called interstitial sites within a metal framework, without significant structural distortion of the framework. Hence, many oxygen stabilized compounds are called after a parent structure type, i.e. $\mathrm{Zr}_{3} \mathrm{NiO}$ has the filled $\mathrm{Re}_{3} \mathrm{~B}$ type structure, and $\mathrm{Zr}_{4} \mathrm{Ni}_{2} \mathrm{O}$ has the filled $\mathrm{Ti}_{2} \mathrm{Ni}$ type structure. Sulfur, on the other hand, is larger, and occupies larger interstitial sites, or can occupy smaller vacant sites only by making the site larger, with a corresponding expansion in the metal framework, as observed for the new sulfur-containing kappa phases and stuffed gamma brasses [21]. The second effect is seen in the ability of sulfur to, in essence, become part of the metal framework, i.e. substitute on a metal atom position in the bcc units in the niobium sulfides, or the layered compounds of mixed niobium/tantalum sulfides, with an accompanying distortion in the framework. The metallic character of sulfur becomes apparent in these phases - that is, the ability of the sulfur orbitals to be involved in delocalized bonding in the conduction band. The corollary to this, then, is the substitution of a metal atom on a sulfur site, as in $\mathrm{Nb}_{9} \mathrm{Ni}_{2-\mathrm{x}} \mathrm{S}_{3+\mathrm{x}}$ [27], and in the kappa phase $\mathrm{Zr}_{9} \mathrm{~W}_{4}(\mathrm{~S}, \mathrm{Ni}) \mathrm{O}_{3}[80]$. One might object to describing the sulfur in these metal-rich sulfides as interstitial atoms. The metal-rich sulfides are novel structures, and the metal frameworks within these structures are also novel. To avoid overextending the use of the term "interstitial", rather than characterizing the sulfur as interstitial sulfur, the mixed tantalum/niobium sulfides and mixed early-late transition metal sulfides are here referred to as sulfur-stabilized intermetallics. The presence of small amounts of sulfur (up to 6 metal atoms for each sulfur atom) enables the formation of new phases which do not exist in the binary intermetallic phases. In a similar way, by calling the new phases oxygen stabilized, it is recognized that the phases do not form in the binary zirconium-nickel intermetallic system. By calling them interstitially stabilized one notes the oxygen atoms occupy small sites which are known to be vacant in some intermetallic compounds 
with the same local structural arrangement. Whether considering sulfides or oxides, the structural chemistry is dominated by the fact that the presence of either of these nonmetal atoms effects the metal-metal bonding in intermetallics. The resulting balance of metal-metal and metal-nonmetal interactions results in new phases, and gives clues about the nature of the bonding.

Specifically, to note the change in the bonding that results from interstitial oxygen, consider the binary zirconiun - nickel system. There are eight known phases in this system: $\mathrm{Zr}_{2} \mathrm{Ni}, \mathrm{ZrNi}$, $\mathrm{Zr}_{9} \mathrm{Ni}_{11}, \mathrm{Zr}_{7} \mathrm{Ni}_{10}, \mathrm{Zr}_{8} \mathrm{Ni}_{21}, \mathrm{ZrNi}_{3}, \mathrm{Zr}_{2} \mathrm{Ni}_{7}, \mathrm{ZrNi}_{5}$ [32]. The phase diagram is complex, and the variation in structure and stoichiometry is striking. Classical chemical concepts, such as oxidation numbers, are not useful in intermetallic systems. Oxidation numbers, such as $\mathrm{Zr}^{+1}$ and $\mathrm{Ni}^{-1}$ for $\mathrm{ZrNi}$, that would have any meaning throughout the series of phases, or even for that particular phase cannot be simply assigned. Intermetallic compounds characteristically fill space efficiently, and the atoms have correspondingly high coordination numbers. The bonding cannot be interpreted as containing two-centered, two-electron bonds. Rather, the bonding within these compounds involves extensive delocalization of electrons.

Today, band calculations can give quantitative analysis of bonding in many known solids. Earlier interpretations of intermetallic compounds were more qualitative. One prevalent concept was the radius ratio rule. This was based on a model of packing of hard spheres. Crystal structures of intermetallics could be generalized, as Laves did, as arrangements of spheres which pack to exhibit high symmetry, fill space most efficiently, and have the greatest number of connections between the atoms [33]. In a general sense this was useful because certain structure types appear over and over in intermetallic systems. There are two weakntsses of this model, however. The idea of hard sphere packing gives no chemical understanding to the structures. Atoms are not hard spheres. A completely nondirectional nature of bonding results. It also led to a proliferation of tables of radii to be used which would satisfy the radius ratio rules for the new structures constantly being 
discovered. Tables for radii take into account all possible factors influencing interatomic distances, including atomic charge and coordination number [34-38]. One result of the use of this model was the rationalization of the reported nonoccurrence of the $\mathrm{Ti}_{2} \mathrm{Ni}$ type structure in the $\mathrm{Zr} / \mathrm{Ni} / \mathrm{O}$ system [39], a phase this study shows does indeed exist. A recent study has successfully classified the structures that form for all binary, ternary and quaternary compounds [110]. This method also depends on the size differences of the constituent atoms, but uses this parameter along with the electronegativity differences of the atoms, and the sum of the valence electrons. The consideration of these three parameters together, rather than individually, increases the success and usefulness of the classification.

While the radius-ratio rules and structural classification are based on purely structural considerations, and no chemical considerations, the concept of Lewis acid - base behavior as it relates to the interactions among the transition metals does not explain structures of intermetallics. Late transition metals have paired electrons in d orbitals unavailable for bonding. Early transition metals have empty $\mathrm{d}$ orbitals. The sharing of electrons between late transition metals, acting as Lewis bases, and early transition metals, acting as Lewis acids, increases the total number of electrons available for bonding, and increases bond strength. This concept explains why; compounds such as $\mathrm{HfP}_{3}$ have such favorable enthalpies of formation [40-41]. In the binary zirconium/nickel system one would expect strong zirconium - nickel bonds according to the their Lewis acid - base properties. From the crystal structures of the phases that form in this system, one can indeed see the high coordination of zirconium by nickel, and of nickel by zirconium, as well as zirconium zirconium and nickel - nickel contacts.

The Brewer-Engel theory relies heavily on the concept of Lewis acid-base interactions and gives a structural component to the concept. The qualitative aspects have been highly successful in predicting the structure and properties of new compounds [42-43]. The structure, or long range 
electronic ordering is determined by the number of $s$ and $p$ electrons. The electrons in the $d$ orbitals are involved in short range interactions. To count the electrons in the s and p orbitals correctly one must consider the electronic configuration of the atom as it is in the compound, not in the electronic ground state of the gaseous atom. For those phases that form, according to the theory, the energy necessary for promotion of electrons from the ground state is more than offset by the bonding energy gained.

One deficiency of this method is the treatment of interstitial elements. They are considered in this model, if at all, only as electron acceptors or electron donors. They are not considered to have an influence on bonding within the network. They are hard spheres which fill space. The effect of adding interstitial atoms is only to possibly change the number of electrons in the $s$ and p orbitals, which may then favor a structure different than that adopted by the interstitial-free compound. A more chemically sound explanation in terms of bonding comes from band theory. In the rigid band approach the addition of oxygen to an intermetallic system provides energetically low-lying core levels, which are filled by electrons from the conduction band, thus the number of slectrons in the conduction band changes, and a corresponding change in structure may be energetically favorable. Furthermore, the addition of oxygen, and the donation of electrons from the conduction band implies the formation of metal-oxygen bonds, and as these bonds form, there is a simultaneous change in the metal-metal bonding within the metal framework, which may favor formation of a new phase.

The idea of electron counts is an important one. Hume-Rothery suggested certain electron concentrations as being important for formation of certain phases. Several systems have been studied in which structural changes corresponding to modification of electron counts by substitution of more or less electron rich elements, or by addition of interstitials, have been observed. This conceptual understanding of electron count and the role of interstitials in intermetallics is being 
supported by recent band energy calculations $[44,45]$.

Typically, when an interstitial element reacts with a binary early-late transition metal compound to form a ternary compound, the compound crystallizes in a common structure type. In fact, only a limited number of structure types are known for interstitially - stabilized phases of mixed early and late transition metals [46]. These phases are: 1) the filled $\mathrm{Ti}_{2} \mathrm{Ni}$ type, 2) the kappa phase type, 3) the filled $\mathrm{Re}_{3} \mathrm{~B}$ type, 4) the filled $\mathrm{Mn}_{5} \mathrm{Si}_{3}$ type (known for $\mathrm{Nb}-\mathrm{M}-\mathrm{O}$ where $\mathrm{M}=\mathrm{Ir}$, $\mathrm{Pt}$ ), and 5) the cubic Laves phase observed in the $\mathrm{Zr}-\mathrm{Ni}-\mathrm{O}$ system $[47,48]$. The first three of these types are found in the zirconium - nickel system with the addition of interstitial atoms, and make up the body of this research. In order of appearance in this dissertation, a single crystal study of the previously reported $\mathrm{Zr}_{3} \mathrm{NiO}$ phase, of the filled $\mathrm{Re}_{3} \mathrm{~B}$ type structure, is presented first. Following this is a discussion of a series of compounds of the filled $\mathrm{Ti}_{2} \mathrm{Ni}$ type, involving the early transition metais zirconium and niobium, and mixed zirconium/titanium and niobium/tantalum. A discussion of the results of band calculations for this phase is included. New zirconium kappa phases have been found and are reported next. Finally, a new structure type has been found for an interstitially stabilized phase made up of a ternary metal framework of zirconium - titanium - nickel. The temary metal system, $\mathrm{Zr}-\mathrm{Ti}-\mathrm{Ni}$, contains phases which do not occur in either of the binary systems $\mathrm{Zr}-\mathrm{Ni}$ or Ti-Ni (i.e. the hexagonal Laves phase $\mathrm{ZrTiNi}[9,10]$, and the $\mathrm{BaPb}_{3}$ type structure $\mathrm{ZrTi}_{2} \mathrm{Ni}_{9}$ $[11,12])$. It is natural to expect that interstitials in this ternary system may stabilize new compounds, with respect to the ternary intermetallics and interstitially stabilized binary compounds. 


\section{EXPERIMENTAL TECHNIQUES}

\section{Synthesis}

This section contains information on experimental techniques common to all the experiments performed in this work. Specific details will be included in the individual sections. The experiments were designed to take advantage of the equipment available in the lab. Specifically, the synthetic procedure of metal rich compounds generally consists of arc melting of the initial reactants, followed by annealing the samples.

Arc melting was performed with a CENTORR Model 5SA Single Arc Furnace, powered by a Hanovia Model 28151 Compact Arc Lamp Power System. Samples of between 0.5 and 1.5 grams were placed on a water cooled copper hearth, and melted under argon by an arc formed between the sample and a thoriated non-consumable tungsten electrode. Depending on the sample, current output was between 50-100 Amps D.C. There has been no indication of contamination by copper in arc melted samples in any of the previous work done in this lab. Likewise, there has been no evidence of copper contamination in any of the samples in this work, either by the formation of copper containing phases, or as detected by elemental analysis. A more significant source of contamination is atmospheric oxygen. The chamber is pumped by a mechanical pump, and backfilled with argon. This pump/purge cycle is repeated 3-5 times, and the chamber is left with a positive pressure of argon $(\sim 3 \mathrm{~atm})$. A safety valve releases pressure at $6 \mathrm{~atm}$. To remove residual oxygen in the chamber prior to melting the sample, a zirconium metal piece is melted first for $30-60$ seconds as an oxygen getter. The calculated collision frequency is sufficiently high that the high reactivity of zirconium towards oxygen is expected to be effective in reducing the amount of oxygen present which may contaminate the sample. This has been true for work done on sulfides, and holds true for this work with oxides. After the initial discovery of the oxides as minor phases, it was desirable 
to find a way of controlling the amount of oxygen present in the sample and thus synthesize bulk samples of the desired phases. This was accomplished by preparing samples, by arc melting, using a stoichiometric amount of a metal oxide. Other sources of oxygen were reduced to a minimum. Surface oxides on the metals were reduced by using metal foils rather than powders. The surface oxides were removed by cleaning with acid solutions immediately prior to use. This was most important for compounds containing titanium and zirconium, both of which are very reactive towards oxygen. The reactivity of these metals to oxygen indicates the high stability of the oxides with respect to the elements. The fact that these metal oxides can be used as reactants in these reactions indicates the high stability of the products with respect to the oxides and the competing intermetallic phases. A problem can arise in the reaction of oxides in that it is difficult to arc melt insulating materials. They often splatter, or fly apart when the arc comes in contact with them. A generally successful technique was to place the oxide powder between layers of metal foils. The arc was brought in contact with the edge of the foil and slowly moved toward the center. In this way the small amount of oxide present dissolved and reacted with the molten metal and the sample maintained its conductive, metallic properties. Typically a sample was arc melted three times, for approximately one minute each time, the sample being tumed over each time to increase homogeneity.

Despite this procedure, the arc melted samples are generally not homogeneous due to the large difference in cooling rate between the part of the sample in contact with the water cooled copper hearth and the top of the sample. All of the samples prepared were between 0.5 and 1.5 grams, and within this range sample size had no apparent affect on homogeneity. The arc melting procedure was often very clean, with little mass loss due to vaporization. The most volatile species was nickel, and if samples were arc melted for longer times the loss of nickel was detected by mass loss as well as by formation of $\mathrm{ZrO}_{2}$ from the excess zirconium. 
The samples show no evidence of decomposition or reactivity with air or moisture, and all subsequent handling was done in air. The homogeneity of the samples could be improved by annealing samples after arc melting. Two types of fumaces were available for annealing. The Marshall/Thermcraft and Astro furnaces are tube furnaces with capabilities of reaching $1200^{\circ} \mathrm{C}$. Samples were placed in fused silica tubes, $10 \mathrm{~mm}$ I.D., $12 \mathrm{~mm}$ O.D., and evacuated to $10^{-5}-10^{-6}$ torr using an oil diffusion pump backed by a mechanical rough pump. Sometimes the samples were annealed as a button resulting from the arc melt. However, greater homogeneity resulted from first crushing the arc-melted button to a powder and cold pressing the powder to form a pellet for annealing. When samples were placed in the silica tube, the tubes were heated while they were being evacuated to try to eliminate as much moisture from the walls of the silica as possible, and finally sealed under vacuum. Sealed tubes were typically $120-150 \mathrm{~mm}$ in length. To ensure the vacuum was not lost in the sealing step each tube was gently heated. If the walls slowly collapsed, this was taken as evidence that the tube was still under vacuum. A single sample was placed in each tube, but several tubes could be placed in the furnace at once. Samples were annealed at varying temperatures, but generally not above $1000^{\circ} \mathrm{C}$ where reaction with oxygen from moisture degassed from the walls of the silica container is more likely.

Annealing at higher temperatures was performed in a Lepel High Frequency Induction Heating Unit. This unit contained a Lepel High Frequency Generator T-20 with Thyratron Regulator T-660. A quarter inch copper tube carried the high frequency field, and surrounded the water cooled quartz jacket which in tum surrounded the sample. The sample chamber was under a dynamic vacuum maintained by an oil diffusion pump backed by a mechanical pump. The sample was not heated until the pressure within the chamber, measured by an ion gauge, was $10^{-6}$ torr. The pressure within the chamber could become as low as $10^{-8}$ torr. The samples were placed in tungsten crucibles. Tungsten is a suitable container for annealing several intermetallics and oxides, as long 
as the sample does not melt. Samples containing zirconium that melted in the crucible often form $\mathrm{W}_{2} \mathrm{Zr}$. Surprisingly, the new kappa phase $\mathrm{Zr}_{9} \mathrm{~W}_{4}(\mathrm{~S}, \mathrm{Ni}) \mathrm{O}_{3}$ was formed because of reaction between the sample and container. Melting the sample is to be avoided exactly for this reason. It is much easier to include tungsten in the starting material than to use the container as a reactant. It also makes the crucibles last longer. The presence of a low melting phase, melting below $1000^{\circ} \mathrm{C}$, presumably the cubic Laves phase in the $\mathrm{Zr}-\mathrm{Ni}-\mathrm{O}$ system $[47,48]$, often resulted in losing the sample due to reaction with the container. To avoid melting samples some were heated in the crucible without a lid. Thus, it could be visually determined whether or not the sample had melted during the annealing procedure. However, this procedure is not without consequence. The temperature of the sample in the induction fumace is determined by optical pyrometry. Each tungsten crucible is made with a hole in the bottom from which nearly black body radiation is emitted. The sample temperature within a closed crucible is higher than the sample temperature within an open crucible, without a lid, when the temperatures read by the pyrometer in the two cases are equal. For this reason, temperatures as measured were used for comparison between samples, and are not to be taken as actual temperatures. No attempt was made to calibrate these measurements. No corrections are applied to pyrometer readings for loss of intensity from passing through the quartz windows or reflectance from the mirror. Actual temperatures within a closed crucible are believed to be at least $50^{\circ} \mathrm{C}$ higher than the temperature read at this temperature range.

Except for the foils, all chemicals were used as received. Foils were placed in acid cleaning solutions just prior to use in order to remove surface oxides. They were immediately rinsed with distilled water and subsequently with alcohol (methanol or ethanol) and air dried. The acid cleaning solution for.zirconium was made from the volume percents of the following $-10 \% \mathrm{HF}, 45 \% \mathrm{HNO}_{3}$, $45 \% \mathrm{H}_{2} \mathrm{O}$. The titanium cleaning solution was made from $60 \%$ by volume of $\mathrm{H}_{2} \mathrm{O}_{2}(30 \%), 10 \%$ $\mathrm{HF}, 30 \% \mathrm{H}_{2} \mathrm{O}$; for niobium the solution contained 50 volume $\% \mathrm{HF}$, and $50 \% \mathrm{HNO}_{3}$. Nickel was 
Table 2.1 Chemicals used in synthesis of new materials

\begin{tabular}{llll}
\hline $\mathrm{Chemical}$ & Source & Purity & Comments \\
\hline $\mathrm{Zr}$ & Alfa & $99.9 \%$ & $0.25 \mathrm{~mm}$ foil \\
$\mathrm{Zr}$ & Alfa & $99+\%$ & powder \\
$\mathrm{Zr}$ & Johnson Matthey & $99.9 \%$ & $-20+60$ mesh $^{\mathrm{a}}$ \\
$\mathrm{ZrO}{ }_{2}$ & Johnson Matthey & $99.9975 \%$ & \\
$\mathrm{Ti}$ & Puratronic & & \\
$\mathrm{Ti}{ }_{2} \mathrm{O}_{3}$ & Ames Laboratory & & foil \\
$\mathrm{Ni}$ & Johnson Matthey & $99+\%$ & \\
$\mathrm{Ni}$ & Inco & $99.99 \%$ & foil \\
$\mathrm{NiO}$ & Fisher Scientific & purified & powder \\
& Johnson Matthey & $99.998 \%$ & \\
$\mathrm{Nb}$ & Puratronic & & -325 mesh \\
$\mathrm{Ta}$ & Alfa & $99.8 \%$ & -60 mesh \\
$\mathrm{Mo}$ & Johnson Matthey & $99.98 \%$ & -200 mesh \\
$\mathrm{W}$ & Alfa & $99.9+\%$ & -100 mesh \\
$\mathrm{Cu}$ & Alfa & $99.98 \%$ & ribbons \\
$\mathrm{Co}$ & J.T. Baker Chemical & $99.98 \%$ & pieces \\
$\mathrm{Si}$ & Co. & $99.5 \%$ & zone refined \\
$\mathrm{S}$ & Alfa & $99.999 \%$ & \\
\hline
\end{tabular}

a This powder contained 10 atomic $\% \mathrm{Ti}$, according to quantitative analysis by XPS.

b Nickel received from Inco was arc-melted under argon and rolled into a foil. Elemental analysis was performed after this treatment. 
cleaned in concentrated $\mathrm{HNO}_{3}$. The materials used are listed in the following table, Table 2.1.

\section{Characterization}

Sample characterization and phase identification was routinely performed by X-ray diffraction techniques. X-ray powder diffraction was used to identify phases present in a sample. Powder patterns were recorded photographically using vaculm Guinier cameras, Enraf-Nonius, Delft Model FR552. The cameras are equipped with quartz monochromators and adjusted to select diffraction from CuK $\alpha 1$ radiation $(\lambda=1.54056 \AA)$. With the $X$-ray generator power set at $20 \mathrm{~mA}$ and $45 \mathrm{kV}$, exposure time was typically two hours for powder samples. Samples were mounted on clear adhesive tape and placed on a rotating holder to eliminate effects of preferred orientation. The films were interpreted by measurement of line positions relative to an internal silicon standard (NIST, a=5.43088 $\AA$ ). These measurements were done automatically on a KEJ Instruments Line Scanner LS-20.

Single crystals were examined by oscillation and Weissenberg photographs on a Charles Supper Company Weissenberg Camera 9000ST. A nickel filter reduced CuK $\beta$ radiation. Photographic techniques are useful for determining lattice parameters and possible space groups.

A Rigaku AFC6R diffractometer, with a rotating anode, was used to collect single crystal diffraction data. This diffractometer was set up to run with MoK $\alpha$ radiation $(\lambda=0.71069 \AA)$ at 50 $\mathrm{kV}$ and $140 \mathrm{~mA}$. The high intensity of the $\mathrm{X}$-ray beam cbtained with this diffractometer made it possible to collect enough weak intensity peaks to solve the structures from very small crystals.

Qualitative elemental analysis was performed by electron spectroscopy for chemical analysis (ESCA) on a Perkin Elmer 5500 multitechnique system, and by energy cispersive spectroscopy with X-rays (EDS) on a Cambridge S-200 scanning tunneling microscope fitted with a Northern Tracor Micro Z-II X-ray detector. Quantitative analysis was done by EDS on polished samples on a JEOL 
JSM-840 electron microscope with KEVEX EDX system.

Magnetic measurements and tests for superconductivity were done on a Quantum Design SQUID magnetometer.

\section{Calculations}

Many of the calculations are performed routinely and quickly on the computer. A list of the programs used is presented in Table 2.2. A brief description of the programs follows. All the calculations were done on a VAX system, except the extended Hückel band calculations, which were carried out on the Iowa State University Project Vincent system.

The first analysis of a sample is often a powder X-ray diffraction experiment. Powder patterns are very useful in identifying the phases present in a sample. The films are scanned automatically in the Line Scanner LS-20. The positions and intensities of the lines are converted to d-spacings, $2 \theta$ values, and relative intensities by the program SCANPI. The d-spacings of the observed pattem can be compared to the values corresponding to known phases, or pattems calculated for new phases, as calculated by the program PWDR. Visual comparison of calculated powder patterns and observed powder pattems is possible by plotting the calculated pattems with the PLOT program. If the phase is positively identified, the $h \mathrm{kl}$ indices can be assigned to the appropriate lines and the LATT program will do a least squares refinement of the lattice parameters based on the observed d-spacings, or $2 \theta$ values, and the assigned $h k l$ values. The lattice parameters of the powdered samples obtained from this calculation are those used in the reports of structural information.

The Rigaku AFC6R X-ray single crystal diffractometer is fully automated for data collection. While several options exist in the data collection procedure, in a successful structural determination the diffractometer will search for several diffraction peaks, and index them. The cell is reduced to a standard cell by the Delauney subroutine. The Laue symmetry is checked before intensity data are actually collected. Data collection often extends to $50-60^{\circ}$ in $2 \theta$. Following the data collection, the lattice parameters are refined based on the position of several high-angle reflections (although parameters from powder samples are reported). Finally, a psi scan is collected for absorption correction purposes. The data are processed and refined by full matrix least squares refinement 
using the accompanying TEXSAN package. The SHELXS direct methods program is used to obtain a starting model for the structure solution. The graphic generation of crystal structures is done with the ORTEP program.

Energy band calculations based on the extended Hückel method were performed on the Project Vincent workstation. The calculations performed gave total energies, Fermi energies, orbital populations and overlap populations. Results could be plotted as DOS curves and COOP curves. Starting parameters for $\mathrm{H}_{\mathrm{ij}}$ values were obtained by using a charge iteration program.

Table 2.2 Computer programs used in this research

\begin{tabular}{lll}
\hline Program & Calculations performed & Reference \\
\hline Charge iteration & Charge iteration & 49,50 \\
$\begin{array}{l}\text { Extended } \\
\text { Hückel }\end{array}$ & Energy band calculations & $51-54$ \\
LATT & Least squares refinement of lattice parameters & 55 \\
PLOT & Plot calculated powder patterns & 56 \\
PWDR & Calculate powder patterns & 57 \\
ORTEP & Graphical display of crystal structures & 58 \\
SCANPI & Calculate d-spacings in observed powder patterns & $59-61$ \\
SHELXS & $\begin{array}{l}\text { Direct methods structural solution for X-ray } \\
\text { diffraction data }\end{array}$ & 62 \\
TEXSAN & $\begin{array}{l}\text { X-ray single crystal structural least squares } \\
\text { refinement }\end{array}$ & 63 \\
\hline
\end{tabular}




\title{
SINGLE CRYSTAL X-RAY STUDY OF $\mathrm{Zr}_{3} \mathrm{NiO}$
}

\author{
Introduction
}

A good starting place for the study of interstitially stabilized phases in the zirconium-nickel system is with the only previously reported $\mathrm{Zr} / \mathrm{Ni} / \mathrm{O}$ temary phase, $\mathrm{Zr}_{3} \mathrm{NiO}$. This compound crystallizes in the filled $\operatorname{Re}_{3} B$ type structure. It was first identified in a study of the zirconium-rich comer of both the $\mathrm{Zr} / \mathrm{Co} / \mathrm{O}$ and $\mathrm{Zr} / \mathrm{Ni} / \mathrm{O}$ temary systems at $950^{\circ} \mathrm{C}$ [39]. The structure for this phase was not known until a single crystal solution was published for $\mathrm{Zr}_{3}$ Co [64]. Subsequently, the phases $\mathrm{Zr}_{3} \mathrm{MO}_{\mathrm{x}}(\mathrm{M}=\mathrm{Fe}, \mathrm{Co}, \mathrm{Ni})$ were examined by powder diffraction data to determinu the range and extent of oxygen occupancy, with related changes in lattice parameters [65]. The iron compound is reported to occur as a binary intermetallic, with no oxygen solubility $(x=0)$. The cobalt compound is found to exhibit a full range of oxygen occupancy $(0 \leq \mathrm{x} \leq 1)$, forming as a binary and with full filling of octahedral sites by oxygen. The nickel compound exists only as an oxide, and does not occur as a binary phase $(0.2 \leq x \leq 1.0)$. The single crystal $X$-ray study confirms the previously reported results [66].

\section{Experimental Details}

A crystal for X-ray study was selected from a sample which had undergone a number of experimental treatments. Initially, zirconium, nickel and sulfur in the molar ratios 6:4:5 were heated in an evacuated silica tube at temperatures up to $690^{\circ} \mathrm{C}$. The resulting mixture was arc melted. Additional zirconium and nickel were added to the sariple to bring the final metal ratio to $n(\mathrm{Zr}): \mathrm{n}(\mathrm{Ni})=3: 1$. The sample was repeatedly crushed, pelletized, and inductively heated to temperatures of $1050-1230^{\circ} \mathrm{C}$ for $12-18$ hours. The sample was soaked in concentrated $\mathrm{HCl}$ for a week to remove a binary sulfide phase, $\mathrm{Zr}_{3} \mathrm{~S}_{2}$, and subsequently heated to $1130^{\circ} \mathrm{C}$ for 5 days: The 
crystal studied here was picked from this final sample, although the oxide phase, as identified by $\mathrm{X}$-ray diffraction films of the powder, was present before the sample was placed in the acid.

Intensity data for this crystal were collected using a Rigaku AFC6R single crystal diffractometer and monochromated MoK $\alpha$ radiation, employing the $\omega-2 \theta$ scan technique up to $55^{\circ}(2 \theta)$. From a total of 422 reflections $( \pm h, k, l), 162$ independent reflections with $\mathrm{F}_{\mathrm{o}}{ }^{2}>3 \sigma\left(\mathrm{F}_{0}{ }^{2}\right)$ were obtained and used for structure analysis. The observed intensities were corrected for Lorentz polarization and absorption effects with the maximum to minimum transmission factor ratio of 1 to 0.768 . No significant decay was observed during the data collection. The crystal data are tabulated in Table 3.1 .

\section{Results and Discussion}

The atomic coordinates and thermal parameters for $\mathrm{Zr}_{3} \mathrm{NiO}$ are reported in Table 3.2, and Table 3.3, respectively. This phase has been shown to exist with variable oxygen content. The fractional oxygen occupancy ranges from 0.2 to 1.0 , and the variation of the lattice parameters as a function of oxygen occupancy has been measured [65]. Full oxygen occupancy in this crystal was indicated by agreement in lattice parameters $(a=3.33 \AA, b=10.99 \AA, c=8.77 \AA$ [65], cf Table 3.1) as well as the single crystal refinement.

The structure may be viewed as being built up from two polyhedral units - trigonal prisms of zirconium centered by nickel atoms, and octahedra of zirconium centered by oxygen atoms (Figure 3.1). The trigonal prisms share triangular faces, forming chains in the $a$ direction. Adjacent chains are offset from each other by $x=1 / 2$. Oxygen atoms occuny the interstitial octahedral site formed by the zirconium atoms from adjacent chains. The octahedra form a zig-zag chain sharing comers in the $c$ direction, and they share edges with adjacent octahedra in the $a$ direction.

The interatomic distances less than $3.5 \AA$ are listed in Table 3.4. The zirconium-zirconium 
Table 3.1 Crystal data for $\mathrm{Zr}_{3} \mathrm{NiO}$

\section{Formula}

Space Group

a $(\AA)$

b (A)

c $(\AA)$

$\mathrm{V}\left(\AA^{3}\right)$

Z

$d_{\text {calc }},\left(\mathrm{g} / \mathrm{cm}^{3}\right)$

Crystal size, $\left(\mu \mathrm{m}^{3}\right)$

$\mu(\operatorname{MoK} \alpha),\left(\mathrm{cm}^{-1}\right)$

Data collection instrument

Radiation (monochromated in incident beam)

Temperature, ${ }^{\circ} \mathrm{C}$

No. unique data, total

with $\mathrm{F}_{0}^{2}>3 \sigma\left(\mathrm{F}_{0}^{2}\right)$

No. parameters refined

Secondary ext. coeff. $\left(10^{-7}\right)$

$\mathbf{R}^{\mathrm{a}}, \mathbf{R}_{\mathbf{w}}{ }^{b}$, GOF $^{c}$

Largest difference peak $\left(\AA^{3}\right)$

Largest negative diff. peak $\left(\AA^{3}\right)$
$\mathrm{Zr}_{3} \mathrm{NiO}$

Cmcm(\#64)

3.353(1)

11.013(4)

8.755(7)

323.3(3)

4

7.153

$60 \times 30 \times 20$

147.71

Rigaku AFC6R

$\operatorname{MoK} \alpha(\lambda=0.71069 \AA)$

23

162

20

7.8

$0.025,0.033,1.149$

$+1.50$

$-1.40$

${ }^{a} \mathbf{R}=\boldsymbol{\Sigma}\left|\mathbf{F}_{0}\right|-\left|F_{c}\right|\left|/ \boldsymbol{\Sigma} \mathbf{F}_{0}\right|$

${ }^{b} R_{w}=\left[\Sigma w\left(\left|F_{o}\right|-\left|F_{c}\right|\right)^{2} / \Sigma w\left|F_{o}\right|^{2}\right] 1 / 2 ; w=1 / \sigma^{2}\left|F_{o}\right|$

${ }^{c}$ GOF $=\Sigma\left(\left(\left|F_{o}\right|-\left|F_{c}\right|\right) / \sigma_{i}\right) /\left(N_{\text {obs refl }}-N_{\text {parameters }}\right)$ 
Table 3.2 Atomic parameters for $\mathrm{Zr}_{3} \mathrm{NiO}$

\begin{tabular}{lllccl}
\hline Atom & Site & $x$ & $y$ & $z$ & $\mathrm{~B}_{\mathrm{eq}}{ }^{\mathrm{a}}\left(\AA^{2}\right)$ \\
\hline $\mathrm{Zr} 1$ & $8 f$ & 0 & $0.3645(1)$ & $0.5601(1)$ & $0.65(5)$ \\
$\mathrm{Zr} 2$ & $4 c$ & 0 & $0.9338(2)$ & $1 / 4$ & $0.69(8)$ \\
$\mathrm{Ni}$ & $4 c$ & 0 & $0.2460(2)$ & $1 / 4$ & $1.2(1)$ \\
$\mathrm{O}$ & $4 a$ & 0 & 0 & 0 & $0.9(6)$ \\
\hline
\end{tabular}

${ }^{a} B_{e q}=8 \pi^{2} / 3 \Sigma_{1}^{3} \Sigma_{1}^{3} U_{i j} a_{i}^{*} a_{j}^{*} \vec{a}_{i}^{*} \vec{a}_{j}^{*}$

Table 3.3 Anisotropic thermal parameters for $\mathrm{Zr}_{3} \mathrm{NiO}$

\begin{tabular}{llllllc}
\hline Atom & $\mathrm{U}_{11}$ & $\mathrm{U}_{22}$ & $\mathrm{U}_{33}$ & $\mathrm{U}_{12}$ & $\mathrm{U}_{13}$ & $\mathrm{U}_{23}$ \\
\hline $\mathrm{Zr} 1$ & $0.0082(7)$ & $0.0071(7)$ & $0.0093(7)$ & 0 & 0 & $-0.0016(5)$ \\
$\mathrm{Zr} 2$ & $0.005(1)$ & $0.012(1)$ & $0.010(1)$ & 0 & 0 & 0 \\
$\mathrm{Ni}$ & $0.022(2)$ & $0.014(1)$ & $0.010(1)$ & 0 & 0 & 0 \\
$\mathrm{O}$ & $0.010(7)$ & $0.018(7)$ & $0.007(6)$ & 0 & 0 & $0.006(6)$ \\
\hline
\end{tabular}


Table 3.4 Interatomic distances less than $3.5 \AA$ in $\mathrm{Zr}_{3} \mathrm{NiO}$

\begin{tabular}{cccccc}
\hline $\mathrm{Zr} 1$ & $-\mathrm{O}$ & $2.305(1) \times 2$ & $\mathrm{Zr} 2$ & $-\mathrm{O}$ & $2.307(2) \times 2$ \\
& $-\mathrm{Ni}$ & $2.657(2) \times 2$ & & $-\mathrm{Ni}$ & $2.662(3) \times 2$ \\
& $-\mathrm{Ni}$ & $3.012(3) \times 1$ & & $-\mathrm{Zr} 1$ & $3.242(2) \times 4$ \\
& $-\mathrm{Zr} 1$ & $3.165(3) \times 1$ & & $-\mathrm{Zr} 1$ & $3.281(2) \times 4$ \\
& $-\mathrm{Zr} 1$ & $3.206(2) \times 2$ & & $-\mathrm{Zr} 2$ & $3.353(1) \times 2$ \\
& $-\mathrm{Zr} 2$ & $3.242(2) \times 2$ & & $-\mathrm{Ni}$ & $3.439(4) \times 1$ \\
& $-\mathrm{Zr} 2$ & $3.281(2) \times 2$ & & & \\
& $-\mathrm{Zr} 1$ & $3.325(4) \times 1$ & $\mathrm{Ni}$ & $-\mathrm{Zr} 1$ & $2.657(2) \times 4$ \\
& $-\mathrm{Zr} 1$ & $3.353(1) \times 2$ & & $-\mathrm{Zr} 2$ & $2.662(3) \times 2$ \\
& & & & $-\mathrm{Zr} 1$ & $3.012(3) \times 2$ \\
0 & $-\mathrm{Zr} 1$ & $2.305(1) \times 4$ & & $-\mathrm{Ni}$ & $3.353(1) \times 2$ \\
& $-\mathrm{Zr} 2$ & $2.307(2) \times 2$ & & $-\mathrm{Zr} 2$ & $3.439(1) \times 1$ \\
\hline
\end{tabular}




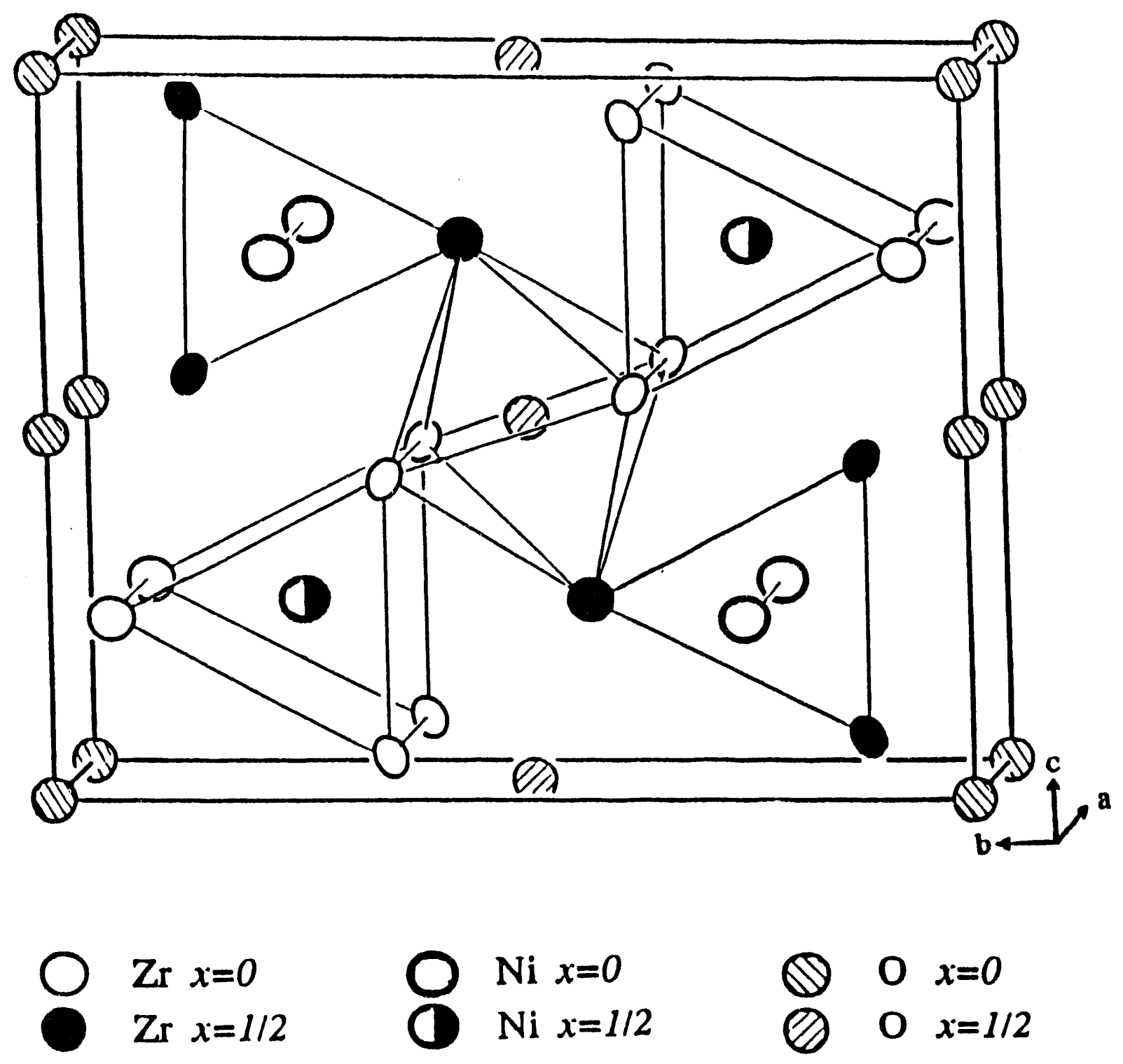

Figure 3.1 Unit cell of $\mathrm{Zr}_{3} \mathrm{NiO}$ showing ocahedral coordination of oxygen and trigonal prismatic coordination of nickel 
distances between the zirconium atoms in adjacent trigonal prisms are short compared to those distances within the prism, suggesting zirconium-zirconium interactions are stronger between the trigonal prisms than within the prism. All the zirconium-zirconium distances in the trigonal prism are greater than $3.3 \AA$. In fact, the $\mathrm{Zr} 1-\mathrm{Zr} 2$ distance on the triangular face of the prism is 3.682 $\AA$. This is significantly larger than the $3.23 \AA$ separation in elemental zirconium and the $3.165 \AA$ separation within the octahedra here, as well as other zirconium-zirconium separations in this oxide (Table 3.4). Although the zirconium-zirconium linkages around the prism are outlined in Figure 3.1, the important interactions within the prism are between the nickel and the zirconium atoms. This is expected on the basis of the behavior of early transition metals and late transition metals, where strong Lewis acid - base interactions are involved. The zirconium-nickel separation here is $2.66 \AA$. This is shorter than the zirconium-nickel distances in $\mathrm{ZrNi}(\mathrm{d}=2.68-2.77 \AA)$ and $\mathrm{Zr}_{2} \mathrm{Ni}$ $(d=2.76 \AA)[67]$.

The role of oxygen in the compounds $\mathrm{Zr}_{3} \mathrm{MO}_{\mathrm{x}}(\mathrm{M}=\mathrm{Fe}, \mathrm{Co}, \mathrm{Ni})$ is that of an electron acceptor. In terms of so-called electron compounds, where a certain electron per atom ratio is necessary for a given phase, the binary $\mathrm{Zr}_{3} \mathrm{Fe}$ is taken to have an ideal composition. Then in moving from iron to cobalt, and then to nickel, the electron/atom ratio increases until the phase becomes unstable with respect to neighboring intermetallic phases. When the metal atoms have more electrons the oxygen acts as an electron sink to maintain the proper electron/atom ratio in the metal framework, enabling the phase to form. In terms of energy band arguments, if the Fermi level in $\mathrm{Zr}_{3} \mathrm{Fe}$ lies at the energy at which all bonding levels are occupied, additional electrons would fill antibonding orbitals. Oxygen, octahedrally coordinated by zirconium atoms, provides low lying orbitals for the additional electrons in the cobalt and nickel compounds.

The magnetic susceptibility of a single phase sample was measured in a field of 3 Tesla, over a temperature range of $6-298 \mathrm{~K}$. The sample was also checked for superconductivity, but 
none was detected. The lattice parameters of this sample were $a=3.3238(4) \AA, b=10.974(1) \AA$, and $c=8.7982(9) \AA$. By Boller's plot [65], this corresponds to a stoichiometry of $\mathrm{Zr}_{3} \mathrm{NiO}_{0.6}$. Figure 3.2 shows paramagnetic behavior for this compound. The figure is not corrected for core diamagnetism, which would increase the molar susceptibility by $0.5 \times 10^{-4} \mathrm{emu} / \mathrm{mole}$ [111]. See also Figure 4.7. 


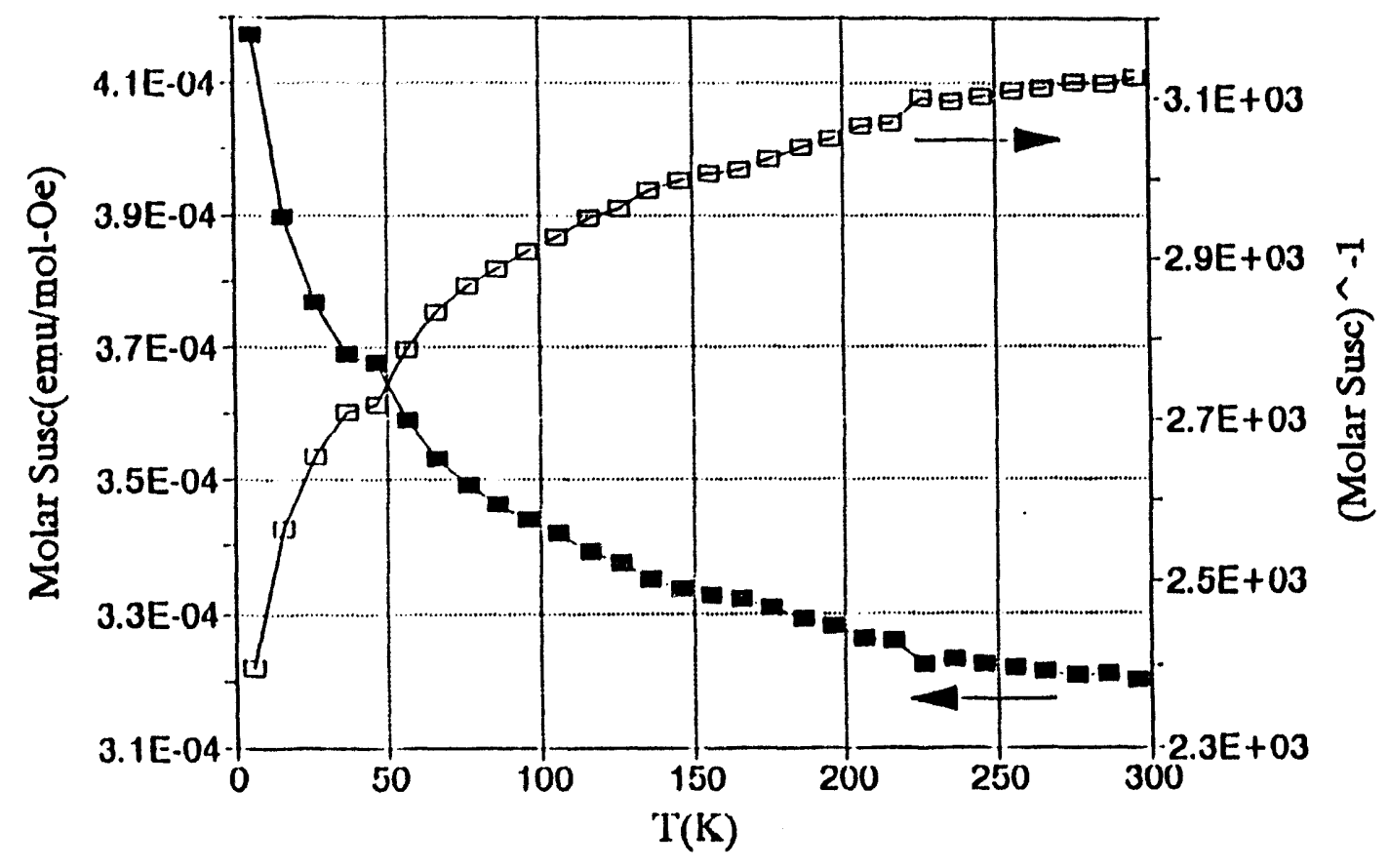

Figure 3.2 Magnetic susceptibility of $\mathrm{Zr}_{3} \mathrm{NiO}_{0.6}$ 


\section{NEW OXIDES OF THE FILLED $\mathrm{Ti}_{2} \mathrm{Ni}$ TYPE STRUCTURE}

\section{Introduction}

The study of new phases of the filled $\mathrm{Ti}_{2} \mathrm{Ni}$ type structure is but one of many potentially fruitful areas of investigation in intermetallics and in interstitially stabilized intermetallics. The chemistry of intermetallics in general is not well understood. The commercial world benefits greatly from the technologically important uses of intermetallic compounds, while scientists continue to incrementally increase their knowledge and understanding of these materials. One area of increasing interest in recent years is the role of interstitials in intermetallics. Many known structures may include undetected interstitials. Discoveries in this field are being made because the interstitials are being specifically looked for. Also, the ability to detect the presence of interstitials has increased. The precision of Guinier cameras makes measurements of lattice parameters from powder data very sensitive to changes in composition, either from changes in metal composition or from the presence of light interstitial atoms. Single crystal diffractometers can provide X-ray beam intensity sufficient to detect and refine light elements present in the intermetallic. Through the results of finding new phases, and the reinvestigation of previously reported phases of the filled $\mathrm{Ti}_{2} \mathrm{Ni}$ type, only now are the details becoming known in a structure for which there are over 150 reported examples.

The metal-atom ordering and oxygen occupancy of four compounds of the filled- $\mathrm{Ti}_{2} \mathrm{Ni}$ type structure have been determined by single crystal X-ray diffraction studies. Three additional phases have been identified and indexed from powder X-ray diffraction data. All the phases crystallize in space group $\mathrm{Fd} \overline{3} \mathrm{~m}$ with the following compositions: $\mathrm{Zr}_{4} \mathrm{Ni}_{2} \mathrm{O}(\mathrm{a}=12.1970(9) \AA), \mathrm{Zr}_{6} \mathrm{Ni}_{4} \mathrm{Ti}_{2} \mathrm{O}_{0.6}$ $(\mathrm{a}=12.0299(9) \AA), \mathrm{Nb}_{6} \mathrm{Ni}_{6} \mathrm{O}(\mathrm{a}=11.2117(5) \AA)$, and $\mathrm{Nb}_{6} \mathrm{Ni}_{4} \mathrm{Ta}_{2} \mathrm{O}_{2}(\mathrm{a}=11.5813(3) \AA)$. Phases identified using powder data are $\mathrm{Nb}_{4} \mathrm{Ni}_{2} \mathrm{O}(\mathrm{a}=11.5933(3) \AA), \mathrm{Zr}_{4} \mathrm{Cu}_{2} \mathrm{O}(\mathrm{a}=12.2659(7) \AA)$, and $\mathrm{Zr}_{6} \mathrm{Co}_{4} \mathrm{Ti}_{2} \mathrm{O}(\mathrm{a}=11.8649(9) \AA)$. A comparison of the structures and oxygen occupancies, as well as 
tentative explanations, are presented based on extended Hückel calculations. The role of interstitial oxygen as an electron acceptor and its affect on metal-metal bonding will be considered.

The $\mathrm{Ti}_{2} \mathrm{Ni}$, the filled $\mathrm{Ti}_{2} \mathrm{Ni}$, and the related $\eta$ carbide type structures have been known for some time [68]. Much of the earlier work revealed the variety of combinations of metals which adopt this framework to make it the most frequently found structure of binary intermetallics of stoichiometry $\mathrm{A}_{2} \mathrm{~B}$ [69]. The simplicity of the formula conceals the subtleties and complexities in the chemistry of these phases. Many of the binary intermetallics may incorporate light interstitial elements [69]. Many more phases form only in the presence of these interstitial atoms, commonly $\mathrm{C}[67,70-72], \mathrm{N}[73,74], \mathrm{O}[46,75,76]$, and even $\mathrm{H}[77]$, and these are the interstitially stabilized phases. Structural reports indicate the interstitial atoms, not considering H, occupy one of two possible octahedral sites, but not both. An additional feature is the possible deviation from an $A_{2} B$ stoichiometry to an $\mathrm{AB}$ stoichiometry. In some systems both ratios are observed, not as a wide solid solution, but as two distinct phases. A review of the literature and list of reported phases suggests there is no general explanation for the variability in compositions, nor is there any correlation to interstitial atom site occupancy and metal/metal ratio. Although much of the work was done a number of years ago, significant recent reports in the literature prompt further investigation of these phases $[46,72,77,78]$. Many reports are based on X-ray powder diffraction data, with the inherent difficulty in refining parameters for light interstitial elements. Some neutron diffraction work has been reported [72,77-79]. Single crystal work has not been previously reported for the oxides or carbides. Presumably this is because of the difficulty in forming single crystals suitable for diffraction experiments. The crystals examined here were all very small, and the successful refinements were possible because of the high $\mathrm{X}$-ray beam intensity obtained from using a diffractometer with a rotating anode.

The filled $\mathrm{Ti}_{2} \mathrm{Ni}$ type structure crystallizes in space group $\mathrm{Fd} \overline{3} \mathrm{~m}$, and the unit cell contains 
96 metal atoms. Adopting the notation by Newsam et. al.[72], the general formula for the oxides is written $\mathrm{M}_{6}^{f} \mathrm{M}_{4}^{e} \mathrm{M}_{2}^{d} \mathrm{O}_{2}^{c} \mathrm{O}_{1}^{a}$. The superscript letters are those of the Wyckoff symbol for the crystallographic site occupied by the superscripted atoms. The subscripts are based on the unit cell formula with $\mathrm{Z}=8$. For a ternary compound $\mathrm{M}^{f}$ and $\mathrm{M}^{e}$ are different transition metals. $\mathrm{M}^{d}$ may either be the same as $\mathrm{M}^{f}$ or $\mathrm{M}^{e}$, depending on the system being considered. The transition metal $M^{f}$ is always to the left of the $M^{e}$ metal atom on the periodic table. The $M^{f}$ atoms form an octahedral network. The $\mathrm{M}^{e}$ atoms have a tetrahedral arrangement. The $\mathrm{M}^{d}$ atoms cap the faces of the tetrahedra formed by the $\mathrm{M}^{e}$ atoms. When the $f$ and $d$ sites are occupied by the same metal the metal:metal ratio is $8: 4$, or $2: 1$. When the $e$ and $d$ sites are occupied by the same metal the metal:metal ratio is $6: 6$, or $1: 1$. There is no mixing reported on the $\mathbf{M}^{d}$ site, and this explains the two ratios reported as distinct phases, and not as a single phase with a large range of homogeneity. The assumption is made that the interstitial oxygen atoms occupy only one of the two possible sites. They occupy either the $16 c$ site, in which they fill distorted octahedra, or the $8 a$ site, in which they fill regular octahedra. Thus for a given ternary system the four possible compositions reported are $\mathrm{M}_{8} \mathrm{M}_{4}^{\prime} \mathrm{O}, \mathrm{M}_{8} \mathrm{M}_{4}^{\prime} \mathrm{O}_{2}, \mathrm{M}_{6} \mathrm{M}_{6}^{\prime} \mathrm{O}$, and $\mathrm{M}_{6} \mathrm{M}_{6}^{\prime} \mathrm{O}_{2}$. Examples of each have been reported.

The $\mathrm{Ti}_{2} \mathrm{Ni}$ structure contains ninety - six metal atoms in the unit cell. When interstitial atoms are present there are up to 104 or 112 atoms in the unit cell. It is hard to visualize or depict a cell this size. It is easiest to consider the building blocks in the unit cell and see how they order. Consider first a large cubic cell divided into two alternating subunits, as in Figure 4.1. Each subunit is one - eighth of the total cell, and the altemating pattem extends in all three directions in space. Figure 4.2 is a projection of one layer of the unit cell depicted in Figure 4.1, and contains four subunits. The subunits in the lower left and upper right are centered by an octahedron. The lower right and upper left subunits are centered by a tetrahedron. The octahedron - centered subunits and 


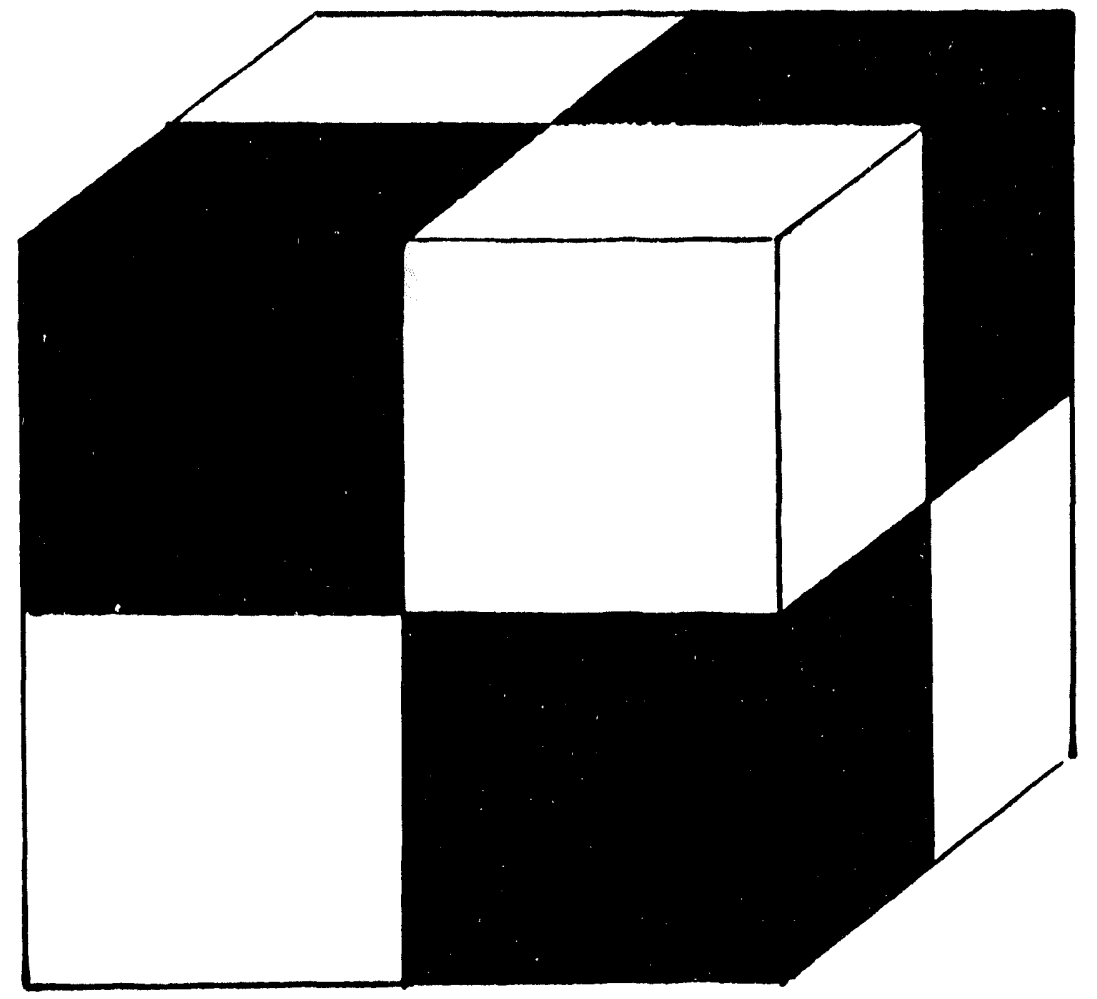

Figure 4.1

A large cubic cell divided into two altemating subunits 


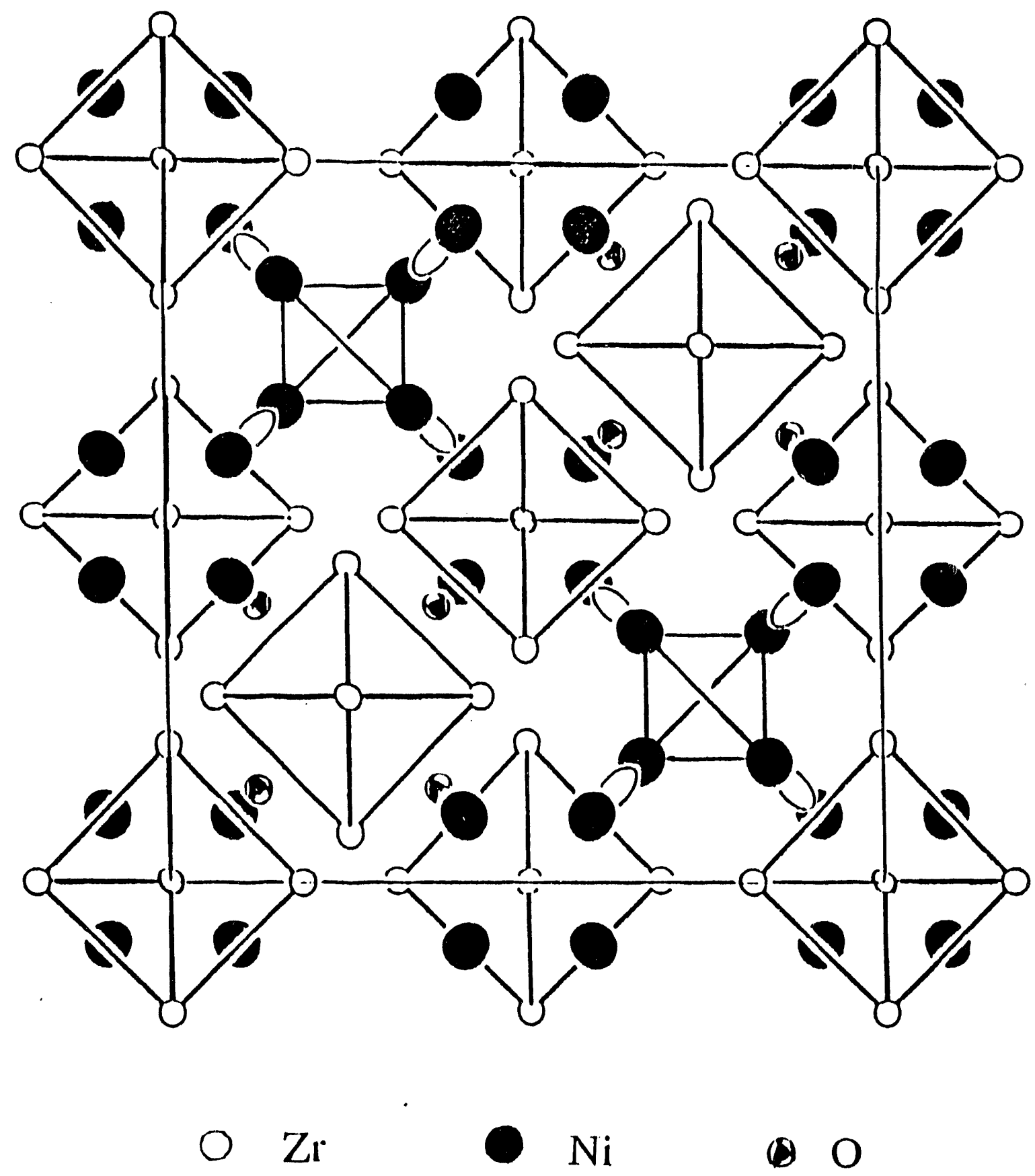

Figure 4.2

Projection of one half the unit cell, in the direction of projection axis, of $\mathrm{Zr}_{4} \mathrm{Ni}_{2} \mathrm{O}$. 
tetrahedron - centered subunits pack in an altemating pattem in all three dimension. Each subunit is displayed individually in Figure 4.3. Figure 4.3 (a) shows the subunit centered by an octahedron in which the central octahedron is surrounded by four more octahedra arranged tetrahedrally at the comers of the subunit. It is also surrounded by four tetrahedra. arranged tetrahedrally at the other four comers of the subunit. Figure 4.3 (b) is centered by a tetrahedron, and is similarly surrounded by four octahedra and four tetrahedra. Note that these two subunits adjoin one another, so that the octahedron at the lower right of Figure 4.3 (a) is the same octahedron at the lower left of Figure 4.3 (b), and so on for the other polyhedra on the shared face.

The diagram for Figure 4.3 is made for the compound $\mathrm{Zr}_{4} \mathrm{Ni}_{2} \mathrm{O}$, where the $\mathrm{M}^{d}$ atom is the same metal as the $M^{f}$ atom, which is zirconium in this case. The $M^{d}$ zirconium atom is seen capping the faces of the central tetrahedron in Figure 4.3 (b). The interstitial oxygen in the $16 c$ site is seen in Figure 4.3 (a), capping four faces of the central octahedron. This atom is actually six coordinated, in a distorted octahedral arrangement, where opposite faces of the distorted octahedron share faces with the regular octahedra outlined. Thus, rather than looking at isolated polyhedra, consider a network built up of these face - sharing octahedra. The subunit in Figure 4.3 (a) viewed as a section of such a network is drawn in Figure 4.4. The central octahedron shares four faces with four other octahedra. Each of these four octahedra, shown shaded and centered by oxygen, share just two opposite faces. The network, then, consists of face - sharing octahedra which alternately share two and four faces. The octahedra shown are alternately centered by oxygen and empty. The face - sharing octahedra form rings made up of 12 octahedra. The void spaces within and between these rings are filled by an interpenetrating network consisting of the tetrahedra and the capping atoms, forming stella quadrangulea. This network is depicted in Figure 4.5. The structure has been described in the literature by both schemes outlined here; as made up of altemating subunits, and as two interpenetrating networks. Additional comments about the structure 
35
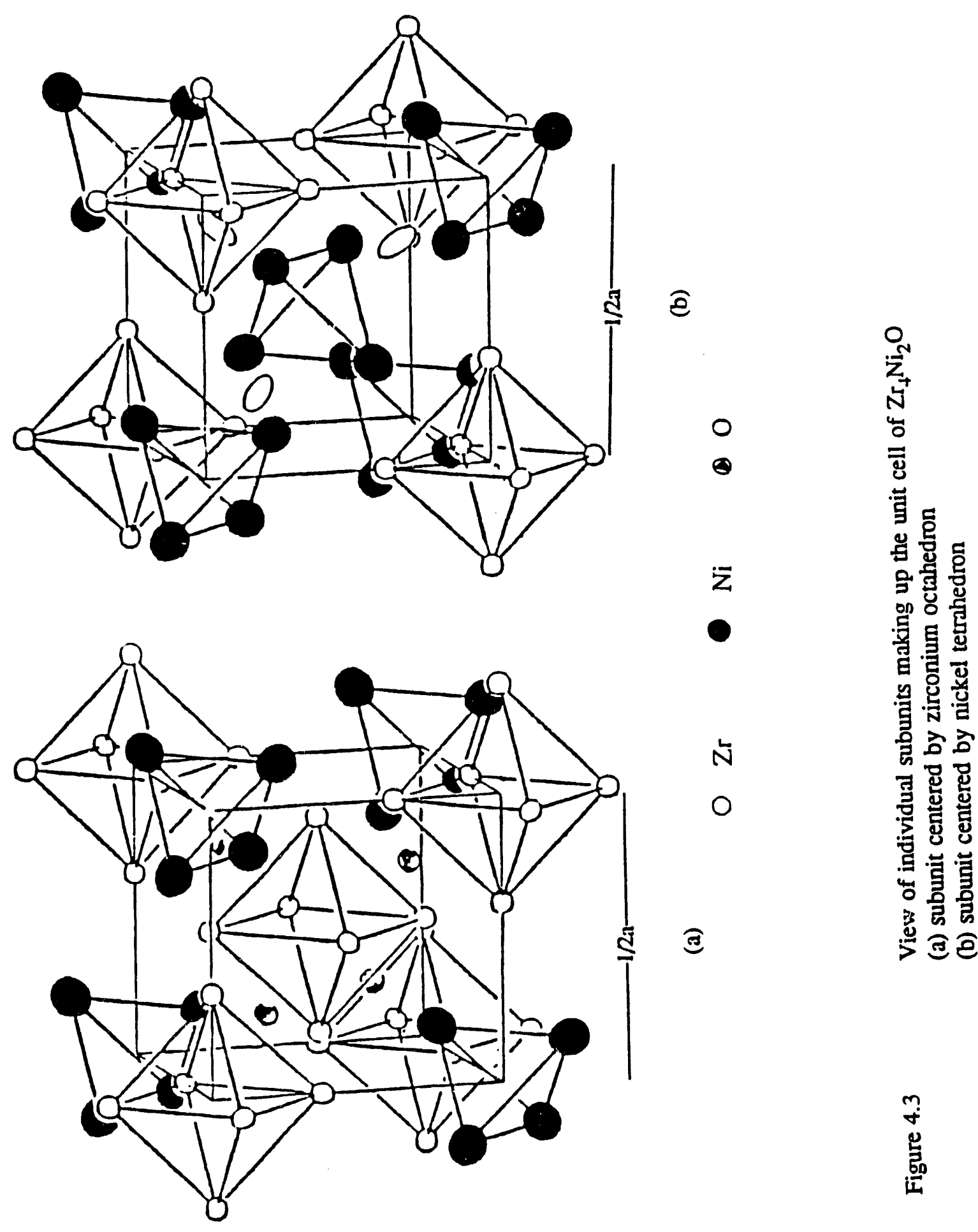


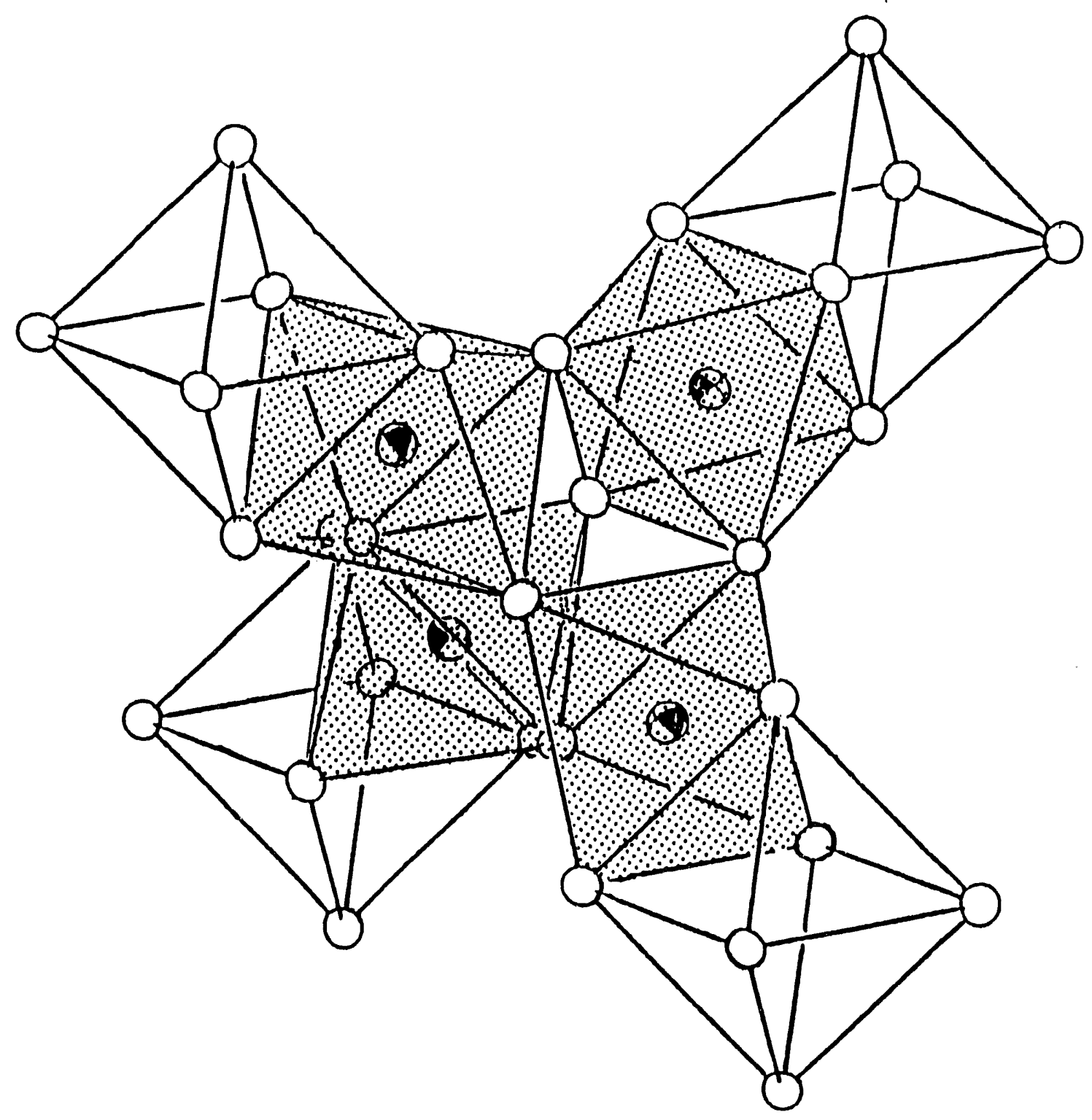

Figure 4.4

Network of face-sharing zirconium octahedron in $\mathrm{Zr}_{4} \mathrm{Ni}_{2} \mathrm{O}$. Shaded octahedron are centered by oxygen, unshaded octahedron are empty. 


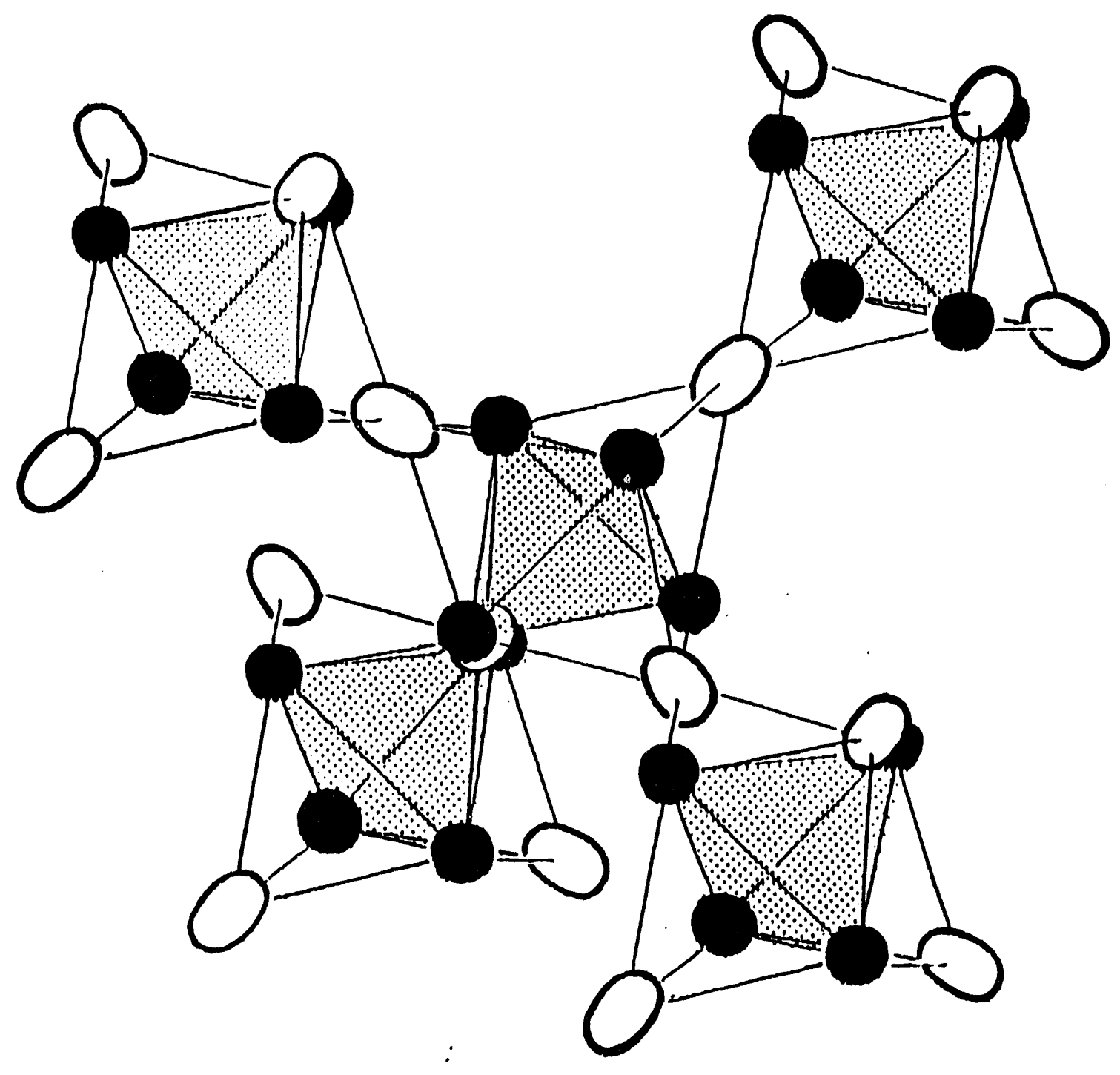

Figure 4.5 Nelwork of stella quadiangulac in $\mathrm{Zr}_{4} \mathrm{Ni}_{2} \mathrm{O}$. Nickel letrahicdra are shaded. 
will be made later, at which point structural features are considered in terms of chemical interactions.

\section{Experimental Details}

All chemicals were used as they were received from the supplier, except as noted in the experimental section earlier. Samples were prepared by two general techniques. The first technique consisted of arc melting the metals and the oxide of either zirconium or nickel. The samples were then annealed under vacuum in an induction furnace. This technique often resulted in a mixture of phases. $\mathrm{ZrO}_{2}$ was always present as a minor phase. Other minor phases present in various samples were $\mathrm{Zr}_{3} \mathrm{NiO}$ and the cubic Laves phase. Apparently, the Laves phase has a low melting point (less than $1000^{\circ} \mathrm{C}$ ) and the presence of this phase masks the refractory nature of this family of compounds. Samples free of this phase remained solid when annealed at $1250-1275^{\circ} \mathrm{C}$. Samples containing niobium all had $\mathrm{NbO}$ as a minor phase, and some also had $\mathrm{Nb}_{7} \mathrm{Ni}_{6}$ present. The desired phase was present upon annealing as low as $1000^{\circ} \mathrm{C}$, but most samples were annealed at $1250^{\circ} \mathrm{C}$. The melting point of $\mathrm{Nb}_{7} \mathrm{Ni}_{6}$ is $1290^{\circ} \mathrm{C}$.

A second method was used successfully for the preparation of a nearly single phase sample of $\mathrm{Zr}_{4} \mathrm{Ni}_{2} \mathrm{O}$. Only the two strongest lines of $\mathrm{ZrO}_{2}$ were barely visible in the powder $\mathrm{X}$-ray diffraction pattem of this phase. A sample of $\mathrm{Zr}$ and $\mathrm{Ni}$ was arc-melted, as before, then ground to small pieces. The metal and an appropriate amount of oxidizing agent, $\mathrm{NaClO}_{4}$, were sealed in an evacuated fused silica tube. Upon heating to $600^{\circ} \mathrm{C}$ for 4 days in a tube furnace the perchlorate decomposed, and crystals of $\mathrm{NaCl}$ formed at the cool end of the tube. The resulting oxide was crushed to a fine powder and pressed into a pellet before annealing as before.

Single crystal X-ray diffraction data collection was done on a Rigaku AFC6R diffractometer, With MoK $\alpha$ radiation $(\lambda=0.71069 \AA)$. All crystals were refined in space group Fd $\overline{3} \mathrm{~m}$. Details of 
crystal data are listed in Table 4.1.

A Quantum Design SQUID magnetometer was used to check for superconductivity and to measure magnetic behavior at a field of $3 \mathrm{~T}$ over the temperature range of $6-298 \mathrm{~K}$.

A JEOL JSM-840 electron microscope was used to examine the zirconium nickel oxides.

\section{Results}

Interest in the $\mathrm{Ti}_{2} \mathrm{Ni}$ type structures initially arose from a study of the interstitially stablized intermetallic phases that form in the $\mathrm{Zr}-\mathrm{Ni}$ system $[66,80,81]$. Two curious results deserved attention. First, previous work on the $\mathrm{Zr}-\mathrm{Ni}-\mathrm{O}$ phase diagram in an intentional search for this phase indicated that it does not exist in equilibrium at $950^{\circ} \mathrm{C}$ [39]. It does exist, however, at $1275^{\circ} \mathrm{C}$, the annealing temperature used in these experiments. This is thus an example of a high temperature solid phase which decomposes at lower temperature, in this case probably to $\mathrm{Zr}_{3} \mathrm{NiO}$ and $\mathrm{Ni}$. Second, there was a noticeable shift in lattice parameters for this phase in several of the samples, as observed in the films of the powder diffraction patterns taken on a Guinier camera. A single crystal was chosen from both a sample with the larger lattice parameter, and a sample with the smaller lattice parameter. The results for the data refinement of the larger cell correspond to the data reported for $\mathrm{Zr}_{4} \mathrm{Ni}_{2} \mathrm{O}$ in Table 4.2. The preliminary solution for the smaller cell was also based on a $\mathrm{Zr} / \mathrm{Ni} / \mathrm{O}$ temary system, and required $\mathrm{Ni}$ vacancies on the $16 d$ site for a suitable refinement, giving a stoichicinetry of $\mathrm{Zr}_{6} \mathrm{Ni}_{6-\mathrm{x}} \mathrm{O}$. This solution was corrected when elemental analysis revealed the presence of titanium, which could be detected in samples prepared with a zirconium starting material which unexpectedly contained significant amounts of titanium. Placing Ti in the $16 d$ site in the structure solution improved the refinement significantly, and the final refinement showed full occupancy on all the metal sites. The results for $\mathrm{Zr}_{6} \mathrm{Ni}_{4} \mathrm{Ti}_{2} \mathrm{O}_{0.6}$ are also in Table 4.2. Efforts to synthesize a compound of stoichiometry $\mathrm{Zr}_{6} \mathrm{Ni}_{6} \mathrm{O}$, without titanium, were unsuccessful. 
Table 4.1 Single crystal data of new filled $-\mathrm{Ti}_{2} \mathrm{Ni}$ type phases

\begin{tabular}{|c|c|c|c|c|}
\hline Formula & $\mathrm{Zr}_{4} \mathrm{Ni}_{2} \mathrm{O}$ & $\mathrm{Zr}_{6} \mathrm{Ni}_{4} \mathrm{Ti}_{2} \mathrm{O}_{0.6}$ & $\mathrm{Nb}_{6} \mathrm{Ni}_{6} \mathrm{O}$ & $\mathrm{Nb}_{6} \mathrm{Ni}_{4} \mathrm{Ta}_{2} \mathrm{O}_{2}$ \\
\hline $\mathrm{a} \AA$ & $12.1970(9)$ & $12.0299(9)$ & $11.2117(5)$ & $11.5813(3)$ \\
\hline$V \AA^{3}$ & $1814.5(4)$ & $1740.9(4)$ & $1409.3(2)$ & $1553.4(1)$ \\
\hline Z & 16 & 8 & 8 & 8 \\
\hline$d_{\text {calc}}, g / \mathrm{cm}^{3}$ & 7.295 & 6.747 & 8.742 & 10.390 \\
\hline Crystal size, $\mu \mathrm{m}^{3}$ & $40 \times 50 \times 70$ & $50 \times 50 \times 100$ & $40 \times 40 \times 40$ & $30 \times 40 \times 50$ \\
\hline$\mu(\operatorname{MoK} \alpha), \mathrm{cm}^{-1}$ & 167 & 169 & 246 & 494 \\
\hline Data collection range, $2 \theta$ & $0-60$ & $0-55$ & $0-55$ & $0-60$ \\
\hline No. refl. measured & 768 & 579 & 482 & 1253 \\
\hline $\begin{array}{l}\text { No. unique data, total } \\
\text { with } \mathrm{F}_{\mathrm{o}}^{2}>3 \sigma\left(\mathrm{F}_{\mathrm{o}}^{2}\right)\end{array}$ & 112 & 87 & 79 & 101 \\
\hline No. parameters refined & 13 & 15 & 11 & 15 \\
\hline Trans. factors, max./min. & 1.116 & 1.168 & 1.146 & 1.179 \\
\hline $\mathbf{R}^{\mathbf{a}}$ & 0.020 & 0.029 & 0.017 & 0.022 \\
\hline $\mathbf{R}_{\mathbf{w}}{ }^{b}$ & 0.024 & 0.031 & 0.023 & 0.029 \\
\hline GOF $^{c}$ & 1.019 & 0.995 & 0.980 & 1.026 \\
\hline Largest peak, e $/ \AA^{3}$ & 1.59 & 1.20 & 0.88 & 1.54 \\
\hline $\begin{array}{l}\text { Largest negative peak, } \\
\mathrm{e} / \AA^{3}\end{array}$ & -1.17 & -1.31 & -1.04 & -3.19 \\
\hline
\end{tabular}

${ }^{a} R=\Sigma\left\|F_{0}|-| F_{c}\right\| / \Sigma\left|F_{o}\right|$

${ }^{b} R_{w}=\left[\Sigma w\left(\left|F_{o}\right|-\left|F_{c}\right|\right)^{2} / \Sigma w\left|F_{0}\right|^{2}\right]^{1 / 2} ; w=1 / \sigma^{2}\left(\left|F_{0}\right|\right)$

${ }^{c}$ GOF $=\Sigma\left(\left(\left|F_{0}\right|-\left|F_{c}\right|\right) / \sigma_{i}\right) /\left(N_{\text {obs refl }}-N_{\text {parameters }}\right)$ 
Table 4.2 Final atomic parameters from single crystal refinement

\begin{tabular}{|c|c|c|c|c|c|}
\hline Atom & Site & $x$ & $y$ & $z$ & $B_{e q}\left(\AA^{2}\right)^{a}$ \\
\hline \multicolumn{6}{|c|}{$\mathrm{Zr}_{4} \mathrm{Ni}_{2} \mathrm{O}$} \\
\hline $\mathrm{Zr} 1$ & $48 f$ & $0.18517(8)$ & 0.0 & 0.0 & $0.51(1)$ \\
\hline $\mathrm{Ni}$ & $32 e$ & $0.8396(1)$ & 0.8396 & 0.8396 & $1.2716(5)$ \\
\hline $\mathrm{Zr} 2$ & $16 d$ & 0.625 & 0.625 & 0.625 & $1.5990(5)$ \\
\hline 0 & $16 c$ & 0.125 & 0.125 & 0.125 & $0.562(2)$ \\
\hline \multicolumn{6}{|c|}{$\mathrm{Zr}_{6} \mathrm{Ni}_{4} \mathrm{Ti}_{2} \mathrm{O}_{0.6}$} \\
\hline $\mathrm{Zr}$ & $48 f$ & $0.1901(1)$ & 0.0 & 0.0 & $0.73(4)$ \\
\hline $\mathrm{Ni}$ & $32 e$ & $0.8326(2)$ & 0.8326 & 0.8326 & $1.1795(7)$ \\
\hline $\mathrm{Ti}$ & $16 d$ & 0.625 & 0.625 & 0.625 & $1.430(1)$ \\
\hline $\mathrm{O}^{\mathrm{b}}$ & $16 c$ & 0.125 & 0.125 & 0.125 & $1.17(3)$ \\
\hline $\mathrm{O}^{\mathrm{b}}$ & $8 a$ & 0.0 & 0.0 & 0.0 & $0.98(3)$ \\
\hline \multicolumn{6}{|c|}{$\mathrm{Nb}_{6} \mathrm{Ni}_{6} \mathrm{O}$} \\
\hline $\mathrm{Nb}$ & $48 f$ & $0.1996(1)$ & 0.0 & 0.0 & $0.47(2)$ \\
\hline $\mathrm{Nil}$ & $32 e$ & $0.8317(1)$ & 0.8317 & 0.8317 & $0.3289(4)$ \\
\hline $\mathrm{Ni} 2$ & $16 d$ & 0.625 & 0.625 & 0.625 & $0.4602(6)$ \\
\hline 0 & $8 a$ & 0.0 & 0.0 & 0.0 & $0.497(4)$ \\
\hline \multicolumn{6}{|c|}{$\mathrm{Nb}_{6} \mathrm{Ni}_{4} \mathrm{Ta}_{2} \mathrm{O}_{2}$} \\
\hline $\mathrm{Nb}^{\mathrm{c}}$ & $48 f$ & $0.1867(1)$ & 0.0 & 0.0 & $0.48(4)$ \\
\hline $\mathrm{Ni}$ & $32 e$ & $0.8311(1)$ & 0.8311 & 0.8311 & $0.422(1)$ \\
\hline $\mathrm{Ta}^{\mathrm{d}}$ & $16 d$ & 0.625 & 0.625 & 0.625 & $0.3491(6)$ \\
\hline 0 & $16 c$ & 0.125 & 0.125 & 0.125 & $1.154(5)$ \\
\hline \multicolumn{6}{|c|}{ Idealized Metal Positions ${ }^{\mathrm{e}}$} \\
\hline M1 & $48 f$ & 0.1875 & 0.0 & 0.0 & \\
\hline M2 & $32 e$ & 0.8250 & 0.8250 & 0.8250 & \\
\hline
\end{tabular}

a $\quad B_{e q}=8 \pi^{2} / 3 \Sigma_{1}^{3} \Sigma_{1}^{3} U_{i j} a_{i}^{*} a_{j}^{*} a_{i}^{*} a_{j}^{*}$

b Refinement of the oxygen occupancy gave results of the $16 \mathrm{c}$ site being $18 \%$ occupied and the $8 a$ site $24 \%$ occupied.

c Refined with mixed Nb/Ta occupancy; Nb 82(2)\%, Ta $18(2) \%$.

d Refined with mixed $\mathrm{Ta} / \mathrm{Nb}$ occupancy; $\mathrm{Ta} 61(3) \%, \mathrm{Nb} 39(3) \%$.

e [84] 
A systematic check for a solid solution between $\mathrm{Zr}_{4} \mathrm{Ni}_{2} \mathrm{O}$ and $\mathrm{Ti}_{4} \mathrm{Ni}_{2} \mathrm{O}$ was not performedbut for low concentrations of titanium, the titanium preferentially substitutes on the $16 d$ site. Furthermore, the oxygen partially occupies both interstitial sites in the sample containing titanium, with total oxygen occupancy given by the formula $\mathrm{Zr}_{6} \mathrm{Ni}_{4} \mathrm{Ti}_{2} \mathrm{O}_{0.6}$. The refinement was carried out considering the possible solutions: $\mathrm{Zr}_{6} \mathrm{Ni}_{4} \mathrm{Ti}_{2}$ (no oxygen), $\mathrm{Zr}_{6} \mathrm{Ni}_{4} \mathrm{Ti}_{2} \mathrm{O}_{1-x}$ (variable oxygen occupancy on the $8 a$ site only), $\mathrm{Zr}_{6} \mathrm{Ni}_{4} \mathrm{Ti}_{2} \mathrm{O}_{2-x}$ (variable oxygen occupancy on the $16 c$ site only), and $\mathrm{Zr}_{6} \mathrm{Ni}_{4} \mathrm{Ti}_{2} \mathrm{O}_{3-x}$ (variable oxygen occupancy on both the $8 a$ and the $16 c$ sites). By careful comparison of each of the refinement solutions, according to Hamilton's test [82], the solution with both sites partially occupied is correct with a $95 \%$ level of confidence. This result raises the question of whether a small amount of oxygen is required for the formation of the phase with a small addition of $\mathrm{Ti}$ (these samples were all made with intentional inclusion of oxygen). The binary intermetallic $\mathrm{Ti}_{2} \mathrm{Ni}$ can reportedly accomodate oxygen to completely occupy of the $16 \mathrm{c}$ site, forming $\mathrm{Ti}_{4} \mathrm{Ni}_{2} \mathrm{O}$ [79]. The corresponding zirconium compound reported here has complete occupation of the $16 c$ site.

Conflicting reports exist for the $\mathrm{Zr}_{4} \mathrm{Co}_{2} \mathrm{O}$ phase. Nevitt and Downey [39] did not find this phase in determining the $950^{\circ} \mathrm{C}$ isothermal section of this temary system. Hollock and Thummler [74] include $\mathrm{Zr}_{4} \mathrm{Co}_{2} \mathrm{O}(\mathrm{a}=12.18 \AA)$ in a list of phases observed. Attempts to synthesize this phase at $1100^{\circ} \mathrm{C}$ were unsuccessful. However, it was observed that this phase formed in samples prepared with the titanium-contaminated zirconium. By analogy with the substitution of $\mathrm{Ti}$ in $\mathrm{Zr}_{4} \mathrm{Ni}_{2} \mathrm{O}$, this is formulated as $\mathrm{Zr}_{6} \mathrm{Co}_{4} \mathrm{Ti}_{2} \mathrm{O}(\mathrm{a}=11.8649(9) \AA)$, with undetermined oxygen occupancy.

The $\mathrm{Zr} / \mathrm{Cu} / \mathrm{O}$ system was also investigated. The synthesis of both $\mathrm{Zr}_{4} \mathrm{Cu}_{2} \mathrm{O}$ and $\mathrm{Zr}_{6} \mathrm{Cu}_{6} \mathrm{O}$ was attempted. With the $\mathrm{Zr}: \mathrm{Cu}$ starting ratio of $2: 1$, the powder pattem indicated the presence of the desired phase as well as binary $\mathrm{Zr}_{2} \mathrm{Cu}$ as a minor phase. When the starting $\mathrm{Zr}$ : $\mathrm{Cu}$ ratio was $1: 1$ the products were the cubic phase and the binary $\mathrm{Zr}_{3} \mathrm{Cu}_{8}$. The lattice parameters of the $\mathrm{Ti}_{2} \mathrm{Ni}$ type 
phase differed only slightly in all of the samples made. For the nearly single phase sample made with a 2:1 starting metal ratio, $a=12.2659(7) \AA$. The smallest cell edge measured for the cubic phase with the $1: 1$ starting ratio was $a=12.2615(6) \AA$. This leads to the conclusion there is only the one phase, $\mathrm{Zr}_{4} \mathrm{Cu}_{2} \mathrm{O}$, with perhaps a slightly varying oxygen content accounting for the differences in observed cell lengths. Characterization of these phases was done by film data from X-ray powder diffraction experiments. The oxygen is assumed to occupy the $16 c$ site. A significant shortening in the unit cell is observed when $\mathrm{Ti}$ is added to form $\mathrm{Zr}_{6} \mathrm{Cu}_{4} \mathrm{Ti}_{2} \mathrm{O}(\mathrm{a}=12.16(2) \AA)$.

The existence of the two distinct phases in the $\mathrm{Nb} / \mathrm{Ni} / \mathrm{O}$ system reported previously is confirmed [74]. Single crystal $\mathrm{X}$-ray diffraction data for $\mathrm{Nb}_{6} \mathrm{Ni}_{6} \mathrm{O}(\mathrm{a}=11.2117(5) \AA)$ was used to determine oxygen occupancy in this phase, which had been reported as $\mathrm{Nb}_{3} \mathrm{Ni}_{3} \mathrm{O}(\mathrm{a}=11.20 \AA)$. $\mathrm{Nb}_{4} \mathrm{Ni}_{2} \mathrm{O}$ has lattice parameter $\mathrm{a}=11.5933(3) \AA$ (previously reported as $11.58 \AA$ ). Comparison of oxygen occupancies in the $\mathrm{Nb} / \mathrm{Ni} / \mathrm{O}$ samples is incomplete because single crystals of $\mathrm{Nb}_{4} \mathrm{Ni}_{2} \mathrm{O}$ have not been found. The difference in lattice parameters clearly indicates the existence of two distinct phases. This result brings into question the reports of the temary carbide system $\mathrm{Nb} / \mathrm{Ni} / \mathrm{C}$, in which the phases $\mathrm{Nb}_{4} \mathrm{Ni}_{2} \mathrm{C}(\mathrm{a}=11.64 \AA)$ [74], and $\mathrm{Nb}_{3} \mathrm{Ni}_{3} \mathrm{C}(\mathrm{a}=11.659-11.667 \AA$ within a homogeneity range) [83] have almost identical cell edge lengths. Samples of the oxides have been prepared which contain both phases in an equilibrium mixture. The existence of two distinct phases shows the $16 d$ site is occupied either entirely by niobium or by nickel, but not by both in a solid solution on this metal site.

$\mathrm{Ta}_{4} \mathrm{Ni}_{2} \mathrm{O}$ is reported by Holleck \& Thümmler [74], but Kotyk \& Stadelmaier [73] find this phase only exists with nitrogen present, as either $\mathrm{Ta}_{4} \mathrm{Ni}_{2} \mathrm{~N}$ or the mixed $\mathrm{Ta}_{4} \mathrm{Ni}_{2}(\mathrm{O}, \mathrm{N})$, but not as the pure oxide. Efforts to synthesize both $\mathrm{Ta}_{4} \mathrm{Ni}_{2} \mathrm{O}$ and $\mathrm{Ta}_{6} \mathrm{Ni}_{6} \mathrm{O}$, annealing at temperatures between $1430-1550^{\circ} \mathrm{C}$, resulted in mixtures of binary phases. However, noting the effect of titanium in the zirconium compounds, the synthesis of mixed $\mathrm{Ta} / \mathrm{Nb}$ compounds was attempted. Both of the 
starting compositions $\mathrm{Ta}_{6} \mathrm{Ni}_{4} \mathrm{Nb}_{2} \mathrm{O}_{2}$ and $\mathrm{Nb}_{6} \mathrm{Ni}_{4} \mathrm{Ta}_{2} \mathrm{O}_{2}$ were tried. Only the latter formed the cubic phase, at $1550^{\circ} \mathrm{C}$, with $(\mathrm{Ta}, \mathrm{Nb})_{7} \mathrm{Ni}_{6}$ present as a minor phase. A single crystal was selected for study by X-ray diffraction. A psi - scan suitable for absorption correction in the refinement process was not collected. As an empirical absorption correction (DIFABS) did not improve the refinement, no correction was applied in the final refinement. The $\mathrm{Nb}$ and $\mathrm{Ta}$ occupancies were allowed to mix in the refinement, resulting in a final stoichiometry of $\left.\left(\mathrm{Nb}_{0.82} \mathrm{Ta}_{0.18}\right)_{6} \mathrm{Ni}_{4}\left(\mathrm{Ta}_{0.61} \mathrm{Nb}_{0.39}\right)_{2}\right)_{2}$, or $\mathrm{Nb}_{5.7} \mathrm{Ni}_{4} \mathrm{Ta}_{2.3} \mathrm{O}_{2}$.

Crystal data for all the single crystal refinements are listed in Table 4.1. Positional and thermal parameters for the four single crystal refinements are listed in Table 4.2. Table 4.3 contains anisotropic thermal parameters. Interatomic distances are shown in Table 4.4. Table 4.5 summarizes all of the phases identified in this study and corresponding lattice parameters.

$\mathrm{Zr}_{4} \mathrm{Ni}_{2} \mathrm{O}, \mathrm{Nb}_{6} \mathrm{Ni}_{4} \mathrm{Ta}_{2} \mathrm{O}_{2}, \mathrm{Nb}_{4} \mathrm{Ni}_{2} \mathrm{O}$, and $\mathrm{Nb}_{6} \mathrm{Ni}_{6} \mathrm{O}$ were checked for superconductivity down to $6 \mathrm{~K}$. None was detected. Magnetic measurements of the $\mathrm{Zr}_{4} \mathrm{Ni}_{2} \mathrm{O}$ and $\mathrm{Nb}_{6} \mathrm{Ni}_{4} \mathrm{Ta}_{2} \mathrm{O}_{2}$ phases from 6 - $297 \mathrm{~K}$ at a field of 3 Tesla show they are both paramagnetic (Figure 4.6). Figure 4.6 (a) shows a peculiar rise in susceptibility with temperature for $\mathrm{Zr}_{4} \mathrm{Ni}_{2} \mathrm{O}$. Note the expanded scale on this figure. The sample contained an estimated $5 \%$ impurity phase of $\mathrm{ZrO}_{2}$. A correction for the diamagnetism of the impurity phase and the core diamagnetism increases the molar susceptibility by $0.7 \times 10^{-4} \mathrm{emu} / \mathrm{mole}$ from that shown in the figure. The source of the glitch at $225 \mathrm{~K}$ in Figure 4.6 (b) for $\mathrm{Nb}_{6} \mathrm{Ni}_{4} \mathrm{Ta}_{2} \mathrm{O}_{2}$ is unknown. When the temperature was cycled the glitch shifted to $240 \mathrm{~K}$, but did not disappear. This sample contained approximately $10 \%$ of an impurity phase of the $\mathrm{Nb}_{7} \mathrm{Ni}_{6}$ type. No magnetic measurements of $\mathrm{Nb}_{7} \mathrm{Ni}_{6}$ or $\mathrm{Ta}_{7} \mathrm{Ni}_{6}$ have been reported, and as it is possible this phase is paramagnetic also, no correction is made to the measured values. Figure 4.7 contains the results of the magnetic measurements on all the samples measured on the same scale. 
Table 4.3 Anisotropic thermal parameters ${ }^{\mathrm{a}}$ for new phases of filled $\mathrm{Ti}_{2} \mathrm{Ni}$ type

\begin{tabular}{|c|c|c|c|c|}
\hline Atom & $\mathrm{U}_{11}$ & $\mathrm{U}_{22}$ & $\mathrm{U}_{12}$ & $\mathrm{U}_{23}$ \\
\hline \multicolumn{5}{|c|}{$\mathrm{Zr}_{4} \mathrm{Ni}_{2} \mathrm{O}$} \\
\hline $\mathrm{Zr} 1$ & $0.0066(3)$ & $0.0064(3)$ & 0 & $0.0010(4)$ \\
\hline $\mathrm{Ni}$ & $0.02025(5)$ & 0.02025 & $0.002(1)$ & 0.002 \\
\hline $\mathrm{Zr} 2$ & $0.01611(5)$ & 0.01611 & $0.009(1)$ & 0.009 \\
\hline 0 & $0.00712(3)$ & 0.00712 & $0.0000(1)$ & 0.0 \\
\hline \multicolumn{5}{|c|}{$\mathrm{Zr}_{6} \mathrm{Ni}_{4} \mathrm{Ti}_{2} \mathrm{O}_{0.6}$} \\
\hline $\mathrm{Zr}$ & $0.009(1)$ & $0.0094(6)$ & 0 & $0.0000(8)$ \\
\hline $\mathrm{Ni}$ & $0.01494(1)$ & 0.01494 & $0.0003(8)$ & 0.0003 \\
\hline $\mathrm{Ti}$ & $0.01812(2)$ & 0.01812 & $0.008(2)$ & 0.008 \\
\hline 0 & $0.0148(4)$ & 0.0148 & $-0.01(3)$ & -0.01 \\
\hline$O^{b}$ & $0.0125(3)$ & & & \\
\hline \multicolumn{5}{|c|}{$\mathrm{Nb}_{6} \mathrm{Ni}_{6} \mathrm{O}$} \\
\hline $\mathrm{Nb}$ & $0.0073(5)$ & $0.0053(4)$ & 0 & $0.0005(4)$ \\
\hline $\mathrm{Ni} 1$ & $0.004167(5)$ & 0.004167 & $0.0006(4)$ & 0.0006 \\
\hline $\mathrm{Ni} 2$ & $0.005830(7)$ & 0.005830 & $-0.0010(6)$ & 0.0010 \\
\hline $\mathrm{O}^{\mathrm{b}}$ & $0.00630(5)$ & & & \\
\hline \multicolumn{5}{|c|}{$\mathrm{Nb}_{6} \mathrm{Ni}_{4} \mathrm{Ta}_{2} \mathrm{O}$} \\
\hline $\mathrm{Nb}$ & $0.0070(8)$ & $0.0055(6)$ & 0 & $-0.0002(5)$ \\
\hline $\mathrm{Ni}$ & $0.00534(1)$ & 0.00534 & $0.0001(6)$ & 0.0001 \\
\hline $\mathrm{Ta}$ & $0.004421(7)$ & 0.004421 & $-0.0007(3)$ & -0.0007 \\
\hline 0 & $0.01461(6)$ & 0.01461 & $-0.005(6)$ & -0.005 \\
\hline
\end{tabular}

a Symmetry requirements for atoms listed first are $U_{22}=U_{33}$, and $U_{12}=U_{13}=0$. For all other atoms, $U_{11}=U_{22}=U_{33}$, and $U_{12}=U_{13}=U_{23} . U_{33}$ and $U_{13}$ values are not explicitly included on table.

b Isotropic refinement 
Table 4.4 Interatomic distances in new filled- $\mathrm{Ti}_{2} \mathrm{Ni}$ type phases

\begin{tabular}{|c|c|c|c|c|c|}
\hline & & $\mathrm{Zr}_{4} \mathrm{Ni}_{2} \mathrm{O}$ & $\mathrm{Zr}_{6} \mathrm{Ni}_{4} \mathrm{Ti}_{2} \mathrm{O}$ & $\mathrm{Nb}_{6} \mathrm{Ni}_{6} \mathrm{O}$ & $\mathrm{Nb}_{6} \mathrm{Ni}_{4} \mathrm{Ta}_{2} \mathrm{O}_{2}$ \\
\hline \multirow[t]{7}{*}{$M 1^{a}$} & $01 \times 1$ & - & $2.287(2)$ & $2.238(1)$ & - \\
\hline & $02 \times 2$ & $2.2776(7)$ & $2.266(2)$ & -- & $2.162(1)$ \\
\hline & $\mathrm{Ni} \times 2$ & $2.7832(9)$ & $2.861(2)$ & $2.691(1)$ & $2.774(1)$ \\
\hline & $\mathrm{Ni} \times 2$ & $3.152(1)$ & $3.075(2)$ & $2.773(1)$ & $2.9912(6)$ \\
\hline & M2 $\times 2$ & $3.164(1)$ & $3.078(1)$ & $2.7920(8)$ & $2.999(1)$ \\
\hline & M1 x4 & $3.194(1)$ & $3.175(1)$ & $2.915(1)$ & $3.058(1)$ \\
\hline & M1 x4 & $3.248(1)$ & $3.234(1)$ & $3.165(1)$ & $3.075(1)$ \\
\hline \multirow[t]{6}{*}{$\mathrm{Ni}$ - } & M2 $\times 3$ & $2.688(1)$ & $2.600(1)$ & $2.4170(6)$ & $2.4928(6)$ \\
\hline & $\mathrm{Ni} \times 3$ & $3.0910(9)$ & $2.811(5)$ & $2.591(1)$ & $2.657(1)$ \\
\hline & M1 x3 & $2.7832(9)$ & $2.861(2)$ & $2.691(1)$ & $2.774(1)$ \\
\hline & M1 x3 & $3.152(1)$ & $3.075(2)$ & $2.773(1)$ & $2.999(1)$ \\
\hline & $01 \times 1$ & -- & $3.488(3)$ & $3.268(2)$ & - \\
\hline & $\mathrm{O} 2 \times 3$ & $3.534(1)$ & $3.590(2)$ & $\cdots$ & $3.388(1)$ \\
\hline \multirow[t]{2}{*}{$\mathbf{M} 2^{\mathrm{b}}$} & $\mathrm{Ni} \times 6$ & $2.6878(8)$ & $2.600(1)$ & $2.4170(6)$ & $2.4928(6)$ \\
\hline & M1 x6 & $3.164(1)$ & $3.078(1)$ & $2.7920(8)$ & $2.9912(6)$ \\
\hline \multirow[t]{2}{*}{$\mathrm{Ol}^{\mathrm{c}}$} & M1 x6 & - & $2.287(2)$ & $2.238(1)$ & $-\cdot$ \\
\hline & $\mathrm{Ni} \times 4$ & - & $3.488(3)$ & $3.268(2)$ & - \\
\hline \multirow[t]{2}{*}{$\mathrm{O} 2^{\mathrm{d}}$} & M1 $\times 6$ & $2.2776(7)$ & $2.266(2)$ & - & $2.162(1)$ \\
\hline & $\mathrm{Ni} \times 6$ & $3.534(1)$ & $3.590(2)$ & $\cdots$ & $3.388(1)$ \\
\hline
\end{tabular}

${ }^{\mathrm{a}} \mathrm{M} 1=\mathrm{Zr}$ or $\mathrm{Nb}$ in $48 f$

${ }^{\mathrm{b}} \mathrm{M} 2=\mathrm{Zr}, \mathrm{Ti}, \mathrm{Ni}$, or $\mathrm{Ta}$ in $16 d$

${ }^{\mathrm{c}} \mathrm{O} 1=\mathrm{O}$ in $8 a$

${ }^{\mathrm{d}} \mathrm{O} 2=\mathrm{O}$ in $16 c$ 
Table 4.5 Lattice Parameters for all new filled- $\mathrm{Ti}_{2} \mathrm{Ni}$ type phases found

\begin{tabular}{lc}
\hline Composition & $\mathrm{a}(\AA)$ \\
\hline $\mathrm{Zr}_{4} \mathrm{Cu}_{2} \mathrm{O}$ & $12.2659(7)$ \\
$\mathrm{Zr}_{4} \mathrm{Ni}_{2} \mathrm{O}$ & $12.1970(9)$ \\
$\mathrm{Zr}_{6} \mathrm{Ni}_{4} \mathrm{Ti}_{2} \mathrm{O}_{0.6}$ & $12.0299(9)$ \\
$\mathrm{Zr}_{6} \mathrm{Co}_{4} \mathrm{Ti}_{2} \mathrm{O}$ & $11.8649(9)$ \\
$\mathrm{Nb}_{4} \mathrm{Ni}_{2} \mathrm{O}$ & $11.5933(3)$ \\
$\mathrm{Nb}_{6} \mathrm{Ni}_{4} \mathrm{Ta}_{2} \mathrm{O}_{2}$ & $11.5813(3)$ \\
$\mathrm{Nb}_{6} \mathrm{Ni}_{6} \mathrm{O}$ & $11.2117(5)$ \\
\hline
\end{tabular}




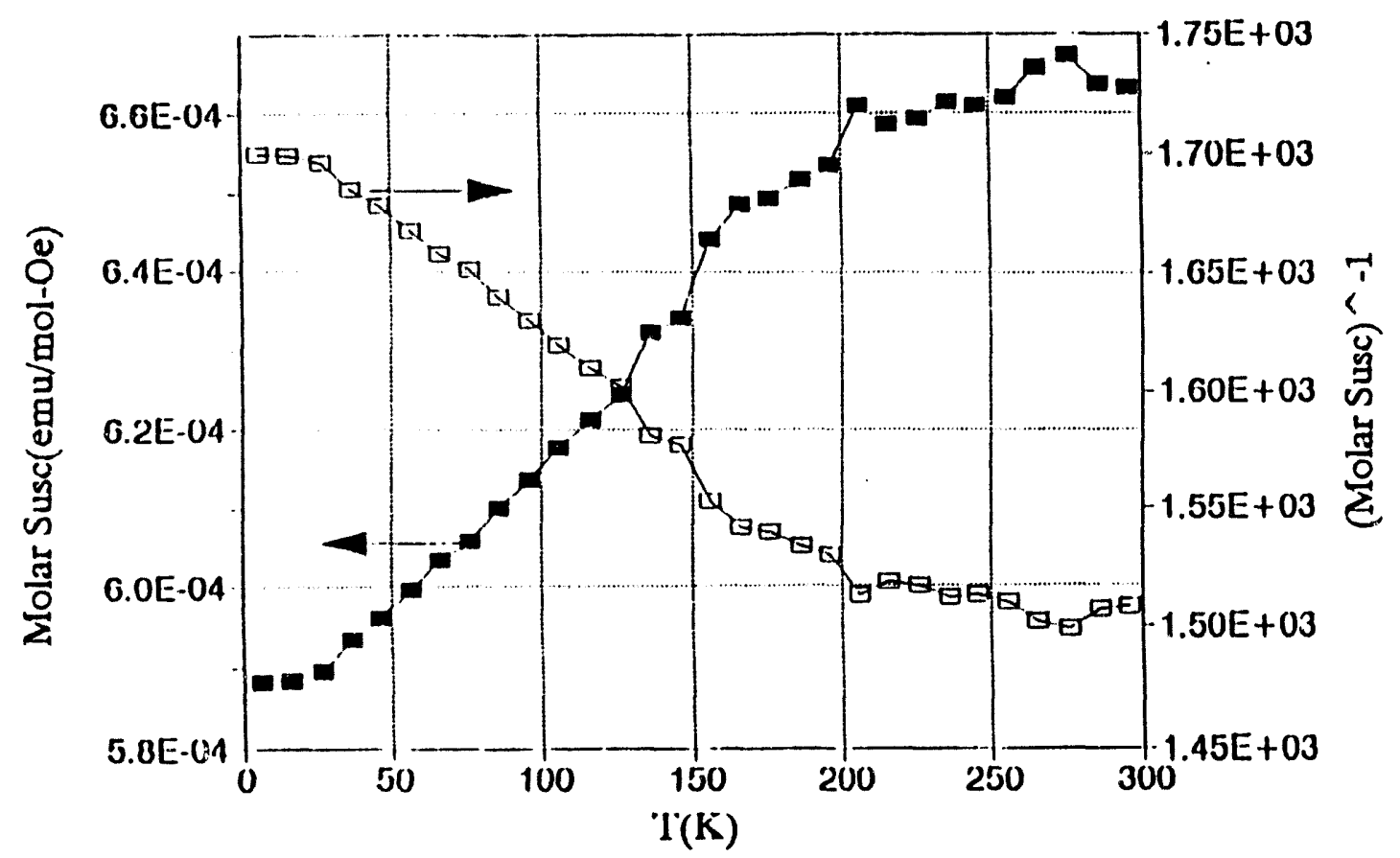

(a)

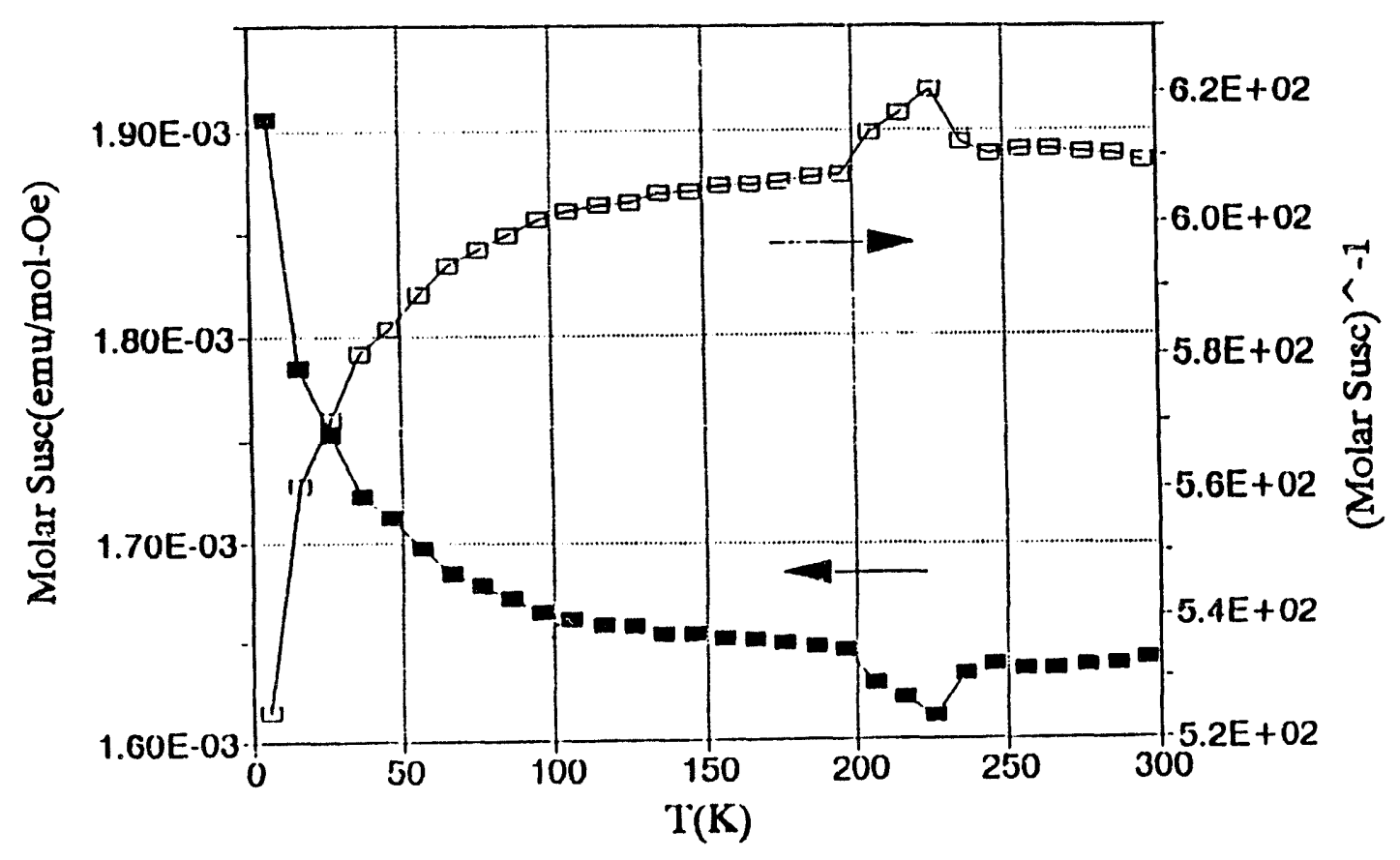

(b)

Figure 4.6 (a) Magnetic susceptibility of $\mathrm{Zr}_{4} \mathrm{Ni}_{2} \mathrm{O}$. (b) Magnetic susceptibility of $\mathrm{Nb}_{6} \mathrm{Ni}_{4} \mathrm{Ta}_{2} \mathrm{O}_{2}$. 

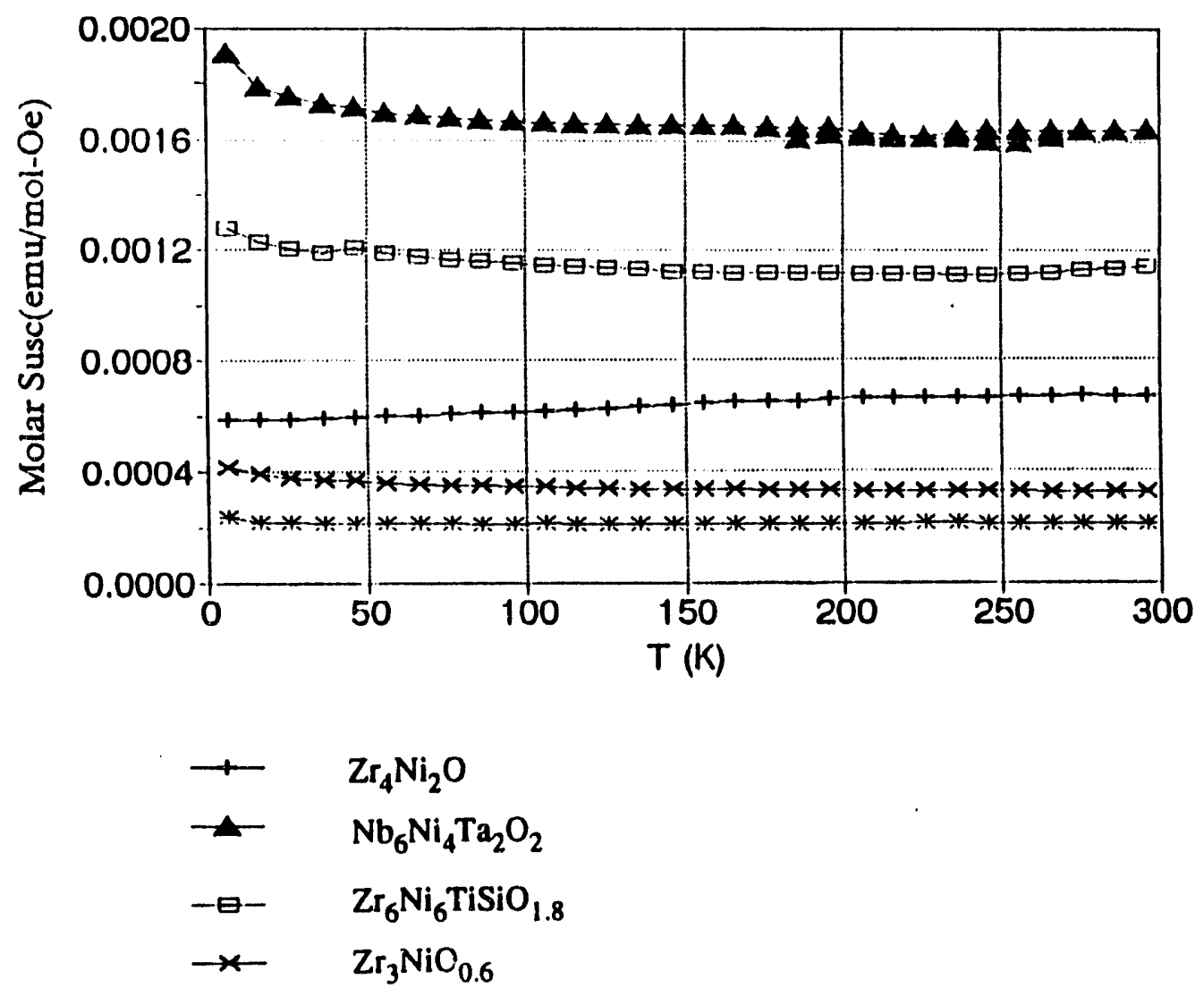

* Cubic Laves phase $\mathrm{Zr} / \mathrm{Ni} / \mathrm{O}$

Figure 4.7 Summary of magnelic propertics of phases studied in this research. 


\section{Band Calculations}

Band calculations were done in an effort to explain the role of oxygen in the $\mathrm{Zr}_{4} \mathrm{Ni}_{2} \mathrm{O}$ phase, and determine if calculations could predict a preferred ordering of oxygen. Calculations were performed also on the compound $\mathrm{Nb}_{6} \mathrm{Ni}_{6} \mathrm{O}$ in an attempt to correlate the oxygen ordering with the metal ratios. The calculations were of the extended Hückel type using the tight binding method. The programs were described previously in the second chapter on Experimental Techniques. Density of states (DOS) diagrams and crystal orbital overlap population (COOP) curves were obtained, in addition to Fermi energies, total energies, orbital populations, and overlap populations of specific interactions. The atomic parameters used for the calculations are listed in Table 4.5. Calculations were done on the primitive cell of the large face center cubic cell. The k-points used for the calculation were chosen automatically by the program. The number of k-points used affects the accuracy of the results, and also determines the computer time required. Ten k-points were used for these calculations.

Table 4.5 Atomic parameters used for extended Hückel calculations

\begin{tabular}{lllllll}
\hline Atom & Orbital & $\mathrm{H}_{\mathrm{ij}}, \mathrm{eV}$ & $\zeta_{1}{ }^{\mathrm{a}}$ & $\zeta_{2}{ }^{\mathrm{a}}$ & $\mathrm{c}_{1}{ }^{\mathrm{b}}$ & $\mathrm{c}_{2}{ }^{\mathrm{b}}$ \\
\hline $\mathrm{Zr}^{\mathrm{c}}$ & $4 \mathrm{~d}$ & -8.65 & 3.84 & 1.505 & 0.6213 & 0.5798 \\
& $5 \mathrm{~s}$ & -7.78 & 1.82 & & & \\
& $5 \mathrm{p}$ & -4.96 & 1.78 & & & \\
$\mathrm{Ni}^{\mathrm{d}}$ & $3 \mathrm{~d}$ & -12.99 & 5.75 & 2.20 & 0.5817 & 0.5800 \\
& $4 \mathrm{~s}$ & -8.86 & 1.925 & & & \\
& $4 \mathrm{p}$ & -4.90 & 1.925 & & & \\
$\mathrm{O}^{\mathrm{e}}$ & $2 \mathrm{~s}$ & -32.3 & 2.275 & & & \\
& $2 \mathrm{p}$ & -14.8 & 2.275 & & & \\
\hline
\end{tabular}

${ }^{a}$ Exponent in the double $\zeta$ function for $\mathrm{d}$ orbitals

${ }^{b}$ Coefficients to exponential terms

${ }^{c}$ Parameters taken from [85]

d Parameters taken from[86]

e Parameters taken from [87] 
The calculations carried out did not give clear answers to the questions asked. A clear preference for ordering of oxygen was not observed in $\mathrm{Zr}_{4} \mathrm{Ni}_{2} \mathrm{O}$, as would be indicated by a lowering of the total energy of the system. To explain the subtle energy differences between oxygen occupying the different crystallographic sites, the possibility that the calculations might be sensitive to the starting parameters was considered. Consequently, a charge iterative procedure was performed to obtain new $\mathrm{H}_{\mathrm{ii}}$, ionization potential, values for zirconium and nickel. These new parameters are listed in Table 4.6 and were used to repeat several of the band calculations performed previously. However, again there was no clear preference calculated for ordering of the oxygen. The charge iteration was done only for zirconium and nickel. The oxygen parameters were kept the same. The iteration was done on the binary $\mathrm{Zr}_{2} \mathrm{Ni}$, which has the $\mathrm{Al}_{2} \mathrm{Cu}$ type structure, with the assumption the parameters of the intermetallic would be very similar to those of the oxide. That this is a fair assumption can be inferred from the fact that the initial values were obtained from calculations on $\mathrm{ZrCl}$ for zirconium and on $\mathrm{Ni}(\mathrm{CO})_{4}$ for nickel. Performing the charge iteration on $\mathrm{Zr}_{2} \mathrm{Ni}$ saved time as well, since it has a much smaller unit cell than the oxide. Eleven cycles were necessary for the parameters to converge to the values listed in the table.

Table 4.6 Atomic parameters obtained from charge iteration on $\mathrm{Zr}_{2} \mathrm{Ni}$

\begin{tabular}{lll}
\hline Atom & Orbital & $\mathrm{H}_{\mathrm{ii}}, \mathrm{eV}$ \\
\hline $\mathrm{Zr}^{\mathrm{a}}$ & $4 \mathrm{~d}$ & -6.72 \\
& $5 \mathrm{~s}$ & -7.06 \\
& $5 \mathrm{p}$ & -3.68 \\
$\mathrm{Ni}^{\mathrm{b}}$ & $3 \mathrm{~d}$ & -8.43 \\
& $4 \mathrm{~s}$ & -6.76 \\
& $4 \mathrm{p}$ & -3.03 \\
\hline
\end{tabular}

a A, B, C parameters for $\mathrm{H}_{\mathrm{ii}}=\mathrm{Aq}^{2}+\mathrm{Bq}+\mathrm{C}$ taken from [88]

${ }^{b}$ A, B, C parameters taken from [89] 
General features of the DOS plots of $\mathrm{Zr}_{4} \mathrm{Ni}_{2} \mathrm{O}$ can be seen in Figures 4.8 and 4.9. Figure 4.8 (a) shows the DOS plot using the initial $H_{\mathrm{ii}}$ values listed in Table 4.5. Figure 4.8 (b) shows the same plot using the $\mathrm{H}_{\mathrm{ii}}$ values obtained from the charge iteration, listed in Table 4.6. The most obvious result of the charge iteration procedure is the shift of all the levels to higher energies, except those for oxygen, for which parameters were not changed. The narrow band below $-15 \mathrm{eV}$ is principally oxygen $2 \mathrm{p}$ in character. Figure 4.8 (a) shows a contracted band between -14 and $-12 \mathrm{eV}$, and a broad band from $-12 \mathrm{eV}$ and up. These bands can be assigned as being principally the nickel $d$ band and zirconium $d$ band, respectively. The $d$ bands for late transition metals are more contracted than are those for early transition metals. In Figure 4.8 (b) the nickel $\mathrm{d}$ band is more contracted and is centered at about $-9 \mathrm{eV}$, overlapping with the zirconium $\mathrm{d}$ band. The zirconium d band has the same general shape both with and without the charge iteration, but it is shifted to higher energies in (b). The broad, shallow $\mathrm{Zr}$ s and $\mathrm{Ni} \mathrm{s}$ bands are in this region also. The projection of the individual atoms on the total DOS is shown in Figure 4.9 for the results from the charge iteration. Figure 4.9 (a) shows the projection of the $\mathrm{Zr} 1$ atoms on the total DOS. These are the zirconium atoms which make up the network of face-sharing octahedra. The oxygen atoms center an alternating set of these octahedra, and the mixing of zirconium with the oxygen $p$ band is seen at low energy. The broad zirconium $d$ band is seen at higher energy. Figure 4.9 (b) similarly shows the broad $d$ band of zirconium in the icosahedral environment. Figure 4.9 (c) shows the narrow nickel $d$ band, with nickel character extending up through the conduction band to higher energy. These general features are the same for both DOS plots in Figure 4.8. In both, the Fermi level is in the middle of the conduction band. The shifting of ionization potentials results in a shift of the calculated Fermi Energy from $-9.386 \mathrm{eV}$ to $-7.205 \mathrm{eV}$. Another consequence of the charge iterative procedure was a change in orbital populations calculated for each atom. These changes are shown in Table 4.7, below. This shows the result of raising the ionization potentials of the metal 


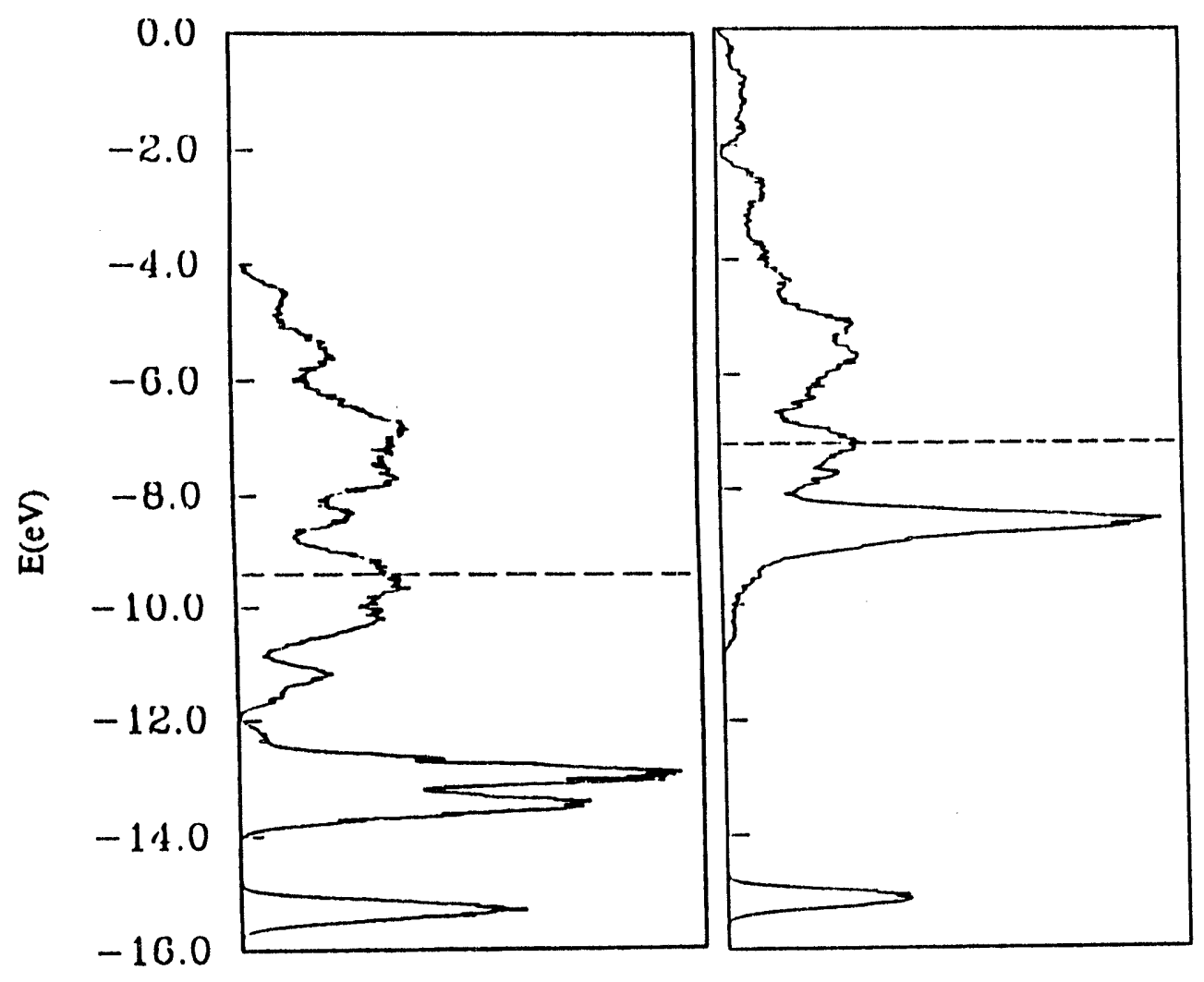

(a)

(b)

Figure 4.8

Total density of states plots for $\mathrm{Zr}_{4} \mathrm{Ni}_{2} \mathrm{O}$. Fermi cnergy indicated by dashed line. (a) DOS before charge iteration. (b) DOS after charge iteration. 


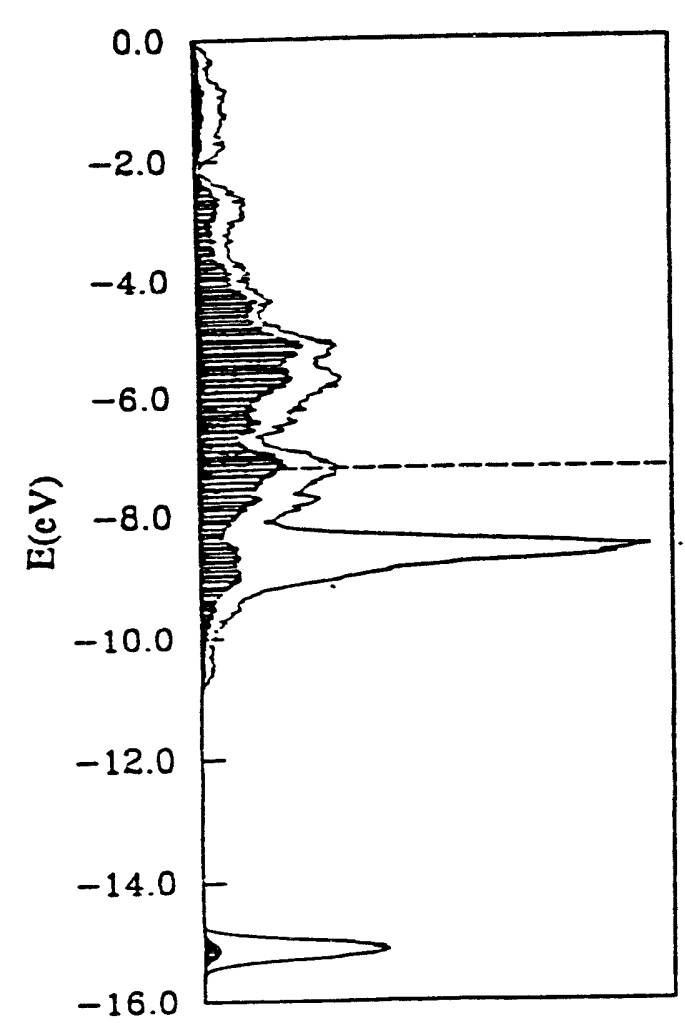

(a)

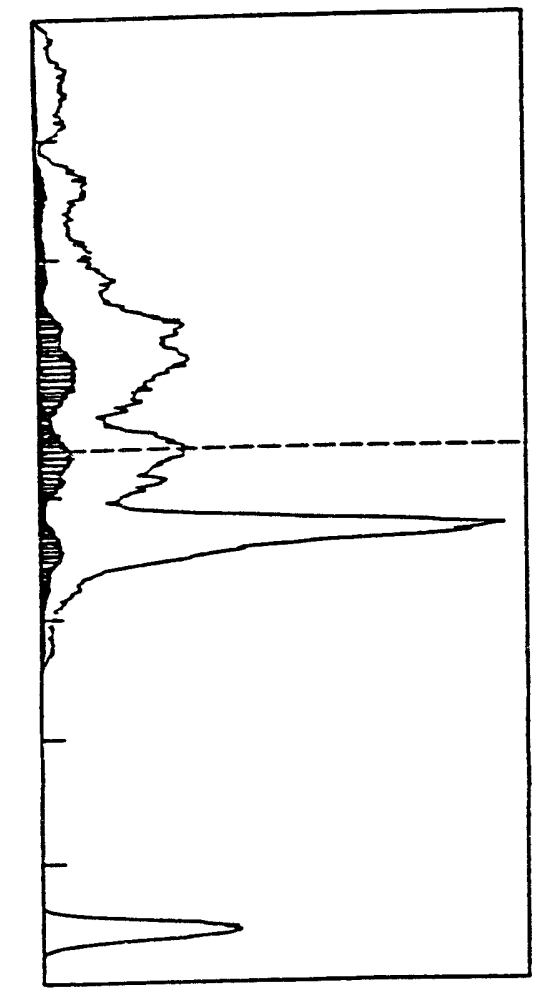

(b)

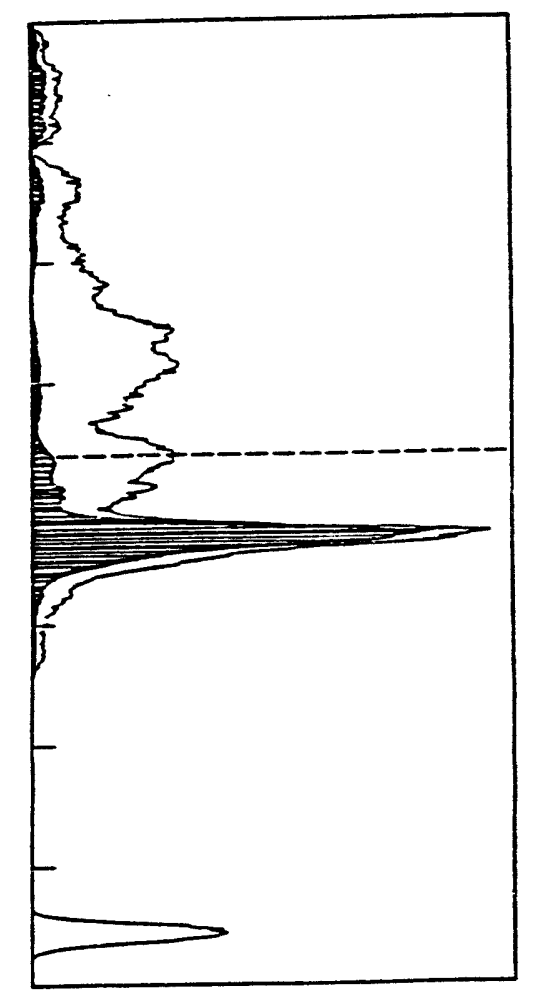

(c)

Figure 4.9

Projection of individual atomic contributions on total DOS for $\mathrm{Zr}_{4} \mathrm{Ni}_{2} \mathrm{O}$.

(a) Projection of $\mathrm{Zr}$ l on total DOS (b) Projection of $\mathrm{Zr} 2$ on total DOS (c) Projection of Ni on total DOS 
atoms to nearly the same level. There is less charge transfer between zirconium and nickel, or less ionic character, indicative of metal - metal bonding and more realistic for intermetallic compounds, as for example, nickel changes from $\mathrm{Ni}^{-0.7}$ when the initial parameters are used, to $\mathrm{Ni}^{-0.3}$ using the parameters obtained from the charge iteration. The $\mathrm{Zr} 2$ becomes negatively charged. Oxygen builds up a higher charge, as these orbitals are kept at low energy even as the metal orbitals rise as a result of the charge iteration.

Table 4.7 Calculated orbital populations

\begin{tabular}{lll}
\hline Atom & Initial parameters & Charge iteration parameters \\
\hline $\mathrm{Zr} 1$ & 3.1 & 3.3 \\
$\mathrm{Ni}$ & 10.7 & 10.3 \\
$\mathrm{Zr} 2$ & 4.0 & 4.3 \\
$\mathrm{O}$ & 7.1 & 7.4 \\
\hline
\end{tabular}

For comparison of results a consistent set of parameters is needed. The results reported here are those obtained using the parameters from the charge iteration procedure. In all of the calculations, the $\mathrm{Zr} 1$ atoms were placed on the "idealized" atom position [84], making all octahedral sites equal in size to avoid biasing the results and favoring a site for oxygen occupancy dependent on size factors. The nickel position was shifted to be between the observed atom position and the "idealized" atom position. The approach taken to this problem was to determine the effect the ordering of oxygen would have in the density of states and the total energy in the $\mathrm{Zr}_{4} \mathrm{Ni}_{2} \mathrm{O}$ phase. Figure 4.10 (a) shows the total density of states for the hypothetical oxygen-free $\mathrm{Zr}_{4} \mathrm{Ni}_{2}$ with the $\mathrm{Ti}_{2} \mathrm{Ni}$ type structure. One can see in Figure 4.10 (b) the effect adding oxygen has to the DOS curve. The nickel band is unaffected by the addition of oxygen, as expecteci, since there are no nickel oxygen interactions. Small changes in the DOS are seen at -7 and $-9 \mathrm{eV}$, as zirconium metal 


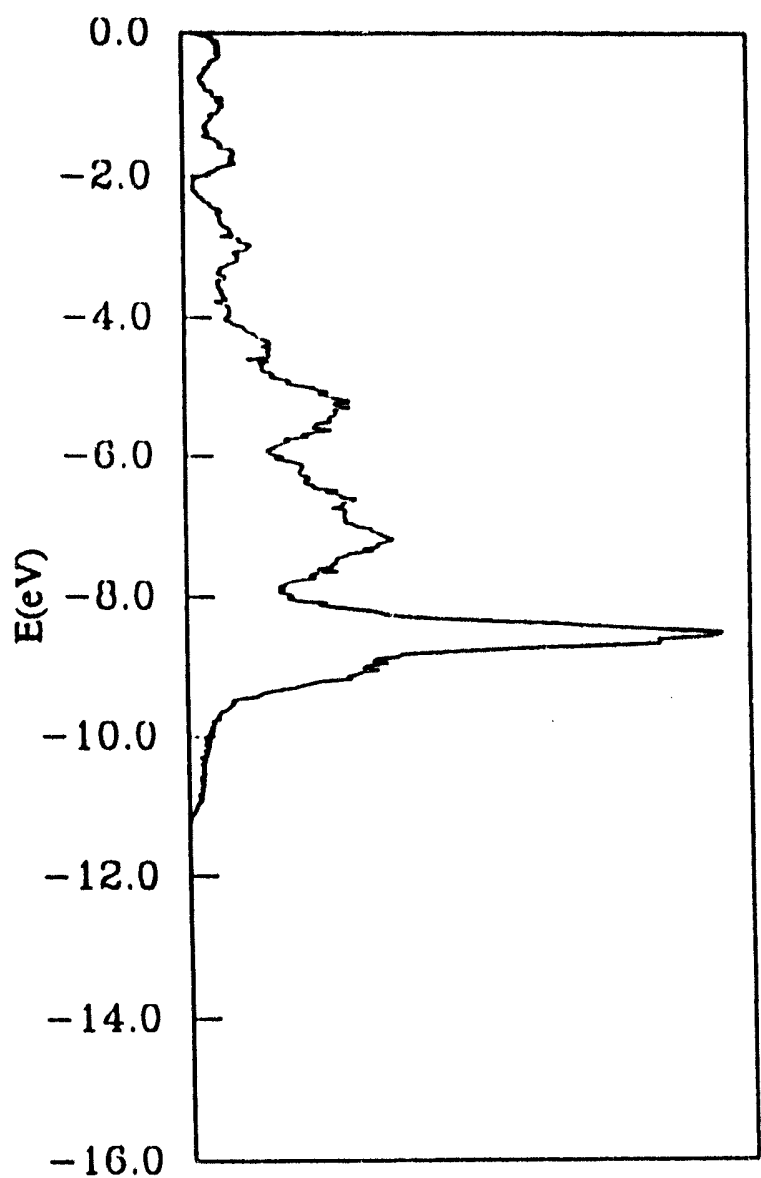

(a)

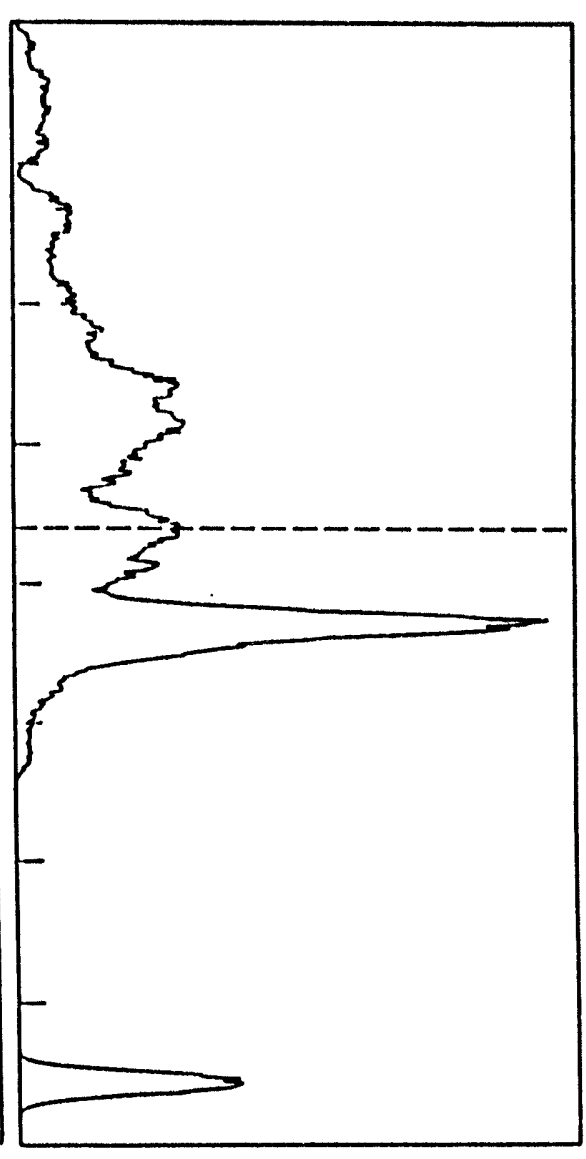

(b)

Figure 4.10

Effect on DOS of adding oxygen to the system

(a) DOS plot for hypothetical $\mathrm{Zr}_{4} \mathrm{Ni}_{2}$

(b) DOS plot for $\mathrm{Zr}_{4} \mathrm{Ni}_{2} \mathrm{O}$. 


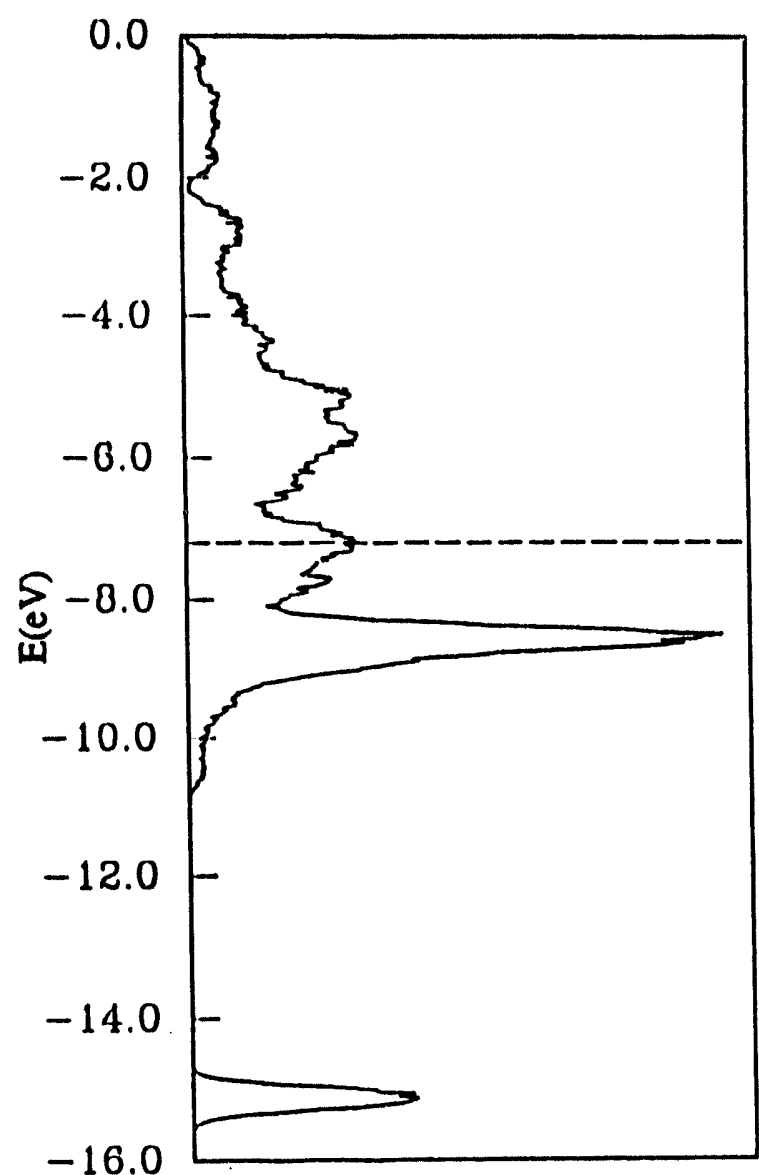

(a)

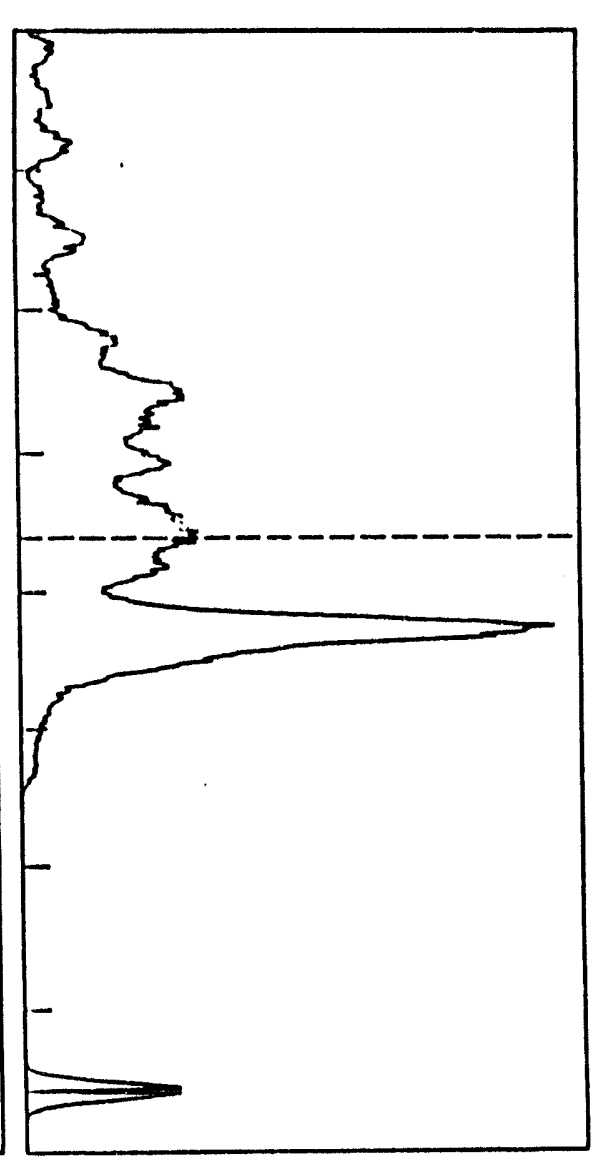

(b)

Figure 4.11

Effect on DOS of oxygen occupying different crystallographic sites.

(a) DOS when oxygen occupies 160 site, as observed in $\mathrm{Zr}_{4} \mathrm{Ni}_{2} \mathrm{O}$.

(b) DOS when oxygen occupies $8 a$ site, as in hypothetical $\mathrm{Zr}_{4} \mathrm{Ni}_{2} \mathrm{O}_{1 / 2}$. 
becomes involved in zirconium - oxygen bond formation. Figure 4.11 compares the effect on the DOS of adding oxygen to the sixteen - fold site, as is observed by the single crystal refinement, and adding oxygen to the other possible octahedral site, an eight · fold site. Little difference is observed between the two plots. The Fermi energies and total energies for each of these calculations are shown in Table 4.8. The bottom row of Table 4.8 is the total energy gain per oxygen atom added to the system. The formation of $\mathrm{Zr}_{4} \mathrm{Ni}_{2} \mathrm{O}$ from $\mathrm{Zr}_{4} \mathrm{Ni}_{2}$ decreases the total energy of the system from $-1225.62 \mathrm{eV}$ to $-1775.43 \mathrm{eV}$, or by $-549.81 \mathrm{eV}$. There are four oxygen atoms in the primitive unit cell, so the energy change per oxygen atom is one-fourth the total change, or $-137.45 \mathrm{eV}$. By comparing the change per oxygen atom, the results of adding different amounts of oxygen can be compared. The table shows the two results differ by only $0.31 \mathrm{eV}$ per oxygen. The calculated preferred ordering is in favor of the observed result, but it is doubtful the difference is significant within the errors of the calculations associated with the approximations of the extended Hückel method.

Table 4.8 Fermi energy and total energy of calculated phases (eV)

\begin{tabular}{llll}
\hline & $\mathrm{Zr}_{4} \mathrm{Ni}_{2}$ & $\mathrm{Zr}_{4} \mathrm{Ni}_{2} \mathrm{O}_{1 / 2}$ & $\mathrm{Zr}_{4} \mathrm{Ni}_{2} \mathrm{O}$ \\
\hline Fermi energy, $\mathrm{E}_{\mathrm{F}}$ & -7.242 & -7.212 & -7.205 \\
Total energy, $\mathrm{E}_{\mathrm{T}}$ & -1225.62 & -1499.91 & -1775.43 \\
$\Delta \mathrm{E}_{\mathrm{T}}$ oxygen & & -137.14 & -137.45 \\
\hline
\end{tabular}

The results of the single crystal refinement of $\mathrm{Nb}_{6} \mathrm{Ni}_{6} \mathrm{O}$ show the oxygen can occupy the eight fold site in the structure. Not only is the oxygen occupancy different in this compound from $\mathrm{Zr}_{4} \mathrm{Ni}_{2} \mathrm{O}$, but the metal/metal ratio is also different. An attempt was made to determine if there was a correlation between the differences in the oxygen and metal orderings. Calculations were done on the compound $\mathrm{Nb}_{6} \mathrm{Ni}_{6} \mathrm{O}$, using for niobium the zirconium parameters from the charge iteration. 
Figure 4.12 illustrates how changing the metal framework from the hypothetical $\mathrm{Nb}_{8} \mathrm{Ni}_{4}$ to the also hypothetical $\mathrm{Nb}_{6} \mathrm{Ni}_{6}$ effects the DOS. The nickel $\mathrm{d}$ band is broadened slightly, as might be expected from additional nickel atoms. Figure 4.13 is the result of the calculations for the observed $\mathrm{Nb}_{6} \mathrm{Ni}_{6} \mathrm{O}$ and the hypothetical $\mathrm{Nb}_{6} \mathrm{Ni}_{6} \mathrm{O}_{2}$. Table 4.9 lists the energies associated with each of these phases. Again, there is little difference observed in the DOS plots. The changes in energy per oxygen atom are such that the observed phase is again favored, but by only $0.15 \mathrm{eV}$. In addition to the uncertainty within the calculations, another caution to the interpretation of these numbers must be added. The calculations do not allow for nonstoichiometry, or partial filling of the sites. If only half of the sixteen - fold sites are occupied by oxygen, the stoichiometry is the same as for the the observed phase, $\mathrm{Nb}_{6} \mathrm{Ni}_{6} \mathrm{O}$. The program does not allow random partial occupancy of any sites. Electron counts can be varied, but the sites must be either completely filled or empty. For this calculation, then, two of the four oxygen sites were filled, and the other two were empty. The total energy for this phase was $-1789.01 \mathrm{eV}$, resulting in a stabilization of $-136.82 \mathrm{eV}$ per oxygen atom. This is only $0.04 \mathrm{eV}$ difference with the calculated energy for the observed structure. If these results show anything, it may be that the important consideration is not which site is occupied, but rather the amount of oxygen the system requires for maximum stabilization.

Table 4.9 Fermi energy and total energy of calculated phases (eV)

\begin{tabular}{llll}
\hline & $\mathrm{Nb}_{6} \mathrm{Ni}_{6}$ & $\mathrm{Nb}_{6} \mathrm{Ni}_{6} \mathrm{O}$ & $\mathrm{Nb}_{6} \mathrm{Ni}_{6} \mathrm{O}_{2}$ \\
\hline Fermi energy, $\mathrm{E}_{\mathrm{F}}$ & -7.087 & -7.027 & -6.817 \\
Total energy, $\mathrm{E}_{\mathrm{T}}$ & -1515.37 & -1789.10 & -2062.22 \\
$\iota \mathrm{E}_{\mathrm{T}}$ oxygen & & -136.86 & -136.71 \\
\hline
\end{tabular}

Crystal orbital overlap population (COOP) curves were calculated for the interactions in $\mathrm{Zr}_{4} \mathrm{Ni}_{2} \mathrm{O}$. The calculated overlap populations are tabulated in Table 4.10. Nickel - nickel overlap 


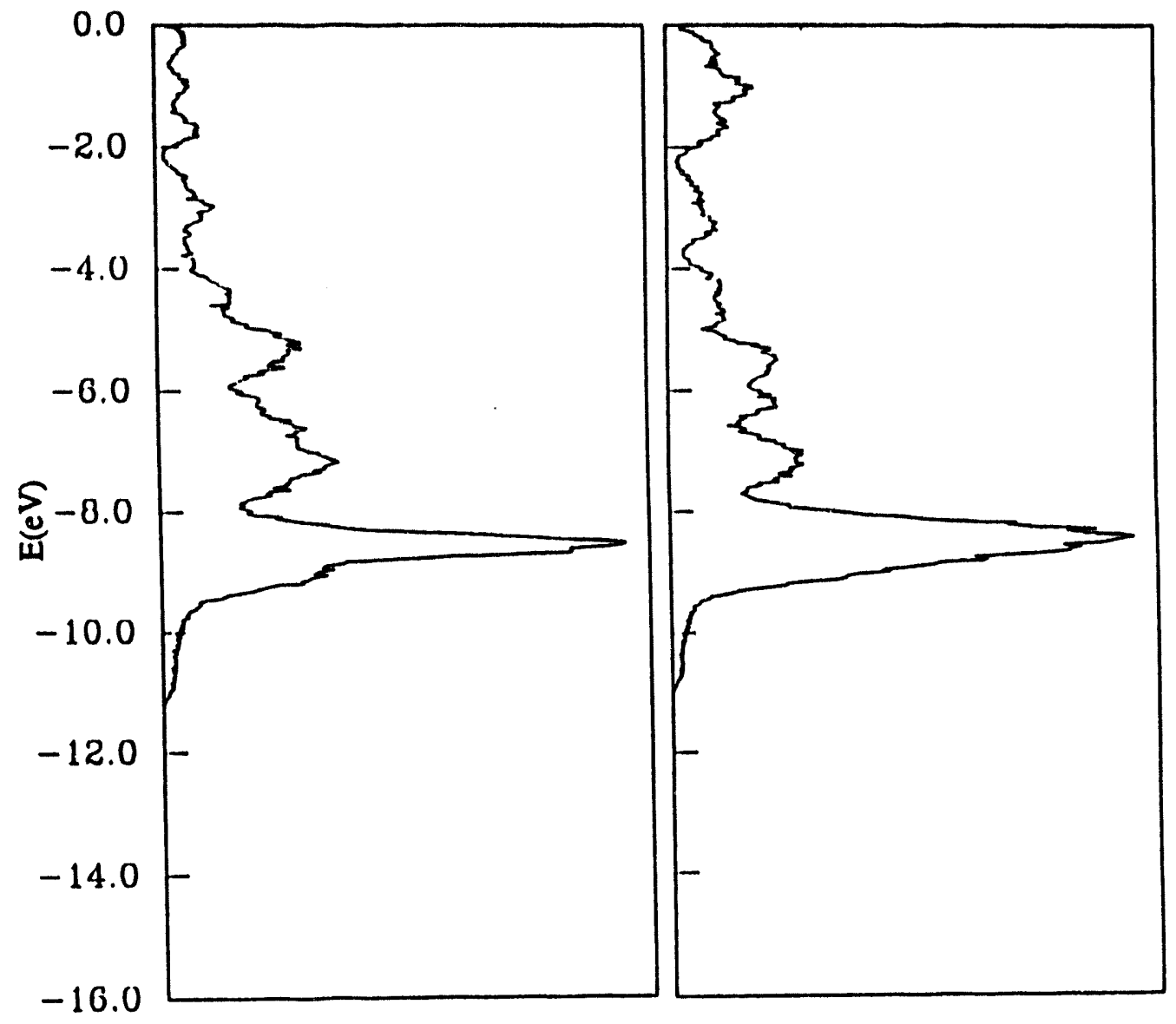

(a)

(b)

Figure 4.12

Effect on DOS of changing metal/metal ratio in $\mathrm{Ti}_{2} \mathrm{Ni}$ type structure.

(a) DOS for $\mathrm{Nb}_{8} \mathrm{Ni}_{4}$

(b) DOS for $\mathrm{Nb}_{6} \mathrm{Ni}_{6}$ 


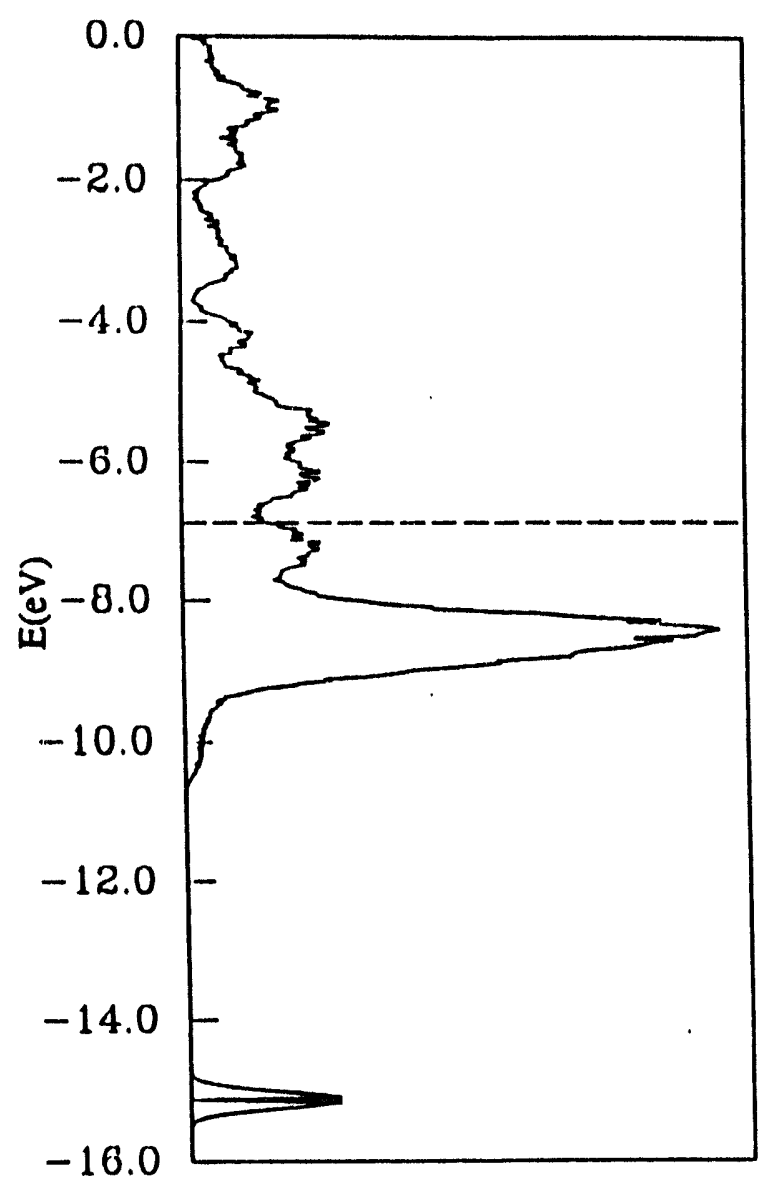

(a)

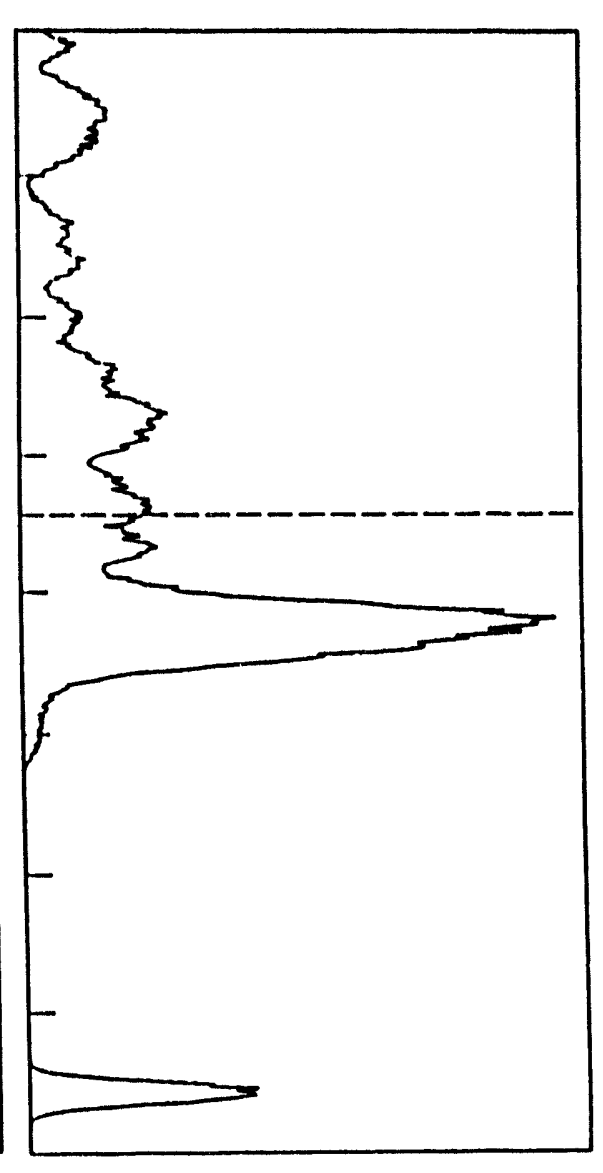

(b)

Figure 4.13

Effect on DOS of oxygen occupying different crystallographic sites.

(a) DOS when oxygen occupies the $8 a$ sile, as observed in $\mathrm{Nb}_{6} \mathrm{Ni}_{6} \mathrm{O}$.

(b) DOS when oxygen occupies the $16 c$ site, as in hypothetical $\mathrm{Nb}_{6} \mathrm{Ni}_{6} \mathrm{O}_{2}$. 
population was very low, about one one-thousandth, and is not included in the table. There are twenty - four symmetry related $\mathrm{Zr} 2$ - Zr1 interactions in the unit call. In fact, there are twenty four symmetry related interactions for each of the combinations listed. The sum of the overlap populations of the symmetry related bonds are plotted in the COOP curves. The program would not yield the sum of all the overlap populations in one curve, so the interactions were broken down into smaller groups. Figure 4.14 (a) contains the sum of all $\mathrm{Zr} 2-\mathrm{Zr} 1$ and $\mathrm{Zr} 2-\mathrm{Ni}$ overlap populations. Figure 4.14 (b) contains the sum of the $\mathrm{Zr} 1-\mathrm{Zr}$ l and the short $\mathrm{Zr} 1-\mathrm{Ni}$ overlap populations. Each of these COOP curves show empty bonding orbitals above the Fermi level. The only indication of antibonding character at the Fermi level is in the COOP curve for $\mathrm{Zr} 1$ - O interactions, in Figure 4.14 (c). The calculation of empty bonding levels was the motivation for the synthesis of more electron - rich compounds than $\mathrm{Zr}_{4} \mathrm{Ni}_{2} \mathrm{O}$, substituting niobium for zirconium, or copper for nickel.

Table 4.10 Overlap populations for $\mathrm{Zr}_{4} \mathrm{Ni}_{2} \mathrm{O}$

\begin{tabular}{lcc}
\hline Atomic interaction & Overlap population & Interatomic distance $(\AA)$ \\
\hline $\mathrm{Zr} 2-\mathrm{Zr} 1$ & 0.1646 & 3.12 \\
$\mathrm{Zr} 1-\mathrm{Ni}$ & 0.1347 & 2.76 \\
$\mathrm{Zr} 1-\mathrm{O}$ & 0.1089 & 2.27 \\
$\mathrm{Zr} 2-\mathrm{Ni}$ & 0.1014 & 2.67 \\
$\mathrm{Zr} 1-\mathrm{Zr} 1$ & 0.0980 & 3.21 \\
$\mathrm{Zr} 1-\mathrm{Ni}$ & 0.0412 & 3.10 \\
\hline
\end{tabular}

Discussion

The $\mathrm{Ti}_{2} \mathrm{Ni}$ type structure has been described in terms of two interpenetrating three-dimensional networks made of idealized octahedra and tetrahedra [84]. Table 4.2 lists the idealized positions that 


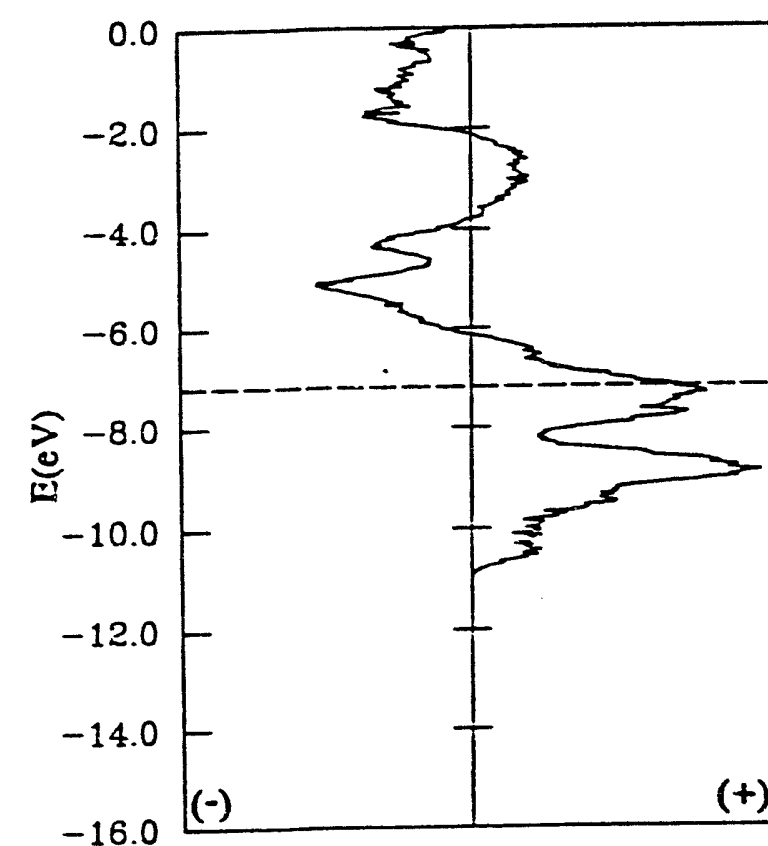

(a)

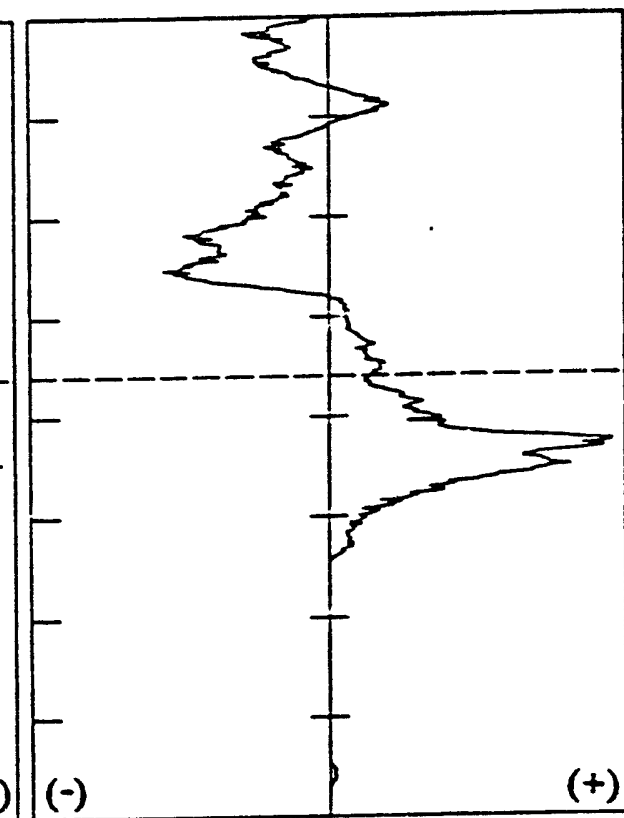

(b)

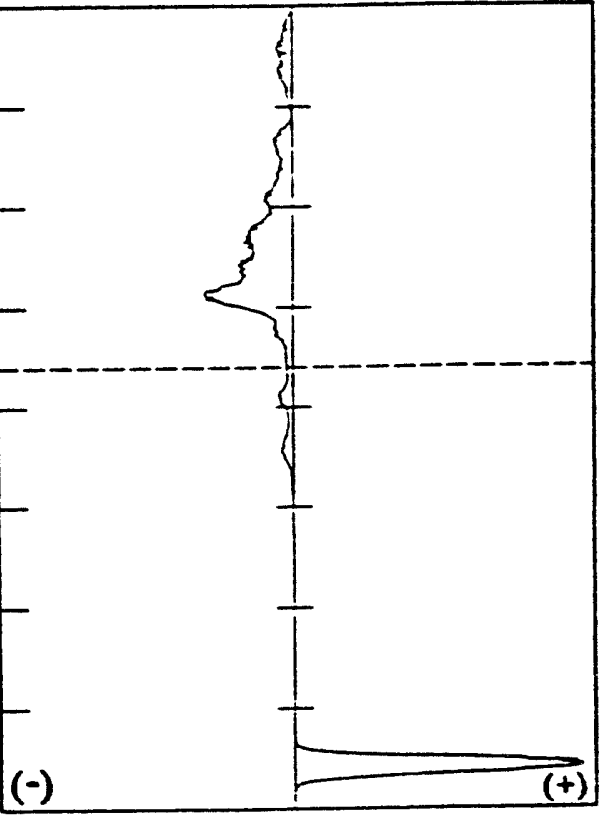

(c)

Figure 4.14 COOP curves for $\mathrm{Zr}_{4} \mathrm{Ni}_{2} \mathrm{O}$. Fermi level indicated by dashed line. Bonding interactions indicated by $(+)$, and antibonding by (-) (a) Sum of Zr2 - Zrl and $\mathrm{Zr} 2$ - Ni overlap populations. (b) Sum of Zrl - Zrl and Zrl - Ni overlap populations. (c) Sum of $Z r 1-O$ overlap populations. 
would give regular polyhedra. A network of octahedra is formed by the metal atoms on the $48 \mathrm{f}$ site. Figure 4.4 shows this network of octahedra, with oygen occupying the $16 c$ site. With the idealized parameters, M1 is at $(x, 0,0)$ with $x=0.1875$, and all the face sharing octahedra are exactly the same size. When $x$ deviates from this position the octahedra centered at an $8 a$ site maintain ideal octahedral symmetry, but the other octahedra, centered at $16 c$ site, lose their four fold symmetry, and become distorted octahedra, or more precisely, trigonal antiprisms. The direction of the deviation of $x$ from ideality is related to the oxygen occupancy. The octahedra, regular or distorted, centered by oxygen are expanded. When oxygen occupies the $8 a$ site, at the origin, the expansion of the regular octahedron corresponds to an increased value for $x$ (compare $\mathrm{Nb}_{6} \mathrm{Ni}_{6} \mathrm{O}$, with $x=0.1996$, and ideal $x=0.1875$ ). Occupancy of the $16 c$ site causes expansion of the distorted octahedra, or trigonal antiprisms, and a corresponding decrease in $x$ (compare $x=0.1852$ in $\mathrm{Zr}_{4} \mathrm{Ni}_{2} \mathrm{O}$ and $x=0.1867$ in $\mathrm{Nb}_{6} \mathrm{Ni}_{4} \mathrm{Ta}_{2} \mathrm{O}_{2}$, with ideal $x=0.1875$ ). The expansion of the oxygen - centered octahedra can be interpreted as resulting from the filled antibonding metal - oxygen orbitals, as seen in Figure 4.12 (c) for $\mathrm{Zr}_{4} \mathrm{Ni}_{2} \mathrm{O}$. Oxygen occupancy is not the full story, however. In the case of the binary $\mathrm{Ti}_{2} \mathrm{Ni}$ [79], with no oxygen, $x=0.189$, and is also expanded from the ideal framework. Likewise, in $\mathrm{Zr}_{6} \mathrm{Ni}_{4} \mathrm{Ti}_{2} \mathrm{O}_{0.6}$, where oxygen is in both sites, $x$ increases. Only one reference suggests the simultaneous occupation of both $8 a$ and $16 c$ sites in $\mathrm{Nb}_{8} \mathrm{Zn}_{4} \mathrm{C}_{3}$ [71], noting the $\mathrm{C}-\mathrm{C}$ separation would be comparable to the spacing between octahedral sites in the filled - $\mathrm{Mn}_{5} \mathrm{Si}_{3}$ type structures. The stoichiometry of this phase was determined by elemental analysis on a heterogeneous sample. The coordination of an interstitial atoms in the $\mathrm{Mn}_{5} \mathrm{Si}_{3}$ structure has a coordination number of $6+$ 2. The interstitial atoms in a $\mathrm{Ti}_{2} \mathrm{Ni}$ structure with all octahedral sites filled would have a coordination number of $6+2$ and $6+4$. Refinement results of $\mathrm{Zr}_{6} \mathrm{Ni}_{4} \mathrm{Ti}_{2} \mathrm{O}_{0.6}$ are the first indication of partial occupancy of both sites. All previous reports in which interstitial atomic parameters are refined indicate occupancy of either the $8 a$ or $16 c$ site, but not both. 
Interpenetrating the octahedral network is another network made of comer-sharing stella quadrangula. See Figure 4.5. An ideal stella quadrangula is defined as consisting "of four regular tetrahedra, each sharing one face with a central, fifth tetrahedron, which is also regular (or four regular tetrahedra each sharing three edges, one with each of its three neighbors)." [84] In these compounds the central tetrahedron is always $\mathrm{Ni}$, on the $32 e$ site, and the other atoms are the metals on the $16 d$ site, which cap the faces of the $\mathrm{Ni}_{4}$ tetrahedra. None of these tetrahedra are centered by interstitial atoms. The fractional coordinate of $x$ for the metal atom at $32 e$ has been converted from the value in the source to the alternate but equivalent value corresponding to the conventional positions. The atom position for $\mathrm{Ni}$ at $32 e,(x, x, x)$, shifts from the ideal $x=0.8250$ to the observed $x=0.8311$ to $x=0.8396$. The effect of increasing the $x$ parameter is to enlarge the central nickel tetrahedron. A look at the distances in Table 4.4 shows these units are far from regular stella quadrangula. In all cases the central $\mathrm{Ni}_{4}$ tetrahedron is expanded $\left(\mathrm{d}_{\mathrm{Ni}-\mathrm{Ni}}>\mathrm{d}_{\mathrm{Ni}-\mathrm{M} 2}\right) . \mathrm{Zr}_{4} \mathrm{Ni}_{2} \mathrm{O}$ shows the largest departure from ideality. For the ideal structural arrangement of this compound, $d_{\mathrm{Ni}-\mathrm{Ni}}$ $=2.5873 \AA$. The observed distance is much larger, $\mathrm{d}_{\mathrm{Ni}-\mathrm{Ni}}=3.0910 \AA$. The distance between the nickel atoms and the zirconium atoms in the octahedral network consequently decreases considerably from the ideal. Compare the observed $d_{\mathrm{Zr} 1-\mathrm{Ni}}=2.783 \AA$ with the ideal $\mathrm{d}_{\mathrm{Zrl}-\mathrm{Ni}}=3.0224 \AA$ in $\mathrm{Zr}_{4} \mathrm{Ni}_{2} \mathrm{O}$. This bond lengthening within the $\mathrm{Ni}_{4}$ tetrahedron suggests $\mathrm{Ni}-\mathrm{Ni}$ interactions are weakening, relative to $\mathrm{Zr}-\mathrm{Ni}$ interactions. This is supported by the calculated overlap populations, where nickel - nickel overlap was more than an order of magnitude lower than the other interactions. The zirconium - nickel overlap populations, on the other hand, were quite significant. See Table 4.10. This suggests that the visual description of the structure in terms of two interpenetrating networks does not accurately portray the chemical interaction between the two networks. Rogl [90] perhaps recognized this, and described the structure in terms of the packing of the icosahedral units around the M2 atoms at the $16 d$ sites. Figure 4.5 only shows the six nickel atoms around M2. 
Table 4.4 lists the coordination also to six M1 atoms, and they arrange in a distorted icosahedral coordination $\mathrm{The} \mathrm{Zr} 1-\mathrm{Zr} 2$ and $\mathrm{Zr} 1-\mathrm{Ni}$ interaction is exactly the bonding connection between the two networks. Note the highest orbital overlap populations in Table 4.10 involve interactions between the two interpenetrating networks, rather than within a network.

The inherent beauty of this structure has not been overlooked by others. Calculations of periodic minimum surfaces for $\mathrm{W}_{3} \mathrm{Fe}_{3} \mathrm{C}$ of this structure type divide the structure into two interpenetrating networks, and suggest the mode for wearing of this high speed steel [91]. Two flaws appear in this article. First, $\mathrm{W}_{3} \mathrm{Fe}_{3} \mathrm{C}$ is not responsible for the characteristic properties of high speed steel [70]. Second, periodic minimum surfaces cannot be generated for certain space groups, Fd $\overline{3} \mathrm{~m}$ among them [92]. However, periodic equi-potential surfaces and periodic zero potential surfaces can be generated for this space group. The potential surfaces of appropriate Coulombic fields are very similar in shape to minimal surfaces, but can be correlated to the spatial distribution of the electrons, and hence correlated to physical properties. For the $\mathrm{Ti}_{2} \mathrm{Ni}$ structure the potential surface resides between the two interpenetrating networks. One can assume that the weakest bound electrons are located close to the potential surface. In a metal, these are the conduction electrons. This view of potential surtaces in no way contradicts the finding here of significant interaction between the two structural networks.

It is interesting to note some structural similarities with other phases here. A two-dimensional analogue to the three-dimensional network of face-sharing zirconium octahedra is seen in the kappa phase [80] and the new $\mathrm{Zr}_{6} \mathrm{Ni}_{6} \mathrm{TiSiO}_{1.8}$ structure [81]. In each case, rings of twelve face-sharing octahedra form. In the case of all three of these structures, icosahedral units fill the void spaces and link the octahedral networks.

The results of this study can be rationalized in a system by system manner. In the $\mathrm{Nb} / \mathrm{Ni} / \mathrm{O}$ system the two phases $\mathrm{Nb}_{4} \mathrm{Ni}_{2} \mathrm{O}$ and $\mathrm{Nb}_{6} \mathrm{Ni}_{6} \mathrm{O}$ occur. This occurance was not observed in the 
$\mathrm{Zr} / \mathrm{Ni} / \mathrm{O}$ system. This may be explained by looking at the phase diagrams of the intermetallic $\mathrm{Zr} / \mathrm{Ni}$ and $\mathrm{Nb} / \mathrm{Ni}$ systems. In the $\mathrm{Nb} / \mathrm{Ni}$ binary system there are only two compounds, $\mathrm{NbNi}_{3}$ and $\mathrm{Nb}_{7} \mathrm{Ni}_{6}$, which compete with formation of the temary oxide. In neither case is the $\mathrm{Nb}: \mathrm{Ni}$ ratio $1: 1$ or $2: 1$. The binary intermetallics in the $\mathrm{Zr} / \mathrm{Ni}$ system, especially $\mathrm{ZrNi}$, compete more favorably with the formation of the ternary oxide. The oxygen occupancy in the $\mathrm{Nb}_{4} \mathrm{Ni}_{2} \mathrm{O}$ phase has not been determined experimentally, but is based on the assumption that the oxygen occupancy in this phase is the same as for $\mathrm{Nb}_{6} \mathrm{Ni}_{4} \mathrm{Ta}_{2} \mathrm{O}_{2}$. The two phases $\mathrm{Nb}_{6} \mathrm{Ni}_{6} \mathrm{O}$ and $\mathrm{Nb}_{4} \mathrm{Ni}_{2} \mathrm{O}$ show different $\mathrm{Nb} / \mathrm{Ni}$ ratios and different oxygen content. The band calculations on $\mathrm{Nb}_{6} \mathrm{Ni}_{6} \mathrm{O}$ suggest the ordering of the oxygen may not be as important as the total amount of oxygen present. Figure 4.15 (a) outlines the possibility of adding different amounts of oxygen to metal frameworks with different $\mathrm{Nb} / \mathrm{Ni}$ ratios. With oxygen acting as an electron sink, the core with more free valence electrons in the conduction band will favor adding more oxygen atoms. Assuming a filled $\mathrm{d}^{10}$ configuration, $\mathrm{Nb}_{8} \mathrm{Ni}_{4}$ contains 80 free valence electrons per primitive unit cell, and $\mathrm{Nb}_{6} \mathrm{Ni}_{6}$ has 60 electrons. Thus $\mathrm{Nb}_{8} \mathrm{Ni}_{4}$ will add two oxygen atoms per formula unit to form $\mathrm{Nb}_{8} \mathrm{Ni}_{4} \mathrm{O}_{2}$ and $\mathrm{Nb}_{6} \mathrm{Ni}_{6}$ will add only one to form $\mathrm{Nb}_{6} \mathrm{Ni}_{6} \mathrm{O}$.

The same conclusion is reached if the oxygen ordering is assumed to determine the metal ratios, rather than the metals determining oxygen ordering as described above. In this case, the two core compounds with different oxygen content, $\mathrm{Nb}_{6} \mathrm{Ni}_{4} \mathrm{O}$ and $\mathrm{Nb}_{6} \mathrm{Ni}_{4} \mathrm{O}_{2}$, can add either niobium or nickel to the $16 d$ site (Figure $4.15(\mathrm{~b})$ ). $\mathrm{Nb}_{6} \mathrm{Ni}_{4} \mathrm{O}$ has 56 free electrons in its conduction band, and $\mathrm{Nb}_{6} \mathrm{Ni}_{4} \mathrm{O}_{2}$ has 52. Since $\mathrm{Nb}_{6} \mathrm{Ni}_{4} \mathrm{O}$ is more electron rich it will more readily add nickel, whose atomic orbitals lie lower in energy than the Fermi level and will act as electron acceptors, than gain electrons by adding niobium. $\mathrm{Nb}_{6} \mathrm{Ni}_{4} \mathrm{O}_{2}$, with fewer free electrons will favor the addition of niobium, whose orbitals lie above the Fermi energy and will act as electron donors to form $\mathrm{Nb}_{8} \mathrm{Ni}_{4} \mathrm{O}_{2}$, or $\mathrm{Nb}_{4} \mathrm{Ni}_{2} \mathrm{O}$. While this explanation is internally consistent, it does not explain the 

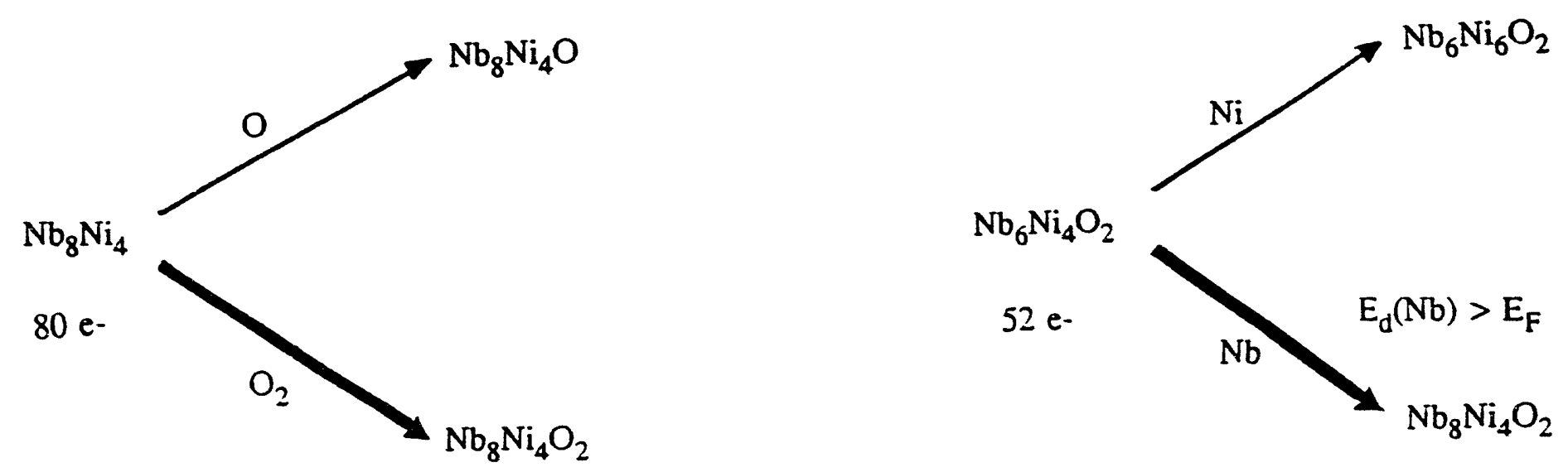

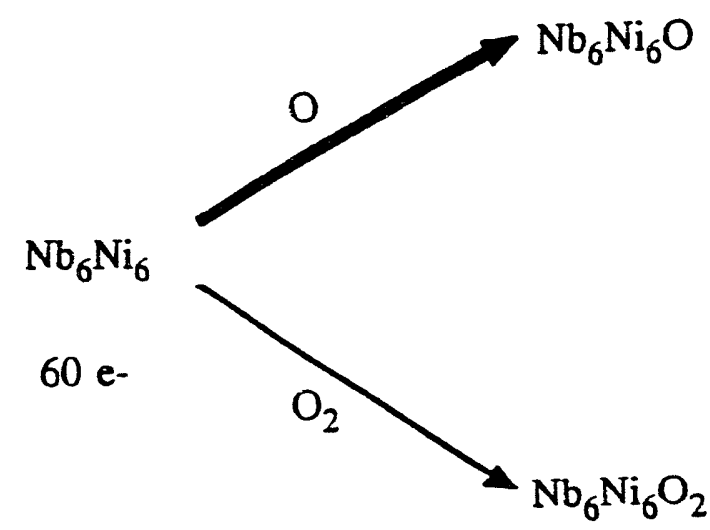

(a)

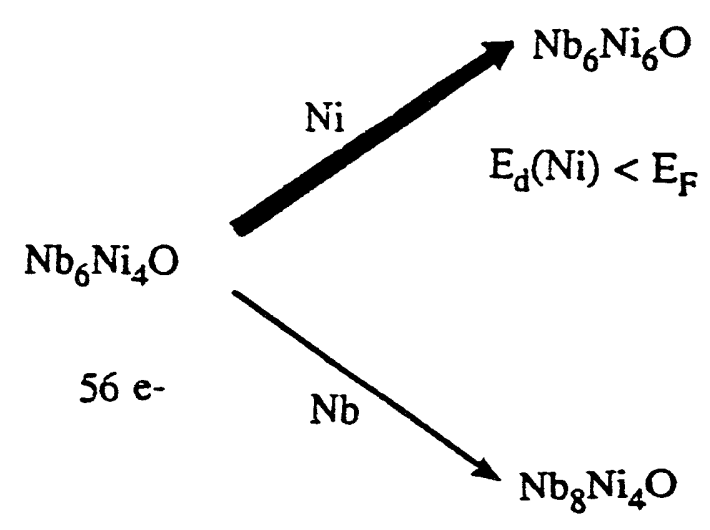

(b) 
formation of phases like $\mathrm{Mo}_{6} \mathrm{Co}_{6} \mathrm{C}$ and $\mathrm{Mo}_{6} \mathrm{Co}_{6} \mathrm{C}_{2}$ where both possible orderings of interstitials are observed for a single metal ratio. $\mathrm{A} \mathrm{Nb}_{6} \mathrm{Ni}_{6} \mathrm{O}_{2}$ phase may also exist, but the corresponding shift in lattice parameters would be minimal, and would require sufficient diffraction data for structural analysis. However, the formation of this phase is unlikely. When additional oxygen was added in the synthesis $\mathrm{NbO}$ and $\mathrm{Ni}$ formed as minor phases.

The formation of only $\mathrm{Nb}_{6} \mathrm{Ni}_{4} \mathrm{Ta}_{2} \mathrm{O}_{2}$, and no other tantalum containing compounds, can be explained on the basis of work on mixed niobium/tantalum sulfides performed previously in this lab $[19,20]$. In these sulfides, the formation of certain phases depends on the relative strengths of metal -sulfur bonds and metal - metal bonds. The same interplay between metal - oxygen and metal metal bonds exists in these oxide phases. Generally speaking, Ta-O bonds are stronger than $\mathrm{Nb}-\mathrm{O}$ bonds, by electronegativity arguments. Also, Ta-M bonding among transition metals is generally stronger than $\mathrm{Nb}-\mathrm{M}$ bonds in a given structure, because of greater d-orbital expansion and overlap of $5 \mathrm{~d}$ transition metals. In the $\mathrm{Ti}_{2} \mathrm{Ni}$ type structure one must consider the balance between the $\mathrm{M}-\mathrm{O}$ and the $\mathrm{M}-\mathrm{M}$ bonding. It was found that $\mathrm{Nb}_{4} \mathrm{Ni}_{2} \mathrm{O}$ forms. In this structure, the oxygen is surrounded by niobium in the $48 f$ site, forming $\mathrm{Nb}_{6} \mathrm{O}$ octahedra. The other niobium atom sees only other metal atoms, icosahedrally coordinated to six nickel and six niobium atoms. When tantalum replaces niobium in the $16 d$ site, oxygen still sees only niobium, but now tantalum can increase the metal-metal interactions in the structure. If, however, tantalum were to replace the other niobium atoms, the stronger Ta-O bonds would come at the expense of the Ta-M bond strength, shifting the balance of metal - oxygen versus metal - metal bond strength, and the phase becomes unstable with respect to formation of the binary phases.

One can consider the role of oxygen in stabilizing the $\mathrm{Ti}_{2} \mathrm{Ni}$ type structure in the $\mathrm{Zr}_{4} \mathrm{Ni}_{2} \mathrm{O}$ phase. Oxygen is also necessary for the formation of the $\mathrm{Hf}_{4} \mathrm{Ni}_{2} \mathrm{O}$ phase [73], but is not necessary for $\mathrm{Ti}_{2} \mathrm{Ni}$. A principle difference between titanium on the one hand, and zirconium and hafnium 
on the other, is the orbital expansion of the $d$ orbitals for zirconium and hafnium and the corresponding increase in metal - metal bond strength. The binary intermetallic phases that form are the arrangements of atoms that maximize the bonding energy between them, and thus minimize the Gibbs free energy. The phases in the $\mathrm{Zr} / \mathrm{Ni}$ system are different than those in the $\mathrm{Ti} / \mathrm{Ni}$ system because the bonding energies of zirconium and titanium are different. When oxygen is added to the $\mathrm{Zr} / \mathrm{Ni}$ system and zirconium - oxygen bonds form, the zirconium - metal bonding decreases. This decrease in metal - metal bonding makes it more like the $\mathrm{Ti} / \mathrm{Ni}$ system, and the filled $\mathrm{Ti}_{2} \mathrm{Ni}$ phase is stabilized with respect to the binary phases. In the mixed $\mathrm{Zr} / \mathrm{Ti}$ phase, $\mathrm{Zr}_{6} \mathrm{Ni}_{4} \mathrm{Ti}_{2} \mathrm{O}_{0.6}$, even less oxygen is required, as would be expected. 


\section{NEW ZIRCONIUM KAPPA PHASES}

\section{Introduction}

The kappa phases are an interesting set of compounds. They exist for a wide variety of interstitial atoms, and for a wide combination of transition metals. Recently, superconductivity has been discovered in a kappa phase [21]. Interest has also been expressed in studying the catalytic properties of these compounds in processes where Chevrel phases have been studied. If a technological interest arises for these kappa phases, many of which have been known for quite some time, they may come under intense physical and chemical study. The work reported here demonstrates that through the use of modern techniques these compounds may each be found to be significantly more complicated than the formula suggests. Both the transition metal framework and the interstitial atoms demonstrate significant deviation from ideality. Specifically, the mixing of $M$ and $\mathrm{M}^{\prime}$ on the metal atom sites can change the stoichiometry substantially from the $\mathrm{M}_{9} \mathrm{M}_{4}^{\prime} \mathrm{X}$ formula. Secondly, the formula, as written, does not reveal the presence of a second interstitial site, the occupation of which may have been undetected in the earlier work. The possibility exists for two different interstitial sites to be occupied by the same element, or by different elements, or for one site to be preferentially occupied in one compound and the other site to be occupied in another compound. The interstitial sites may also undergo substitution and/or exhibit partial occupancy or nonstoichiometry. Each of these are considered later in more detail, but this serves to illustrate that the findings of this study will be important in any future work on these kappa phases. Specifically, the presence of light interstitial elements must be considered, i.e. by performing the synthesis with both the intentional and unintentional presence of oxygen, for example, and noting changes in lattice parameters. In some cases, the formation of the phase may be affected by the presence of the interstitial atoms. Chemical analysis, i.e. by EDS, is important for determining ranges of substition 
in metal atoms, and in the interstitial atoms. Finally, the importance of the precision of single crystal diffraction studies cannot be overstated.

Many examples of the hexagonal kappa phase in ternary systems have been reported since their original discovery $[93,94]$. The kappa phase is of the general form $M_{9} M_{4}^{\prime} X$, where $M$ and $M^{*}$ are transition metals, $M$ being the more electropositive of the two. Table 5.1 shows the surprising variability and adaptability in the elements which fill the $X$ position in the kappa phase. $X$ can be one of several p-group elements or an iron group $3 d$ transition metal.

Table 5.1 Known kappa phases $\left(\mathrm{M}_{9} \mathrm{M}_{4}^{\prime} \mathrm{X}\right)^{\mathrm{a}}$

\begin{tabular}{|c|c|c|c|}
\hline$M-M^{\prime}-X$ & $\mathrm{X}$ & $M-M^{\prime}-X$ & $\mathrm{X}$ \\
\hline Zr-Os-X & 0 & Ti-Fe-X & 0 \\
\hline $\mathrm{Zr}-\operatorname{Re}-\mathrm{X}$ & B,O & Ti-Mn-X & 0 \\
\hline $\mathrm{Zr}-\mathrm{Mo}-\mathrm{X}$ & $\mathrm{B}, \mathrm{O}, \mathrm{Fe}, \mathrm{Co}, \mathrm{Ni}^{\mathrm{b}}, \mathrm{S}^{\mathrm{b}}$ & $\mathrm{Mo}-\mathrm{Cu}-\mathrm{X}$ & $\mathrm{Al} / \mathrm{C}$ \\
\hline $\mathrm{Zr}-\mathrm{W}-\mathrm{X}$ & $\mathrm{B}, \mathrm{O}, \mathrm{S}^{\mathrm{b}}, \mathrm{S} / \mathrm{Ni}^{\mathrm{b}}$ & Mo-Ni-X & $\mathrm{Al} / \mathrm{C}$ \\
\hline $\mathrm{Zr}-\mathrm{Nb}-\mathrm{X}$ & $S^{c}$ & Mo-Co-X & $\mathrm{Al} / \mathrm{C}$ \\
\hline $\mathrm{Zr}-\mathrm{Ta}-\mathrm{X}$ & $S^{c}$ & Mo-Fe-X & $\mathrm{Al} / \mathrm{C}$ \\
\hline Hf-Os-X & $\begin{array}{l}\mathrm{B}, \mathrm{O}, \mathrm{Si}, \mathrm{P}, \mathrm{S}, \mathrm{Ge}, \mathrm{As} \\
\mathrm{Se}, \mathrm{Fe}, \mathrm{Co}, \mathrm{Ni}\end{array}$ & Mo-Mn-X & $\mathrm{Al} / \mathrm{C}$ \\
\hline Hf-Re-X & $\begin{array}{l}\mathrm{B}, \mathrm{O}, \mathrm{Si}, \mathrm{P}, \mathrm{S}, \mathrm{Ge}, \mathrm{As} \\
\mathrm{Se}, \mathrm{Fe}, \mathrm{Co}, \mathrm{Ni}\end{array}$ & W-Ni-X & $\mathrm{C}$ \\
\hline Hf-Mo-X & $\begin{array}{l}\mathrm{B}, \mathrm{O}, \mathrm{Si}, \mathrm{P}, \mathrm{S}, \mathrm{Ge}, \mathrm{As}, \\
\mathrm{Se}, \mathrm{Fe}, \mathrm{Co}, \mathrm{Ni}\end{array}$ & W-Co-X & $\mathrm{C}$ \\
\hline Hf-W-X & $\begin{array}{l}\text { B,O,P,S,Ge,As,Se, } \\
\mathrm{Fe}, \mathrm{Co}, \mathrm{Ni}\end{array}$ & W-Fe-X & C, $\mathrm{Al} / \mathrm{C}$ \\
\hline $\mathrm{Hf}-\mathrm{Nb}-\mathrm{X}$ & $S^{c}$ & W-Mn-X & $\mathrm{C}, \mathrm{Al} / \mathrm{C}$ \\
\hline Hf-Ta-X & $S^{c}, S^{d}, S / S e^{d}$ & W-Cr-X & $\mathrm{C}$ \\
\hline
\end{tabular}

a Table adapted from [94]

b $[80]$

c [21]

d [95] 
The above formulation is somewhat simplified in that it does not reveal the fact that the interstitial elements can occupy different interstitial sites. To take this into account the formula can be rewritten $\mathrm{M}_{9} \mathrm{M}_{4}^{\prime} \mathrm{X}_{1} \mathrm{X}_{3}^{\prime}$, where $\mathrm{X}$ is an interstitial atom on the $2 c$ position, a trigonal prismatic site, and $\mathrm{X}^{\prime}$ is an interstitial atom on the $6 \mathrm{~g}$ position, an octahedral site. It has been convenient up until now to consider just one interstitial site because all previous reports, with three exceptions, have indicated occupancy of only one site or the other, but not both. These exceptions are the carbides W-Fe-C and W-Co-C, where both sites are simultaneously occupied, but with $50 \%$ of the $2 c$ site vacant $[96,97]$. Hf-Mo-S has also been reported with complete filling of the $2 c$ site, but only partial filling (6-9\%) of the $6 \mathrm{~g}$ site by $\mathrm{S}$ [98]. The temary Hf-Mo-Ge kappa phase is found to be a quatemary, Hf-Mo-Ge-O, with germanium on the $2 c$ site, and oxygen on the $6 g$ site, and vacancies on both sites [99]. Besides these three exceptions, the kappa phases are reported to have only one interstitial site occupied. The oxides are thought to contain oxygen in the octahedral site, and all other interstitial atoms, $\mathrm{X}$, occupy the larger trigonal prismatic site. The results of this study demonstrate that simultaneous occupation of both sites is at least a common, and sometimes necessary, condition. The new zirconium-containing kappa phases, $\mathrm{Zr}_{9} \mathrm{~W}_{4} \mathrm{SO}_{\mathrm{x}}, \mathrm{Zr}_{9} \mathrm{Mo}_{4} \mathrm{SO}_{\mathrm{x}}$, and $\mathrm{Zr}_{9} \mathrm{~W}_{4}(\mathrm{~S} / \mathrm{Ni}) \mathrm{O}_{3}$, have been synthesized. The $\mathrm{Zr}_{9} \mathrm{~W}_{4} \mathrm{Ni}$ phase has been determined to be oxygen stabilized. The lattice parameters of the new phases are reported, as well as the single crystal refinement of the nickel substituted sulfide. This last compound is an example of nickel substitution for sulfur in metal rich chalcogenides, a previously reported effect [27]. In addition, this compound shows the ability of the structure to fully occupy the octahedral interstitial sites with oxygen.

Before proceeding further with the chemistry of the kappa phase it is useful to look more closely at the structure of this phase. The unit cell is hexagonal $\left(\mathrm{P}_{3} / \mathrm{mmc}\right)$ with a cla ratio riearly equal to one. Figure 5.1 shows in projection a layer network of face sharing octahedra. In terms of the $M_{9} M_{4}^{\prime} X_{1} X_{3}^{\prime}$ formula, this figure contains only the $M_{9} X_{3}^{\prime}$ portion. The hexagonal unit cell is 


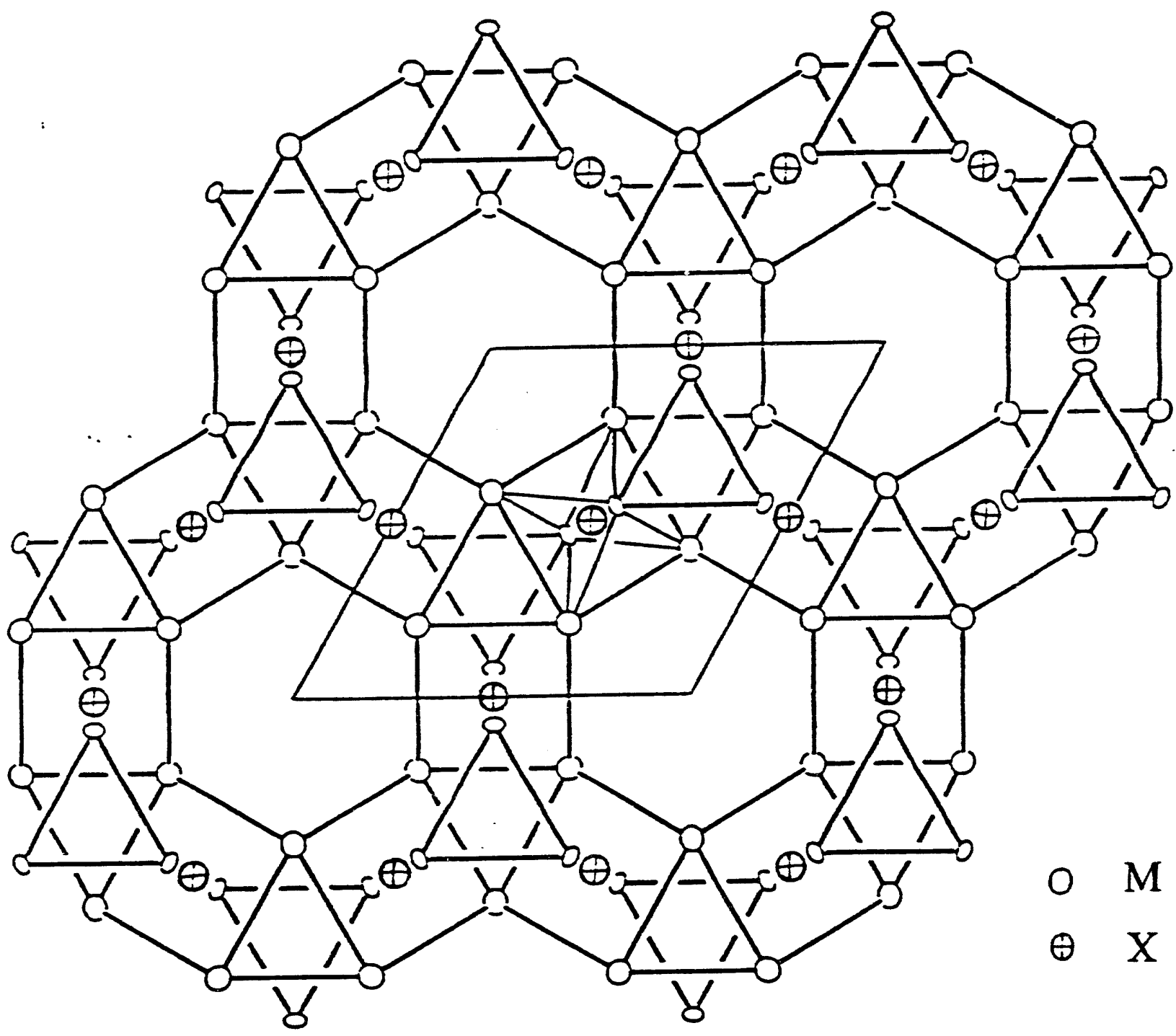
is outlined for clarity. Altemating octahedra are centered by interstitial atom $X^{\prime}$. 
outlined. The octahedron in the center of the unit cell is also outlined for clarity, and is centered by an $\mathrm{X}^{\prime}$ atom. This octahedron shares two opposite faces with octahedra which are seen in projection along their three fold axis. The face sharing octahedra form rings containing twelve octahedra. The octahedra are alternately centered and empty. In terms of a zirconium network of face sharing octahedra there is a surprising relation between the kappa phase and the $\mathrm{Ti}_{2} \mathrm{Ni}$-type structure. In the kappa phase a two-dimensional hexagonal layer forms from these octahedra, which are alternately filled and empty. In the cubic $\mathrm{Ti}_{2} \mathrm{Ni}$-type structure, these rings of face sharing octahedra form a three-dimensional network. In these cases, similar building blocks arrange to form strikingly different structures. Oxygen is essential to the formation of this network of octahedra in these kappa phases as well as in the $\mathrm{Ti}_{2} \mathrm{Ni}$-type phases containing zirconium.

The interstitial sites are more clearly seen viewing along the [110] direction. In Figure 5.2 trigonal prismatic sites and two crystallographically distinct octahedral sites are shown. The trigonal prisms are tricapped, although only one face is shown capped in the figure. The octahedra above and below the trigonal prism have their center at the $4 f$ site and are vacant in all known cases. The octahedra which are occupied by interstitial atoms are those shown between the trigonal prisms. These form a zig-zag chain of comer-sharing octahedra along the $c$-axis. This network shown consists only of the metal $\mathrm{M}$ atoms.

Figure 5.3 is a projection of the complete structure. Icosahedral units fill the voids in the octahedral network. T L $_{\text {¿se }}$ icosahedra share faces to form a chain along the $c$-axis. The icosahedra are all centered by metal $\mathrm{M}^{\prime}$ atoms (Figure 5.4).

Such is the structure of the kappa phase. The variability in $\mathrm{X}$ and $\mathrm{X}^{\prime}$ 'suggests the formation of this phase depends largely on the strength of the metal-metal interactions within the framework of this structure. In fact, the kappa phase may be considered a filled variant of the intermetallic compounds $\mathrm{Mn}_{3} \mathrm{Al}_{10}$ and $\mathrm{Co}_{4} \mathrm{Al}_{10}$. 


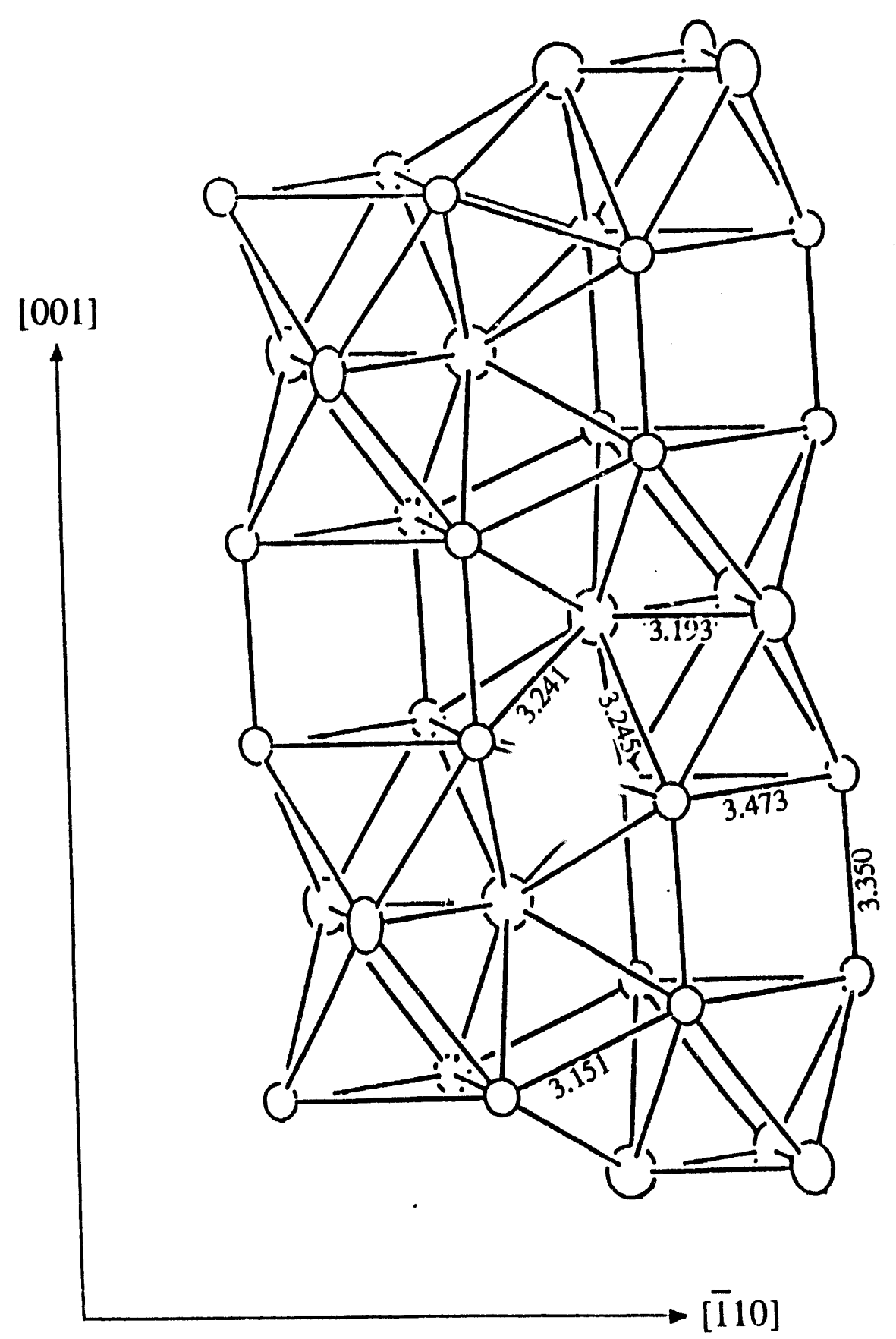

Figure 5.2 Portion of the kappa phase structure, showing only the metal aloms M, projected along a plane almost perpendicular to the (110) planc. Octahedral and trigonal prismatic interstitial sites cicarly secn. Distances shown for $\mathrm{Zr}_{9} \mathrm{~W}_{4}(\mathrm{~S} / \mathrm{Ni}) \mathrm{O}_{3}$. 


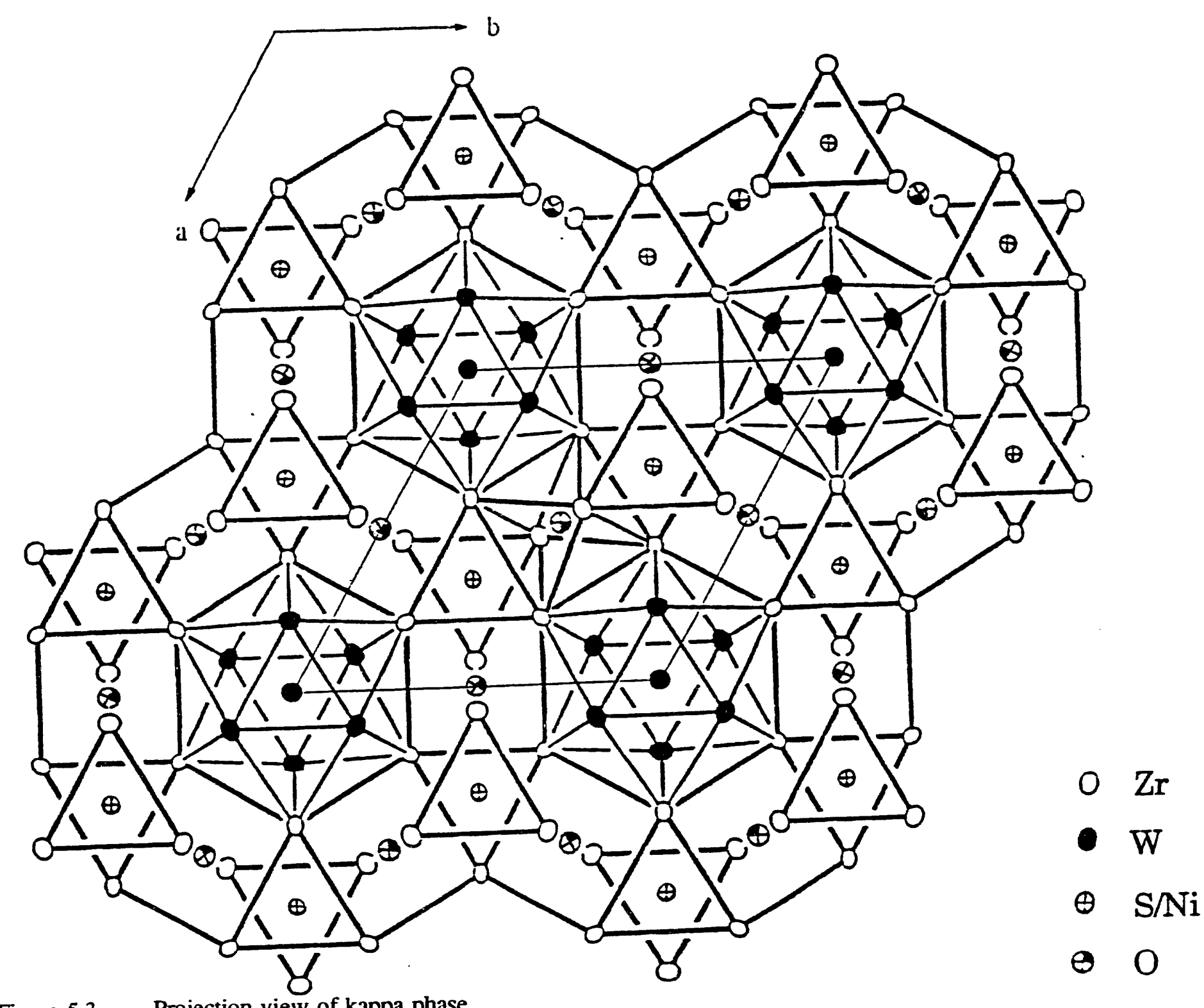

Figure 5.3 Projection view of kappa phase. 
$\pi$
0
0
0
0
0

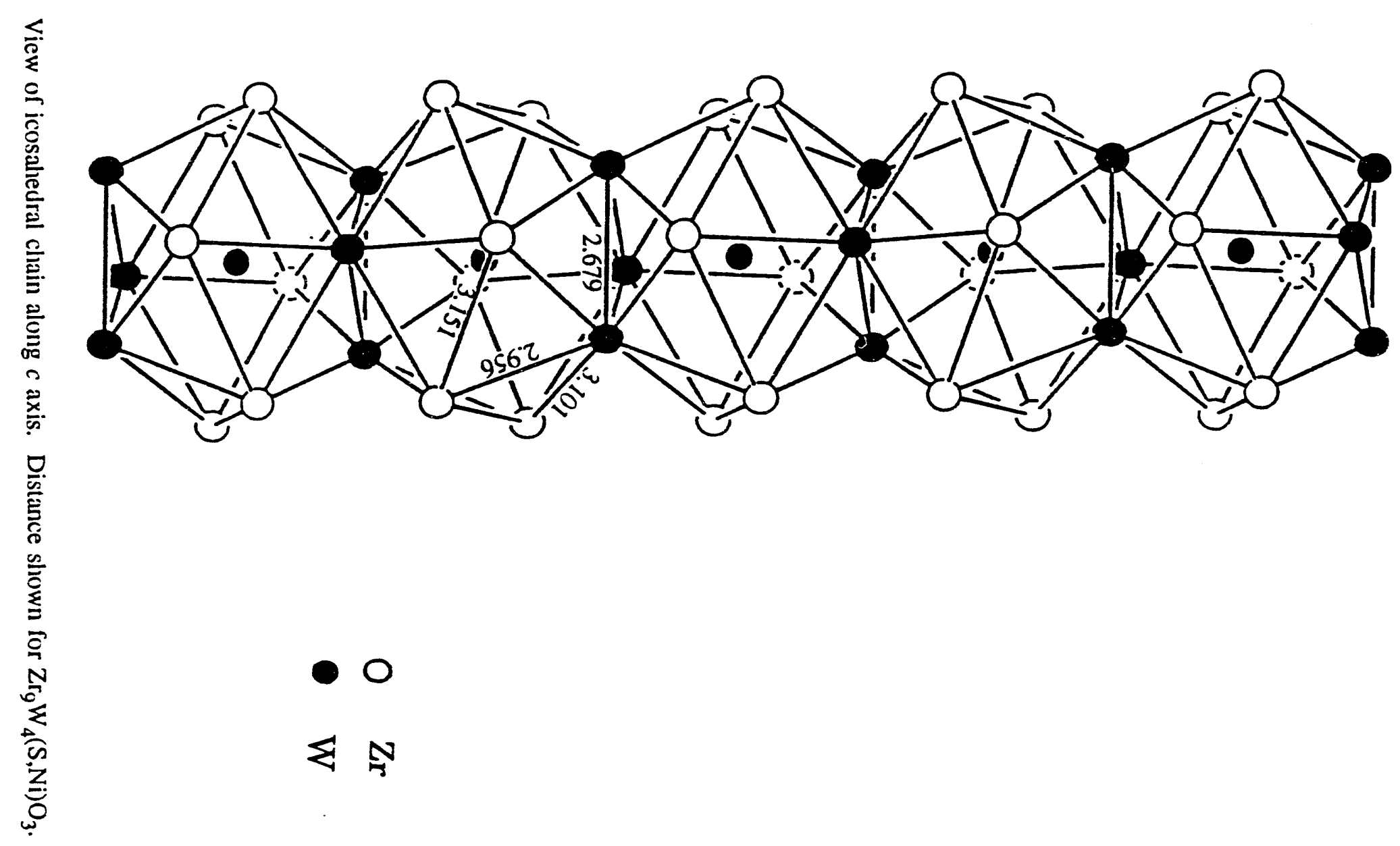




\section{Experimental Details}

The single crystal used for the refinement was picked from a multi-phase sample of zirconium, nickel, and sulfur which melted and reacted with the tungsten crucible at $1400^{\circ} \mathrm{C}$. The stoichiometry of the sample was initially taken to be " $\mathrm{Zr}_{3} \mathrm{NiS}$ ". The product contained the kappa phase as a major phase, with $\mathrm{Zr}_{3} \mathrm{~S}_{2}$ and another (unknown) phase present as minor phases. The crystal was small but regular shaped. Intensity data for this crystal were collected using a Rigaku AFC6R single crystal diffractometer and monochromated MoK $\alpha$ radiation, employing the $\omega-2 \theta$ scan technique up to $55^{\circ}$ in $2 \theta$. The observed intensities were corrected for Lorentz polarization and absorption effect. Table 5.2 contains the crystal data.

The bulk synthesis of all samples was carried out by initially combining elemental zirconium and sulfur powders in the mole ratio $\mathrm{n}(\mathrm{Zr}) / \mathrm{n}(\mathrm{S})$ of $9 / 1$ and heating in an evacuated silica tube at $450^{\circ} \mathrm{C}$ until no visible traces of elemental sulfur remained. The temperature was raised to $800^{\circ} \mathrm{C}$ and held there for several days. The resulting zirconium sulfide was mixed with powders of the other metals and pressed into pellets. The pellets were arc-melted on a water cooled copper hearth in an argon atmosphere with a tungsten electrode. Each arc-melted sample was annealed in a tungsten crucible in an induction furnace at about $1200^{\circ} \mathrm{C}$ for $6-18$ hours.

X-ray powder pattems were obtained with a vacuum Guinier camera FR552 (Enraf-Ninius, Delft, The Netherlands) and CuK $\alpha 1$ radiation, with silicon as an internal standard. The powder patterns were indexed by comparison to the kappa phases, and the lattice parameters were calculated by least-squares refinement.

\section{Results and Discussion}

The initial refinement of the single-crystal data led to the nominal formula $\mathrm{Zr}_{9} \mathrm{~W}_{4} \mathrm{~S}$. Three corrections were necessary for the final refinement. Initially, the thermal parameters for the sulfur 
Table 5.2 Crystal data for $\mathrm{Zr}_{9} \mathrm{~W}_{4}(\mathrm{~S} / \mathrm{Ni}) \mathrm{O}_{3}$

\begin{tabular}{|c|c|}
\hline Formula & $\mathrm{Zr}_{9.22} \mathrm{~W}_{3.78} \mathrm{~S}_{0.67} \mathrm{Ni}_{0.33} \mathrm{O}_{3.00}$ \\
\hline Space group & $\mathrm{P6}_{3} / \mathrm{mmc}(\# 194)$ \\
\hline a $(\AA)$ & $8.688(7)$ \\
\hline c $(\AA)$ & $8.558(5)$ \\
\hline$V\left(\AA^{3}\right)$ & $559.4(7)$ \\
\hline $\mathbf{Z}$ & 2 \\
\hline $\mathrm{d}_{\text {calc }}\left(\mathrm{g} / \mathrm{cm}^{3}\right)$ & 9.627 \\
\hline Crystal size $\left(\mathrm{mm}^{3}\right)$ & $0.04 \times 0.02 \times 0.02$ \\
\hline$\mu(\mathrm{MoK} \alpha)\left(\mathrm{cm}^{-1}\right)$ & 480.79 \\
\hline Data collection instrument & Rigaku AFC6R \\
\hline $\begin{array}{l}\text { Radiation (monochromated in } \\
\text { incident beam) }\end{array}$ & $\operatorname{MoK} \alpha(\lambda=0.71069)$ \\
\hline Octants measured & $\pm h, k, \pm l$ \\
\hline No. reflections measured & 1904 \\
\hline $\begin{array}{l}\text { No. unique data, total } \\
\text { with } \mathrm{F}_{\mathrm{o}}^{2}>3 \sigma\left(\mathrm{F}_{\mathrm{o}}{ }^{2}\right)\end{array}$ & 162 \\
\hline No. parameters refined & 24 \\
\hline Trans. factors, $\max / \mathrm{min}$ & $1.000 / 0.560$ \\
\hline Secondary ext. coeff. $\left(10^{-7}\right)$ & 2.496 \\
\hline $\mathbf{R}^{\mathrm{a}}, \mathbf{R}_{\mathrm{w}}^{\mathrm{b}}, \mathrm{GOF}^{\mathrm{c}}$ & $0.026,0.026,0.975$ \\
\hline Largest difference peak (e/ $\AA^{3}$ ) & +3.78 \\
\hline Largest negative peak $\left(\mathrm{e} / \AA^{3}\right)$ & -2.17 \\
\hline $\begin{array}{l}R=\Sigma\left\|F_{o}|-| F_{c}\right\| / \Sigma\left|F_{o}\right| \\
R_{w}=\left[\Sigma w\left(\left|F_{o}\right|-\left|F_{c}\right|\right)^{2} / \Sigma w\left|F_{o}\right|^{2}\right]^{1 /}\end{array}$ & \\
\hline
\end{tabular}


were unreasonably small. Placing nickel on that position gave equally unreasonable results. Placing mixed sulfur/nickel occupancy on the $2 c$ site improved the results considerably. Kappa phases are known which contain either sulfur or nickel, as well as $\operatorname{man}_{j^{\prime}}$ other elements, but this is the first example of mixed occupancy of this site. EDS measurements also detect the presence of both sulfur and nickel in this phase. The atoms in this site are tricapped trigonal-prismatically coordinated to zirconium atoms. Nickel substitution of sulfur has been observed in the metal rich sulphides $\mathrm{Nb}_{6} \mathrm{Ni}_{x} \mathrm{~S}_{3-x}$, and $\mathrm{Nb}_{9} \mathrm{Ni}_{2-x} \mathrm{~S}_{3+x}$ [27], in which nickel substitutes for sulfur in highly coordinated capped trigonal-prismatic sites. Substitution of sulfur by nickel is consistent with the ability of sulfur to be involved in delocalized, metallic bonding.

An additional change was necessary, since the Fourier difference map calculated during refinement indicated the presence of an atom at the $6 g$ position. As noted previously, other reports have indicated partial occupancy of the octahedral position by oxygen (up to $48 \%[99,100]$ ). The result of the refinement in this work yielded total oxygen occupancy of this site. This is the first example of both the $2 c$ and the $6 g$ sites being fully occupied. The experimental steps for sample preparation offered several opportunities for inclusion of oxygen. As discussed in the introduction, techniques for solid state synthesis of early transition-metal sulfides are susceptible to oxygen inclusion. The determination of partial or complete oxygen occupancy in the known kappa phases is incomplete, and the results obtained here suggest that such occupation is in all cases a real possibility.

The final step in the refinement was to allow partial zirconium substitution of the tungsten on the $6 h$ and $2 a$ sites [98-103], as substantial $M^{-} \mathbf{M}^{\circ}$ mixing has been observed in other phases. The variability in $\mathrm{M}-\mathrm{M}^{\prime}$ mixing has been correlated with the variability observed in lattice parameters of these phases. Full details of the refinement results are in the following tables. Table 5.3 lists the atomic parameters, including percent mixing on those sites refined with mixed 
occupancy. Anisotropic thermal parameters are in Table 5.4. Interatomic distances less that $3.7 \AA$ are listed on Table 5.5.

A few of the interatomic distances are labelled in Figure 5.2 and Figure 5.4. The zirconiumzirconium distances within the trigonal prism range from 3.350 to $3.473 \AA$ (Figure 5.2). This range is similar to the distances in the trigonal prism in $\mathrm{Zr}_{3} \mathrm{NiO}$, where $\mathrm{d}_{\mathrm{Zr}-\mathrm{Zr}}=3.325-3.682 \AA$. In both structures, these distances are much larger than the distance between the zirconium and the central atom, which is $2.612 \AA$ in the kappa phase with mixed $\mathrm{S} / \mathrm{Ni}$ occupancy, and $2.657 \AA$ in $\mathrm{Zr}_{3} \mathrm{NiO}$, where just nickel occupies the central position. The octahedral arrangement of zirconium atoms is significantly distorted. Along one edge $\mathrm{d}_{\mathrm{Zrl}-\mathrm{Zr} 1}=3.151 \AA$, while along the edge shared with the trigonal prism it is $3.473 \AA$. Consequently, the zirconium-oxygen distances are different, with $\mathrm{d}_{\mathrm{Zr} 1-\mathrm{O}}$ $=2.345 \AA$ and $\mathrm{d}_{\mathrm{Zn} 2-\mathrm{O}}=2.240 \AA$.

The possibility of filling the $4 f$ site by placing oxygen in this octahedral site at $(1 / 3,2 / 3$, 0.598 ) can be considered. The zirconium-oxygen distances would be between 2.26 and $2.39 \AA$. The short oxygen-oxygen distance would be only $2.60 \AA$, and with the oxygen in the $6 g$ position the separation would be $2.64 \AA$. For the same reason as discussed in the $\mathrm{Ti}_{2} \mathrm{Ni}$ type structures, full occupancy of both sites simultaneously is not expected.

A bulk sample of the $\mathrm{Zr}_{9} \mathrm{~W}_{4}\left(\mathrm{~S}_{0.7} \mathrm{Ni}_{0.3}\right) \mathrm{O}_{3}$ phase was prepared, and had the same lattice parameters as the minor phase from which the crystal was picked. Very little work on zirconiumcontaining kappa phases has been done. Only two previous reports for $\mathrm{Zr}$-W-X kappa phases exist, so an attempt was made to synthesize both the $\mathrm{Zr}-\mathrm{W}-\mathrm{S}$ and $\mathrm{Zr}-\mathrm{W}-\mathrm{Ni}$ phases. In the synthesis of these phases, if the kappa phase was present after the arc melting step, as determined by X-ray powder diffraction films, the sample was then annealed. If the phase was not present after arc melting, it generally did not appear upon annealing. In preparing these new phases oxygen was not added in the starting material as a metal oxide, but oxygen was undoubtedly present as surface or 
low level bulk oxide in the zirconium. The zirconium used was in a powder form, and was stored on a shelf rather than in a dry box. Thus, while the presence of oxygen is certain, the amount of Table 5.3 Atomic parameters for $\mathrm{Zr}_{9} \mathrm{~W}_{4}(\mathrm{~S}, \mathrm{Ni}) \mathrm{O}_{3}$

\begin{tabular}{lcccccc}
\hline Atom & Site & $x$ & $y$ & $z$ & Occupancy $(\%)$ & $\mathrm{B}_{\mathrm{eq}}(\AA)^{\mathrm{a}}$ \\
\hline $\mathrm{Zr} 1$ & $12 k$ & $0.2001(2)$ & 0.4002 & $0.0543(2)$ & 100 & $0.4(1)$ \\
$\mathrm{Zr} 2$ & $6 h$ & $0.5442(2)$ & 0.0883 & $1 / 4$ & 100 & $0.5(2)$ \\
$\mathrm{W} 1$ & $6 h$ & $0.8928(1)$ & 0.7857 & $1 / 4$ & $94(2)$ & $0.35(7)$ \\
$\mathrm{Zr}$ & & & & & 6 & \\
$\mathrm{~W} 2$ & $2 a$ & 0 & 0 & 0 & $95(2)$ & $0.26(6)$ \\
$\mathrm{Zr}$ & & & & & 5 & \\
$\mathrm{~S}$ & $2 c$ & $1 / 3$ & $2 / 3$ & $1 / 4$ & $67(6)$ & $0.9(3)$ \\
$\mathrm{Ni}$ & & & & & 33 & \\
$\mathrm{O}$ & $6 g$ & $1 / 2$ & 0 & $1 / 2$ & 100 & $0.7(4)$ \\
\hline
\end{tabular}

${ }^{\mathrm{a}} \mathrm{B}_{\mathrm{eq}}=8 \pi^{2} / 3 \Sigma_{1}^{3} \Sigma_{1}^{3} \mathrm{U}_{\mathrm{ij}} \mathrm{a}_{\mathrm{i}}^{*} \mathrm{a}_{\mathrm{j}}^{*} \overrightarrow{\mathrm{a}}_{\mathrm{i}}^{*} \overrightarrow{\mathrm{a}}_{\mathrm{j}}^{*}$

Table 5.4 Anisotropic thermal parameters for $\mathrm{Zr}_{9} \mathrm{~W}_{4}(\mathrm{~S}, \mathrm{Ni}) \mathrm{O}_{3}$

\begin{tabular}{lllllcc}
\hline Atom & \multicolumn{1}{c}{$\mathrm{U}_{11}$} & \multicolumn{1}{c}{$\mathrm{U}_{22}$} & $\mathrm{U}_{33}$ & $\mathrm{U}_{12}$ & $\mathrm{U}_{13}$ & $\mathrm{U}_{23}$ \\
\hline $\mathrm{Zr} 1$ & $0.005(1)$ & $0.008(1)$ & $0.004(1)$ & 0.004 & $0.002(2)$ & 0.001 \\
$\mathrm{Zr} 2$ & $0.005(1)$ & $0.009(2)$ & $0.006(1)$ & 0.004 & 0 & 0 \\
$\mathrm{~W} 1$ & $0.0050(6)$ & $0.0038(7)$ & $0.0041(7)$ & 0.0019 & 0 & 0 \\
$\mathrm{~W} 2$ & $0.004(1)$ & 0.004 & $0.002(1)$ & 0.002 & 0 & 0 \\
$\mathrm{~S} / \mathrm{Ni}$ & $0.012(5)$ & 0.012 & $0.008(6)$ & 0.006 & 0 & 0 \\
$\mathrm{O}^{\mathrm{a}}$ & $0.008(5)$ & & & & & \\
\hline
\end{tabular}

${ }^{a}$ Isotropic thermal parameter refined for oxygen 
Table 5.5 Interatomic Distances for $\mathrm{Zr}_{9} \mathrm{~W}_{4}(\mathrm{~S} / \mathrm{Ni}) \mathrm{O}_{3}$. Values listed for distances less than $3.7 \AA$.

\begin{tabular}{|c|c|c|c|c|c|c|c|}
\hline \multirow{11}{*}{$\mathrm{Zr} 1$} & -0 & $2.345(2)$ & $\times 2$ & W1 & - W2 & $2.679(2)$ & $\times 2$ \\
\hline & $-\mathrm{S} / \mathrm{Ni}$ & $2.612(2)$ & x 1 & & $-W 1$ & $2.793(4)$ & $\times 2$ \\
\hline & - W1 & $2.956(2)$ & $\times 1$ & & $-\mathrm{Zr} 2$ & $2.951(3)$ & $\times 2$ \\
\hline & $-W 2$ & $3.047(3)$ & $\times 1$ & & - Zrl & $2.956(2)$ & $\times 2$ \\
\hline & $-W 1$ & $3.101(3)$ & $\times 2$ & & - Zrl & $3.101(3)$ & $\times 4$ \\
\hline & $-\mathrm{Zr} 1$ & $3.151(3)$ & $\times 2$ & & & & \\
\hline & $-\mathrm{Zr} 2$ & $3.241(3)$ & $\times 2$ & & & & \\
\hline & $-\mathrm{Zr} 2$ & $3.245(2)$ & $\times 2$ & W2 & $-\mathrm{W} 1$ & $2.679(2)$ & $\times 6$ \\
\hline & $-\mathrm{Zr} 1$ & $3.350(4)$ & $\times 1$ & & $-\mathrm{Zr} 1$ & $3.047(3)$ & $\times 6$ \\
\hline & - Zr1 & $3.473(5)$ & $\times 2$ & & & & \\
\hline & & & & $\mathrm{S} / \mathrm{Ni}$ & $-\mathrm{Zr} 1$ & $2.612(2)$ & $\times 6$ \\
\hline \multirow[t]{6}{*}{$\mathrm{Zr} 2$} & -0 & $2.240(2)$ & $\times 2$ & & $-\mathrm{Zr} 2$ & $3.172(4)$ & $\times 3$ \\
\hline & $-W 1$ & $2.951(3)$ & $\times 2$ & & -0 & $3.300(2)$ & $\times 6$ \\
\hline & $-\mathrm{S} / \mathrm{Ni}$ & $3.172(4)$ & x 1 & & & & \\
\hline & $-\mathrm{Zr} 2$ & $3.193(6)$ & $\times 2$ & 0 & $-\mathrm{Zr} 2$ & $2.240(2)$ & $\times 2$ \\
\hline & $-\mathrm{Zr} 1$ & $3.241(3)$ & x 4 & & $-\mathrm{Zr} 1$ & $2.345(2)$ & $\times 4$ \\
\hline & $-\mathrm{Zr} 1$ & $3.245(2)$ & $\times 4$ & & $-\mathrm{S} / \mathrm{Ni}$ & $3.300(2)$ & $\times 2$ \\
\hline
\end{tabular}


oxygen is undetermined. By this method $\mathrm{Zr}_{9} \mathrm{~W}_{4} \mathrm{SO}_{\mathrm{x}}$ was prepared. $\mathrm{Zr}_{9} \mathrm{~W}_{4} \mathrm{Ni}$ did not form, even when oxygen was intentionally added, as $\mathrm{ZrO}_{2}$ or $\mathrm{NiO}$, in the starting material. Thus, there is not a continuous range of solid solubility between the two endmembers $\mathrm{Zr}_{9} \mathrm{~W}_{4} \mathrm{SO}_{\mathrm{x}}$ and $\mathrm{Zr}_{9} \mathrm{~W}_{4} \mathrm{NiO}_{\mathrm{x}}$, since the nickel endmember does not form. A few more experiments were done to investigate the extent of nickel substitution for sulfur. The four molar ratios $n(\mathrm{~S}) / \mathrm{n}(\mathrm{Ni}) 3 / 1,2 / 1,1 / 1$, and $1 / 3$ were used in the starting materials. The kappa phase formed when the $n(\mathrm{~S}) / \mathrm{n}(\mathrm{Ni})$ ratio was $3 / 1$ and $2 / 1$, but did not form when it was $1 / 1$ or $1 / 3$. The maximum extent of nickel substitution may be that found in the sample from which the crystal was picked. In all of these experiments there was a small (1-3\%) mass loss in the arc melting step due to vaporization of sulfur and/or nickel. Consequently, in all these samples, minor phases present were elemental zirconium, tungsten, or $\mathrm{W}_{2} \mathrm{Zr}$.

The kappa phase $\mathrm{Zr}_{9} \mathrm{Mo}_{4} \mathrm{Ni}$ has been previously reported [97]. The preparation of this compound from the elements, by the arc melting method, was not successful. When the synthesis was tried again using $\mathrm{NiO}$ in the starting materials, the kappa phase was observed by $\mathrm{X}$-ray powder diffraction. Thus it appears that complete oxygen occupancy of the $6 g$ site may be necessary for the formation of the kappa phase. The importance of oxygen for the formation of the phase is dependent on the elements making up the metal framework, as well as the interstitial element X. Indeed, the role of the metal framework and the difference between tingsten and molybdenum is evident in the fact that the kappa phase forms for $\mathrm{Zr} / \mathrm{Mo} / \mathrm{Ni} / \mathrm{O}$, but not for $\mathrm{Zr} / \mathrm{W} / \mathrm{Ni} / \mathrm{O}$. The $\mathrm{Zr}_{9} \mathrm{Mo}_{4} \mathrm{SO}_{x}$ phase was also synthesized, and since $\mathrm{Zr}_{9} \mathrm{Mo}_{4} \mathrm{NiO}_{\mathrm{x}}$ is also known, and sulfur/nickel substitution has been observed on the tungsten analogue, it might expected that a solid solution form: retween these two. The lattice parameters for these new kappa phases are listed below in Table 5.6.

By looking at the list of known kappa phases, many other possibilities of mixed 
Table 5.6 Lattice parameters for new kappa phases

\begin{tabular}{llll}
\hline & $\mathrm{a}(\AA)$ & $\mathrm{c}(\AA)$ & $\mathrm{V}\left(\AA^{3}\right)$ \\
\hline $\mathrm{Zr}_{9} \mathrm{Mo}_{4} \mathrm{SO}_{\mathrm{x}}$ & $8.685(2)$ & $8.571(2)$ & $559.8(2)$ \\
$\mathrm{Zr}_{9} \mathrm{~W}_{4} \mathrm{SO}_{\mathrm{x}}$ & $8.671(2)$ & $8.607(3)$ & $560.4(3)$ \\
$\mathrm{Zr}_{9.2} \mathrm{~W}_{3.8} \mathrm{~S}_{0.67} \mathrm{Ni}_{0.33} \mathrm{O}_{3}$ & $8.688(4)$ & $8.558(7)$ & $559.4(7)$ \\
\hline
\end{tabular}

interstitial sites can be considered. Examples, like $\mathrm{Zr}_{9} \mathrm{~W}_{4}(\mathrm{~S}, \mathrm{Ni}) \mathrm{O}_{3}$, where another element only partially substitutes for the interstitial atom, or examples of complete solubility ranges might be found. In the former case, new understanding may be gained concerning the role of metal-metal bonding in this phase (i.e. $\mathrm{W}$ vs $\mathrm{Mo}$ in $\mathrm{Zr}-\mathrm{M}-\mathrm{Ni}$ ). In the latter case, in which the identity of the interstitial atoms is of little consequence, the effect of orbital interactions and electron counts may be such that the Fermi level crosses a region of nonbonding bands. The properties to be found for mixed interstitial phases are not known and present a fertile area for future study. Exceptions to this are the recently discovered superconductivities in $\mathrm{Hf}-\mathrm{Nb}-\mathrm{S}, \mathrm{Zr}-\mathrm{Nb}-\mathrm{S}$, and $\mathrm{Hf}-\mathrm{Ta}-\mathrm{Se}[21,95]$. In general, it can be stated that the single crystal and powder diffraction results obtained here strongly suggest that the known kappa phases (Table 5.1) could contain currently undetected interstitials and could exhibit currently undetermined variations in stoichiometry. 


\section{$\mathrm{Zr}_{6} \mathrm{Ni}_{6} \mathrm{TiSiO}_{\mathbf{x}}:$ A NEW STRUCTURE TYPE \\ WITH A MIXED EARLY-LATE TRANSITION METAL FRAMEWORK}

\section{Introduction}

An interstitially stabilized intermetallic in a mixed early-late transition metal system has been found to crystallize in a new structure type. The new compound, $\mathrm{Zr}_{6} \mathrm{Ni}_{6} \mathrm{TiSiO}_{\mathrm{x}}(\mathrm{x}=1.8)$, was synthesized by melting $\mathrm{Zr}, \mathrm{Ni}, \mathrm{Si}$, and $\mathrm{Ti}_{2} \mathrm{O}_{3}$ in an arc furnace, followed by annealing in vacuum at $900-1150^{\circ} \mathrm{C}$. The crystal structure was determined by refinement of single crystal $\mathrm{x}$-ray diffraction data. The structure was refined in the centrosymmetric space group $\mathrm{P} \overline{3} \mathrm{~m} 1, \mathrm{Z}=2$, with lattice parameters $a=b=8.2778(9) \AA$, and $c=7.444(1) \AA\left(R=0.030, R_{w}=0.033\right)$. Oxygen atoms center zirconium trigonal antiprisms, which share faces to form a three dimensional network. The titanium and silicon atoms are coordinated by icosahedra of nickel, or zirconium and nickel atoms. A structural comparison with the kappa-phase will be discussed.

A substantial diversity of structures of binary compounds in mixed early-late transition metal systems, particularly in the $\mathrm{Zr}-\mathrm{Ni}$ system, is described in the literature [47,104]. Typically, when an interstitial element reacts with a binary early-late transition metal compound to form a ternary compound, the compound crystallizes in a common structure type. In fact, only a limited number of structure types are known for phases of mixed early and late transition metals which are interstitially stabilized [46]. This work has described the importance of the presence of small amounts of oxygen in stabilizing phases in the $\mathrm{Zr}-\mathrm{Ni}$ system which do not appear as true binary intermetallic compounds.

The ternary metal system, $\mathrm{Zr}-\mathrm{Ti}-\mathrm{Ni}$, contains phases which do not occur in either of the binary systems $\mathrm{Zr}-\mathrm{Ni}$ or Ti-Ni (i.e. the hexagonal Laves pirase $\mathrm{ZrTiNi}[105,106]$, and the $\mathrm{BaPb}_{3}$ type 
structure $\left.\mathrm{ZrTi}_{2} \mathrm{Ni}_{9}[107,108]\right)$. It is natural to expect that interstitials in this temary system may stabilize new compounds, with respect to the ternary intermetallics and interstitially stabilized binary compounds. There are some examples of temary, and quatemary, phases which form with the addition of an interstitial atom, such as oxygen in the case of a few kappa-phases (eg.. $\left.\mathrm{Zr}_{9} \mathrm{~W}_{4}(\mathrm{~S}, \mathrm{Ni}) \mathrm{O}_{3}\right)[80,94,99]$. In this section the structure of a new interstitially stabilized compound with the composition $\mathrm{Zr}_{6} \mathrm{Ni}_{6} \mathrm{TiSiO}_{1.8}$ is reported.

\section{Experimental Details}

Samples were prepared from materials and by procedures described previously. All samples were arc melted three times on a water cooled copper plate with a thoriated nonconsumable tungsten electrode in an argon atmosphere. The arc melted buttons were subsequently crushed and pressed into pellets and annealed in evacuated silica tubes at $900-1150^{\circ} \mathrm{C}$ for $2-3$ days. All samples contained $\mathrm{ZrO}_{2}$ as a minor phase.

The single crystal used for the structural investigation was picked from a sample of a $\mathrm{Zr}$-Ti-Ni alloy which reacted with the silica tube in the annealing process. Subsequent reactions included silicon and oxygen in the starting materials. All handling of materials was done in air. Details of crystal data are listed in Table 6.1.

Semiquantitative analysis by energy dispersive $\mathrm{x}$-ray analysis (EDS) was carried out on a Cambridge S-200 scanning electron microscope with a Northern Tracor Micro Z-II x-ray detector. Surface analysis by $\mathrm{x}$-ray photoelecron spectroscopy was performed on a Perkin Elmer 5500 multitechnique system.

A Quantum Design SQUID magnetometer was used to check for superconductivity and to measure magnetic behavior at a field of $3 \mathrm{~T}$ over the temperature range $6-298 \mathrm{~K}$. 
Table 6.1 Crystal data for $\mathrm{Zr}_{6} \mathrm{Ni}_{6} \mathrm{TiSiO}_{\mathrm{x}}$

Formula

Space group

a $\AA$

c $\AA$

$\mathrm{V} \AA^{3}$

Z

$\mathrm{d}_{\text {cale }}, \mathrm{g} / \mathrm{cm}^{3}$

Crystal size, $\mathrm{mm}^{3}$

$\mu(\mathrm{MoKa}), \mathrm{cm}^{-1}$

Data collection instrument

Radiation (monochromated in incident beam)

Temperature, ${ }^{\circ} \mathrm{C}$

Scan method

Octants measured

Data collection range, $2 \theta$, deg

No. refl. measured

No. unique data, total

with $\mathrm{F}_{0}^{2}>3 \sigma\left(\mathrm{F}_{0}^{2}\right)$

No. parameters refined

Trans. factors, $\max . / \mathrm{min}$.

Secondary extinction coefficient

$\mathbf{R}^{\mathrm{a}}, \mathbf{R}_{\mathbf{w}}^{\mathrm{b}}, \mathrm{GOF}^{\mathrm{c}}$

Largest peak, e/ $/ \AA^{3}$

Largest negative peak, e $/ \AA^{3}$
$\mathrm{Zr}_{5.39} \mathrm{Ni}_{6.00} \mathrm{Ti}_{1.71} \mathrm{Si}_{0.90} \mathrm{O}_{1.80}$

P $\overline{3} \mathrm{~m} 1$ (164)

$8.2778(9)$

7.444(1)

441.7(1)

2

7.366

$0.08 \times 0.04 \times 0.04$

200.84

Rigaku AFC6R

$\operatorname{MoK}_{\alpha}(\lambda=0.71069 \AA)$

$23 \pm 1$

$2 \theta-\omega$

$\pm h \pm k l$

0-60

2897

272

37

1.500

$2.0(8) \times 10^{-7}$

$0.030,0.033,1.006$

$+1.44$

$-1.89$

${ }^{a} R=\Sigma\left\|F_{0}|-| F_{c}\right\| / \Sigma\left|F_{o}\right|$

${ }^{b} R_{w}=\left[\Sigma w\left(\left|F_{o}\right|-\left|F_{c}\right|\right)^{2} / \Sigma w\left|F_{0}\right|^{2}\right]^{1 / 2} ; w=1 / \sigma^{2}\left(\left|F_{o}\right|\right)$

${ }^{c} \mathrm{GOF}=\Sigma\left(\left(\left|\mathrm{F}_{\mathrm{o}}\right|-\left|\mathrm{F}_{\mathrm{c}}\right|\right) / \sigma_{\mathrm{i}}\right) /\left(\mathrm{N}_{\text {obs refl }} \mathrm{N}_{\text {parameters }}\right)$ 


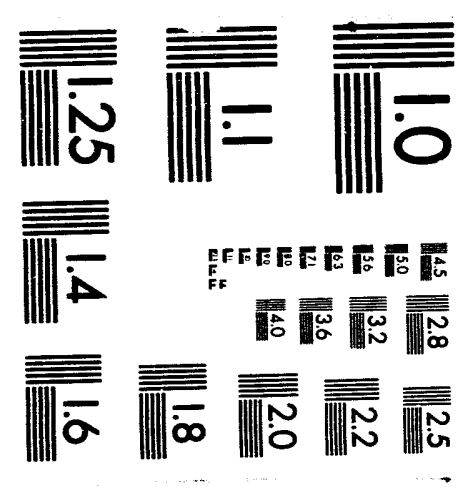





\section{Results}

The crystal was found to exhibit Laue symmetry $\overline{3} \mathrm{~m} 1$, and the single crystal refinement was carried out in the centrosymmetric space group $\bar{P} \overline{3} \mathrm{~m} 1$. The refinement converged with the placement of the $\mathrm{Zr}, \mathrm{Ni}, \mathrm{Ti}, \mathrm{Si}$, and $\mathrm{O}(1)$ atoms at the proper sites. The refinement improved significantly when titanium was allowed to partially occupy the $\operatorname{Zr}(2)$ position, and also to partially occupy the Si position. At this point, a peak in the Fourier difference map suggested the presence of another oxygen atom, $O(2)$. This atom was added to the refinement, and the multiplicities of both oxygen atoms were allowed to vary. The final positional parameters, equivalent $B$ values, and occupancies of all sites are listed in Table 6.2. The refinement reported here was calculated using a $F_{o}^{2}>3 \sigma\left(F_{o}^{2}\right)$ cutoff. An additional refinement using a $1 \sigma$ cutoff resulted in $R=0.054$ and $R_{w}=$ 0.043 and no significant change in the thermal or positional parameters. The anisotropic thermal parameters of all non-oxygen atoms are in Table 6.3. Structure factor amplitudes, including unobserved reflections, are in the appendix.

A projection of the whole structure is shown in Figure 6.1. The structure can be described by viewing two connected, alternating layers, the projections of which are shown in Figures 6.2 and 6.3. The layers are labeled A and B, as shown in Figure 6.4. Figure 6.2 shows layer A, centered at $z=1 / 2$ and containing only the atoms within the range $z=1 / 2 \pm 1 / 3$. This layer consists of a network of face-sharing zirconium trigonal antiprisms which form buckled rings. This structural unit matches the description of the kappa phase (compare Figure 5.3). The bold lines mark the $\mathrm{Zr}$ - $\mathrm{Zr}$ connections that outline the rings. Titanium atoms in an icosahedral environment are in the center of the rings. A common feature in oxygen-stabilized intermetallics of zirconium is the presence of oxygen in the center of the zirconium trigonal antiprisms. The antiprisms in the buckled ring are centered by oxygen in two distinct crystallographic sites, one of which $(\mathrm{O}(2))$ is only approximately one third occupied (this is the antiprism with the three-fold axis along the c-axis, as viewed in the 
Table 6.2 Positional parameters for $\mathrm{Zr}_{6} \mathrm{Ni}_{6} \mathrm{TiSiO}_{\mathrm{x}}$

\begin{tabular}{lcccccc}
\hline Atom & Site & $\mathrm{x}$ & $\mathrm{y}$ & $\mathrm{z}$ & $\left.\mathrm{B}_{\mathrm{eq}}{ }^{\mathrm{a}} \AA^{2}\right)$ & $\%$ occup \\
\hline $\mathrm{Ni}(1)$ & $6 i$ & $0.1129(2)$ & -0.1129 & $0.2553(3)$ & $0.54(2)$ & 100 \\
$\mathrm{Ni}(2)$ & $6 i$ & $0.1726(2)$ & -0.1726 & $0.9326(3)$ & $0.54(2)$ & 100 \\
$\mathrm{Zr}(1)$ & $6 i$ & $0.4598(1)$ & -0.4598 & $0.1953(2)$ & $0.63(2)$ & 100 \\
$\mathrm{Zr}(2)$ & $6 i$ & $0.2073(1)$ & -0.2073 & $0.5688(2)$ & $0.49(3)$ & $79(2)$ \\
$\mathrm{Ti}$ & & & & & & $21(2)$ \\
$\mathrm{Ti}(1)$ & $1 a$ & 0 & 0 & 0 & $0.4(2)$ & 100 \\
$\mathrm{Ti}(2)$ & $1 b$ & 0 & 0 & $1 / 2$ & $0.7(2)$ & 100 \\
$\mathrm{Si}$ & $2 d$ & $1 / 3$ & $2 / 3$ & $0.874(1)$ & $0.4(2)$ & $90(4)$ \\
$\mathrm{Ti}$ & & & & & & $10(4)$ \\
$\mathrm{O}(1)$ & $3 f$ & $1 / 2$ & 0 & $0.367(9)$ & $0.4(8)$ & $36(6)$ \\
$\mathrm{O}(2)$ & $2 d$ & $1 / 3$ & $2 / 3$ & & & $96(4)$ \\
\hline
\end{tabular}

${ }^{a} B_{e q}=8 \pi^{2} / 3 \Sigma_{i}^{3} \Sigma_{1}^{3} U_{i j}{ }_{i j} a_{i}^{*} a_{j}^{*} a_{i}^{*} a_{j}^{*}$ 
Table 6.3 Anisotropic thermal parameters for $\mathrm{Zr}_{6} \mathrm{Ni}_{6} \mathrm{TiSiO}_{\mathrm{x}}$

\begin{tabular}{lllllll}
\hline Atom & $\mathrm{U}_{11}$ & $\mathrm{U}_{22}$ & $\mathrm{U}_{33}$ & $\mathrm{U}_{12}$ & $\mathrm{U}_{13}$ & $\mathrm{U}_{23}$ \\
\hline $\mathrm{Ni}(1)$ & $0.0081(8)$ & 0.0081 & $0.006(1)$ & $0.0052(9)$ & $-0.0004(4)$ & 0.0004 \\
$\mathrm{Ni}(2)$ & $0.0077(7)$ & 0.0077 & $0.006(1)$ & $0.0044(8)$ & $0.0001(4)$ & -0.0001 \\
$\mathrm{Zr}(1)$ & $0.0087(6)$ & 0.0087 & $0.008(1)$ & $0.0054(7)$ & $-0.0004(3)$ & 0.0004 \\
$\mathrm{Zr}(2)$ & $0.0051(7)$ & 0.0051 & $0.007(1)$ & $0.0015(7)$ & $-0.0005(4)$ & 0.0005 \\
$\operatorname{Ti}(1)$ & $0.005(2)$ & 0.005 & $0.003(4)$ & 0.003 & 0 & 0 \\
$\operatorname{Ti}(2)$ & $0.007(2)$ & 0.007 & $0.013(4)$ & 0.003 & 0 & 0 \\
$\mathrm{Si}$ & $0.003(2)$ & 0.003 & $0.007(4)$ & 0.002 & 0 & 0 \\
$\mathrm{O}(1)$ & $0.009(3)^{\mathrm{a}}$ & & & & & \\
$\mathrm{O}(2)$ & $0.01(1)^{\mathrm{a}}$ & & & & & \\
\hline
\end{tabular}

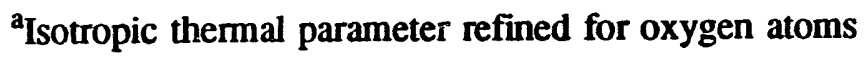




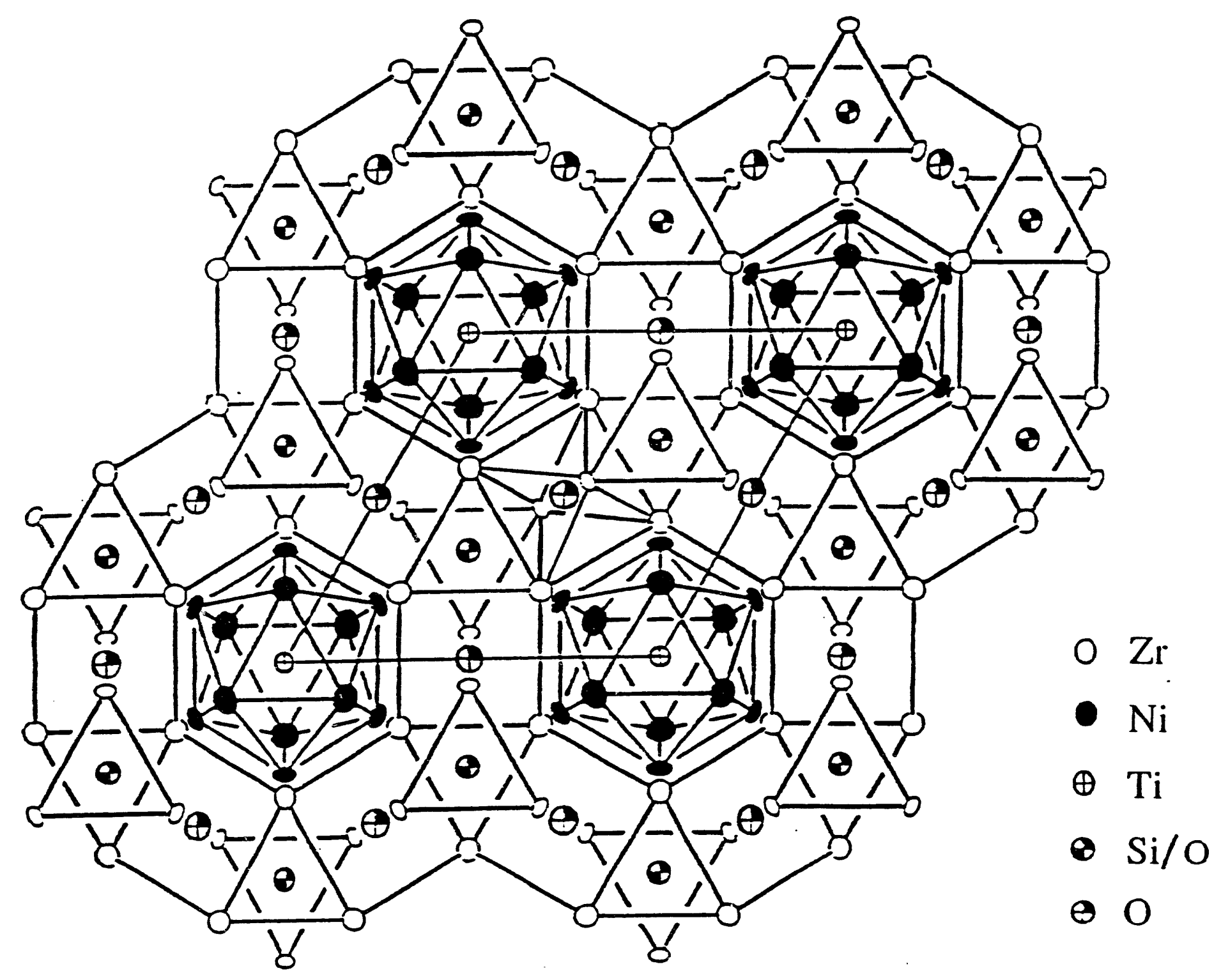

Figure 6.1 Projection along the $c$ axis of the $\mathrm{Zr}_{6} \mathrm{Ni}_{6} \mathrm{TiSiO}_{\mathrm{x}}$ structure 


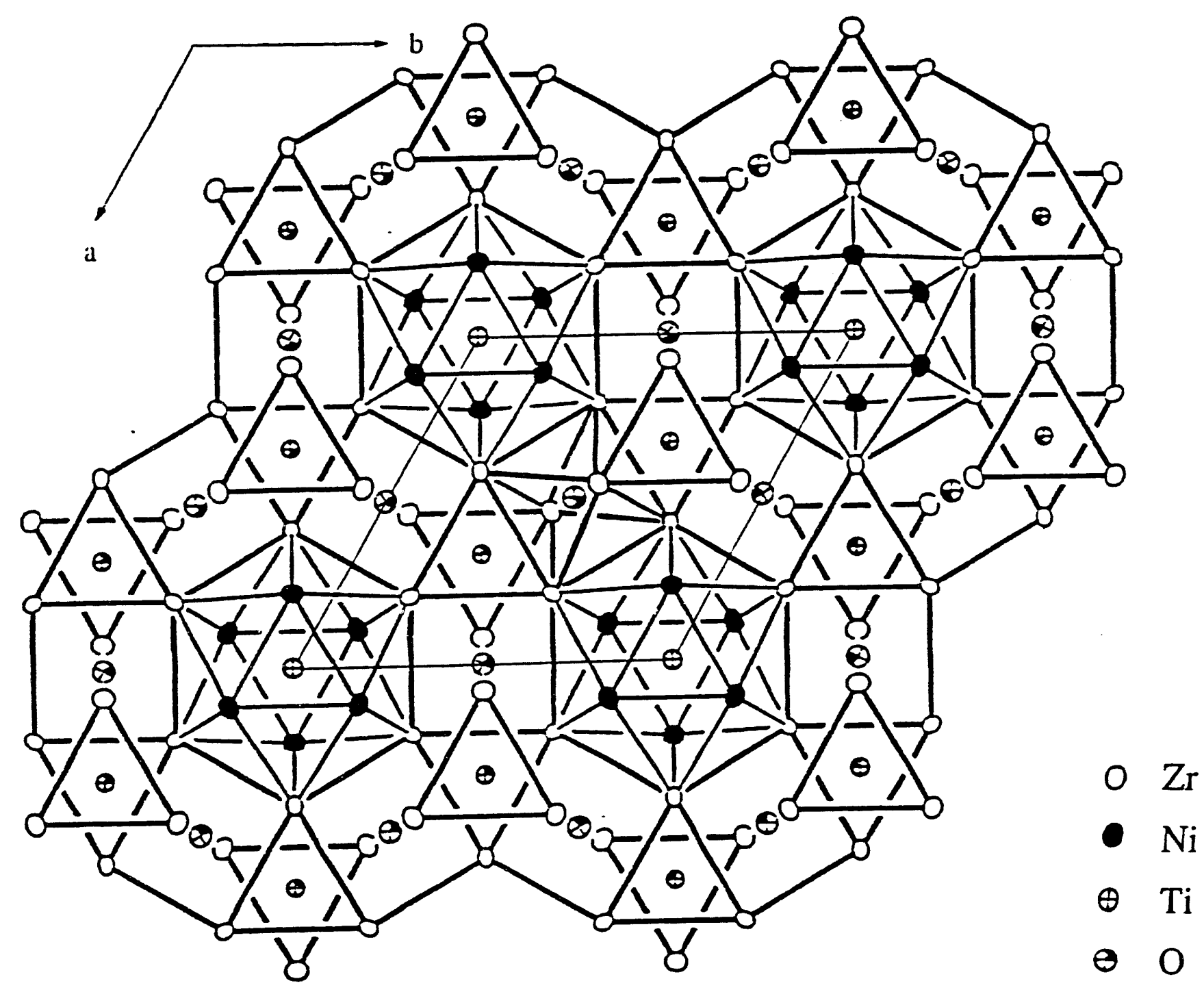

Figure 6.2 Projection of Layer A, showing atoms at positions with $\mathrm{z}=1 / 2 \pm .33(\mathrm{Ni}(2), \mathrm{Ti}(1)$, and $\mathrm{Si}$ not in this layer). $\mathrm{Zr}$ trigonal antiprism outlined at cell center. 


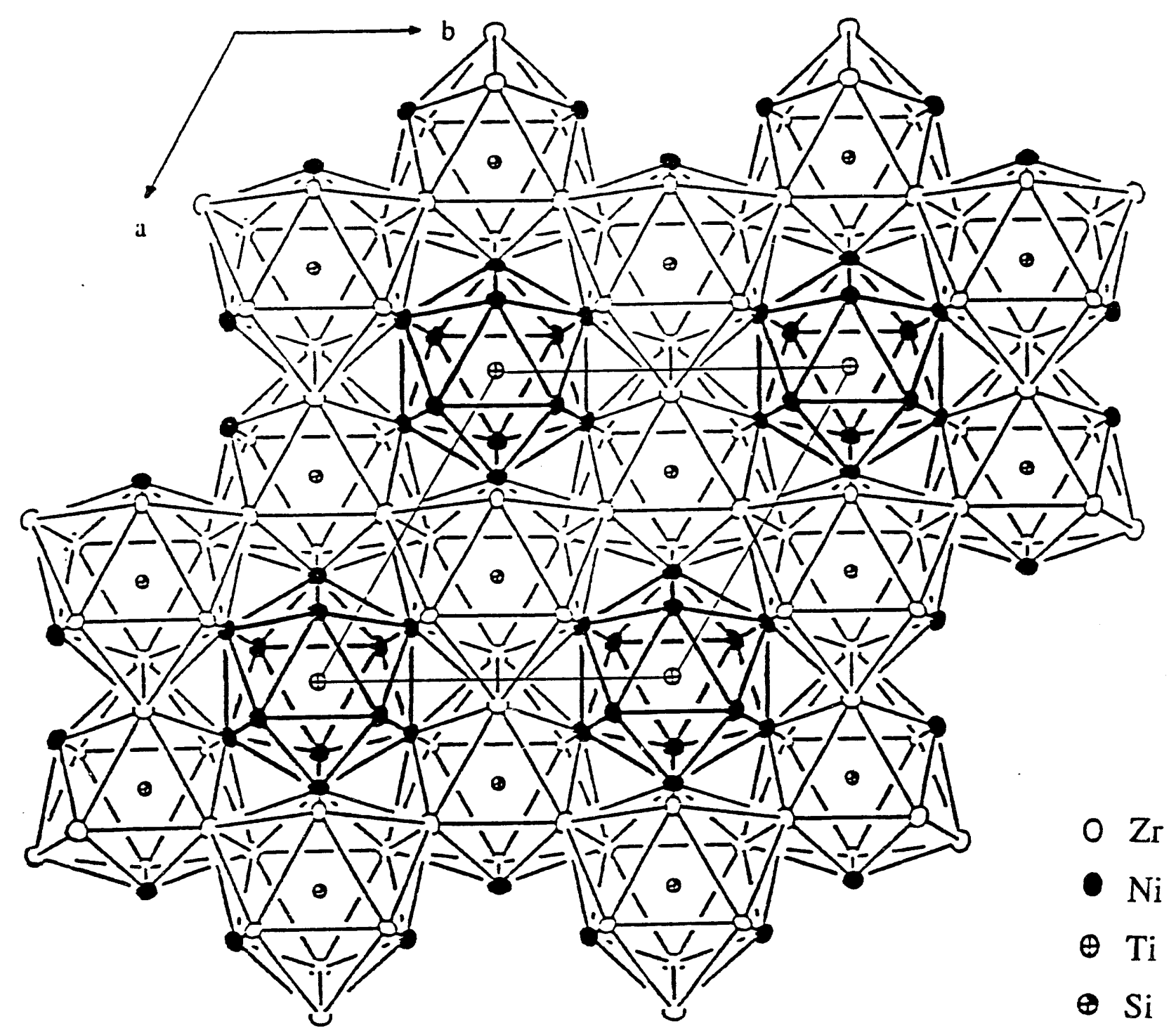

Figure 6.3 Projection of Layer B, showing atoms at positions with $-1 / 2<\mathrm{z}<1 / 2(\mathrm{O}(1), \mathrm{O}(2)$, and $\mathrm{Ti}(2)$ at $\mathrm{z}=1 / 2$ not in this layer). 


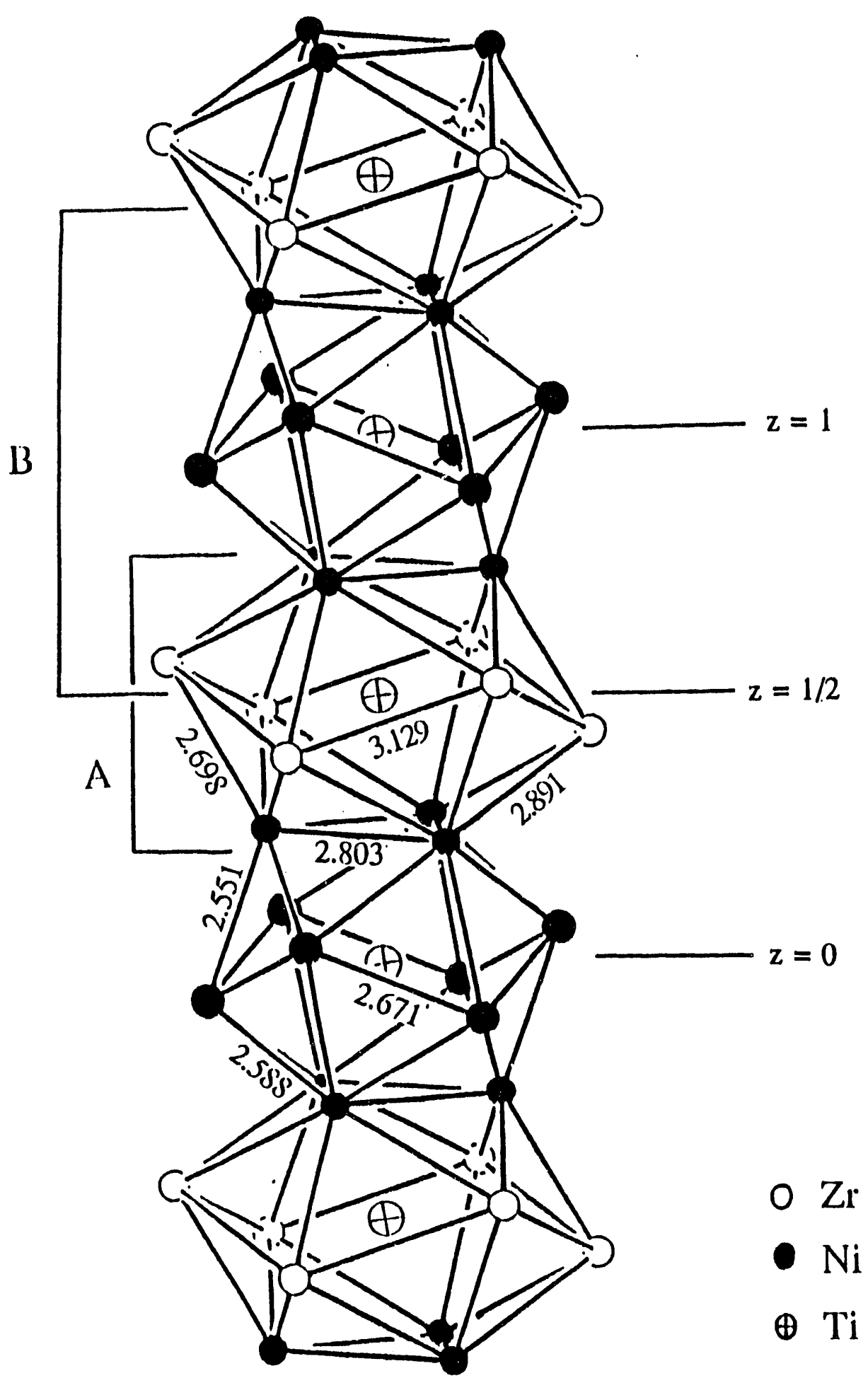

Figure 6.4 View along the c-axis. Icosahedral coordination of $\mathrm{Ti}$ atoms shown. Side view of regions included in Layers A and B, which are shown in projection in Figures 6.2 and 6.3, respectively. 
projection in Figure 6.1). The antiprisms in the ring, then, form an altemating pattern of filled, and partially filled antiprisms. The $\mathrm{Zr}-\mathrm{O}$ distances $(2.22-2.35 \AA)$ are typical of oxygen-centered zirconium antiprisms in intermetallic compounds $\left(\mathrm{d}_{\mathrm{Zr}-\mathrm{O}}=2.305-2.307 \AA\right.$ in $\mathrm{Zr}_{3} \mathrm{NiO}$ [66] and $2.27 \AA$ in $\mathrm{Zr}_{4} \mathrm{Ni}_{2} \mathrm{O}$ ). The short $\mathrm{O}(1)-\mathrm{O}(2)$ distance (2.59 $\AA$ ) suggests that full occupancy of both sites would be energetically unfavorable, similar to the situation of filling adjacent octahedral sites in the $\mathrm{Ti}_{2} \mathrm{Ni}$ type structures [72]. The icosahedron around the titanium atom consists of 6 zirconium and 6 nickel atoms. Distances in the $\mathrm{Ni}_{6} \mathrm{Zr}_{6}$ icosahedron are indicated in Figure 6.4. Figure 6.5 shows the distances within the zirconium network. All interatomic distances less than $3.6 \AA$ are listed in Table 6.4 .

Figure 6.3 shows the projection along $\mathrm{c}$ of layer $\mathrm{B}$, centered at $\mathrm{z}=0$ and including all atoms except those at $\mathrm{z}= \pm 1 / 2$. The bold outlines show the $\mathrm{Ni}_{12}$ icosahedra, centered by titanium at the unit cell origin. Figure 6.4 illustrates how this $\mathrm{Ni}_{12}$ icosahedron shares faces and stacks with the $\mathrm{Ni}_{6} \mathrm{Zr}_{6}$ icosahedron centered at $\mathrm{z}=1 / 2$. The $\mathrm{Ni}_{12}$ unit is a fairly regular icosahedron, with a slight expansion at the top and bottom $\left(d_{\mathrm{Ni1}-\mathrm{Ni1}}=2.80 \AA\right.$, compared to $\mathrm{d}_{\mathrm{Ni1}-\mathrm{Ni2}}=2.55 \AA$ or $\left.\mathrm{d}_{\mathrm{Ni2}-\mathrm{Ni2}}=2.67 \AA\right)$. This expansion is necessary to allow face-sharing chains to form with the larger and more irregular $\mathrm{Ni}_{6} \mathrm{Zr}_{6}$ icosahedron. The central titanium atom has very short titanium-nickel distances in all of these icosahedra (2.44-2.52 $\AA$ ). They are shorter, in fact, than any of the nickel-nickel distances (2.55-2.80 $\AA$ ). A calculation of Pauling bond orders [4] was carried out on this compound, and the short distances and high coordination give the titanium atoms an unusually high bond order in comparison to the other transition metal atoms. This short titanium-nickel distance, however, was also observed in $\mathrm{Ti}_{2} \mathrm{Ni}$ and the filled- $\mathrm{Ti}_{2} \mathrm{Ni}, \mathrm{Ti}_{4} \mathrm{Ni}_{2} \mathrm{O}$, structures $\left(\mathrm{d}_{\mathrm{Ti}-\mathrm{Ni}}=2.48 \AA\right.$ and $2.46 \AA$, respectively), in which Ti atoms also center icosahedra [79]. This may be surprising if one considers that the atomic radius of titanium is larger than that of nickel. It is not so surprising when the Lewis acid - base interaction is considered because strong titanium - nickel acid - base interactions 
(a)

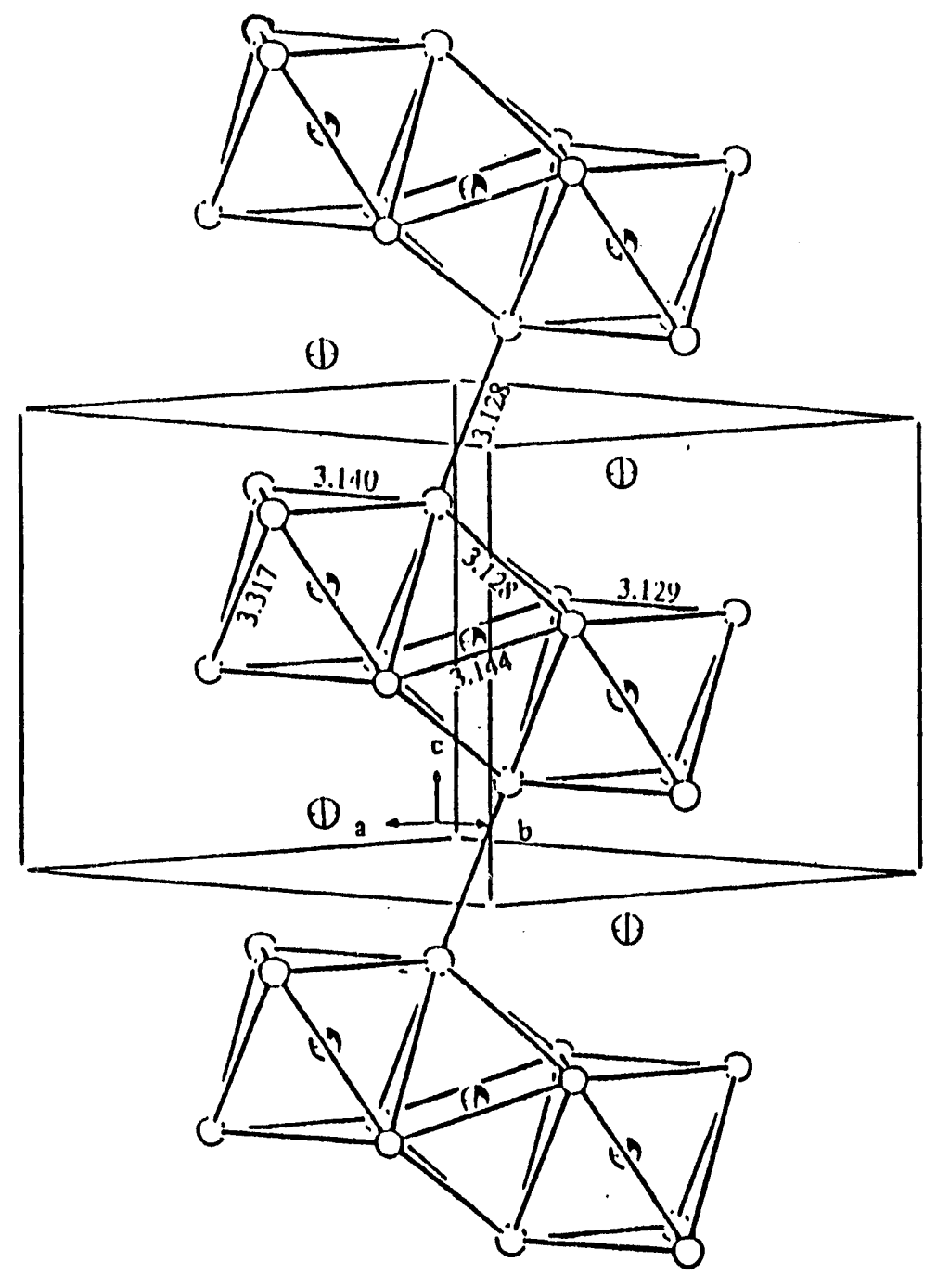

(1)

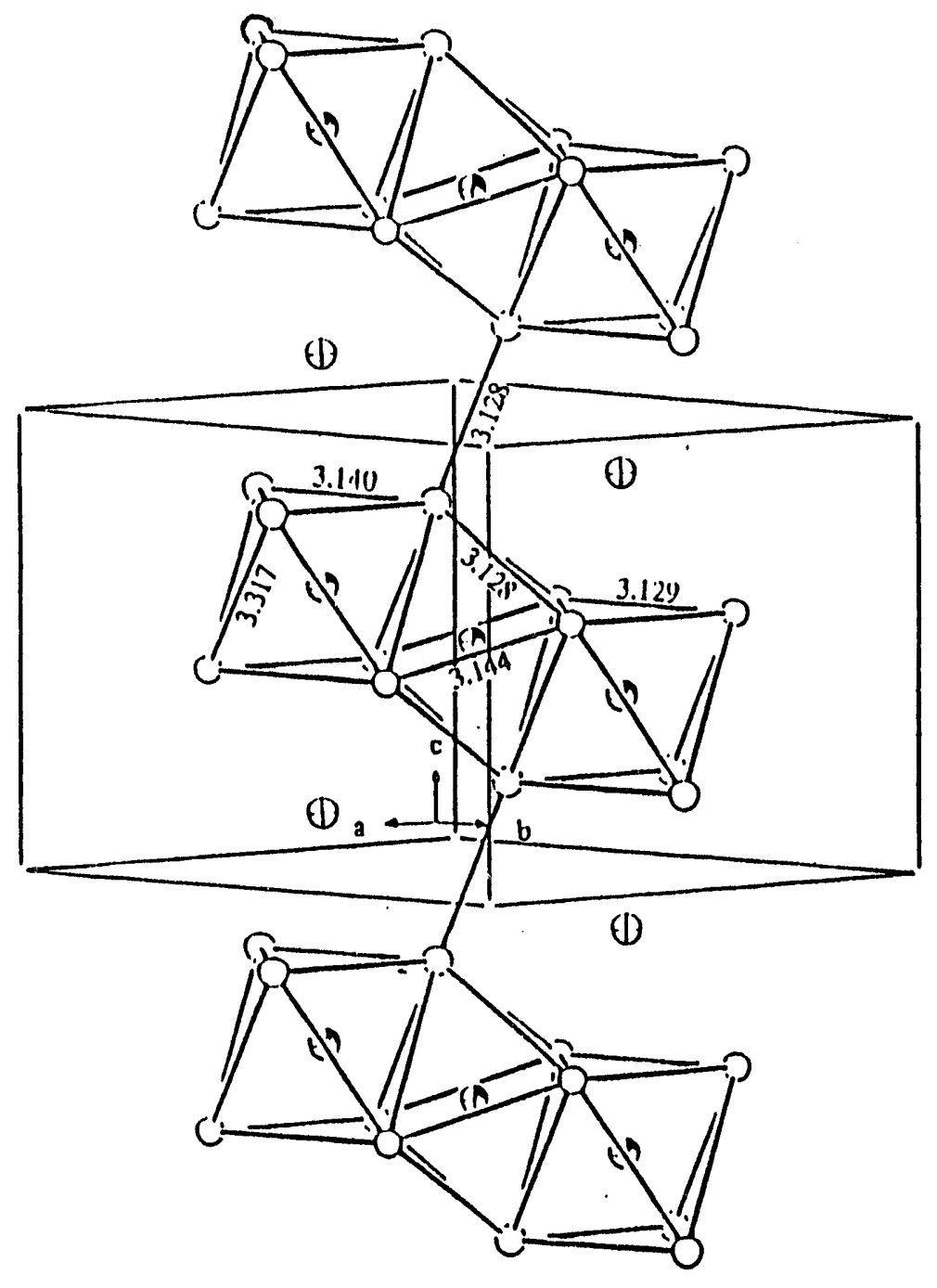

(b)

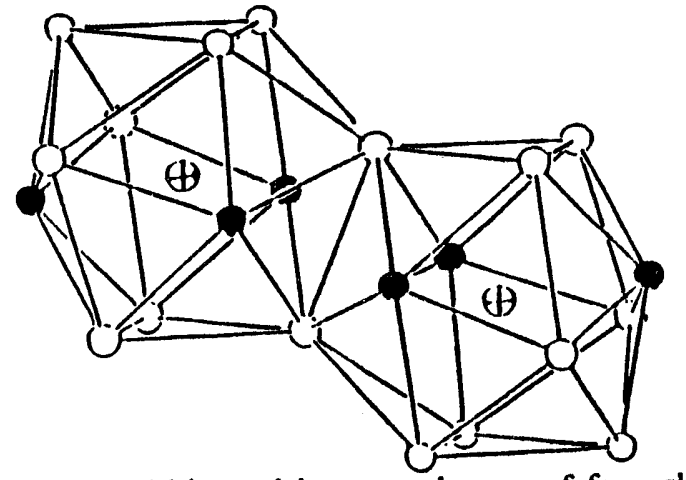

o $\mathrm{Zr}$

- Ni

(1) $\mathrm{Si}$

(1) $\mathrm{O}$

Figure 6.5 (a) $\mathrm{Zr}$ - $\mathrm{Zr}$ distances within and between layers of face-sharing trigonal antiprisms.

(b) two edge-sharing silicon-centered icosalıedra, which lie between the zirconium layers in (a). 
Table 6.4 Interatomic distances in $\mathrm{Zr}_{6} \mathrm{Ni}_{6} \mathrm{TiSiO}_{\mathbf{x}}(\AA)$ (distances less than $3.6 \AA$ listed)

\begin{tabular}{|c|c|c|c|c|c|c|c|}
\hline \multirow[t]{11}{*}{$\operatorname{Zr}(1)-$} & $O(2)$ & $2.22(4)$ & $\times 1$ & $\operatorname{Zr}(2)-$ & $O(1)$ & $2.2179(6)$ & $\times 2$ \\
\hline & $O(1)$ & $2.340(1)$ & x 1 & & $O(2)$ & $2.35(4)$ & $\times 1$ \\
\hline & $\mathrm{Ni}(1)$ & $2.784(2)$ & $\times 2$ & & $\mathrm{Ni}(1)$ & $2.698(2)$ & $\times 1$ \\
\hline & $\mathrm{Ni}(2)$ & $2.860(1)$ & $\times 2$ & & $\mathrm{Ni}(2)$ & $2.754(2)$ & $\times 1$ \\
\hline & $\mathrm{Ni}(2)$ & $2.871(2)$ & $\times 2$ & & $\mathrm{Ni}(1)$ & $2.891(2)$ & $\times 2$ \\
\hline & $\mathrm{Si}$ & $3.001(6)$ & $\times 1$ & & $\mathrm{Si}$ & $2.903(6)$ & $\times 1$ \\
\hline & $\mathrm{Si}$ & $3.011(2)$ & $\times 1$ & & $\operatorname{Ti}(2)$ & $3.017(2)$ & $\times 1$ \\
\hline & $\operatorname{Zr}(1)$ & $3.128(3)$ & $\times 1$ & & $\operatorname{Zr}(1)$ & $3.128(2)$ & $\times 2$ \\
\hline & $\operatorname{Zr}(2)$ & $3.128(2)$ & $\times 2$ & & $\operatorname{Zr}(2)$ & $3.129(3)$ & $\times 2$ \\
\hline & $\operatorname{Zr}(1)$ & $3.140(3)$ & $\times 2$ & & $\operatorname{Zr}(2)$ & $3.144(2)$ & $\times 2$ \\
\hline & $\operatorname{Zr}(2)$ & $3.317(2)$ & $\times 2$ & & $\operatorname{Zr}(1)$ & $3.317(2)$ & $\times 2$ \\
\hline \multirow[t]{10}{*}{$\mathrm{Ni}(1)$ - } & $\operatorname{Ti}(2)$ & $2.436(2)$ & $\times 1$ & $\mathrm{Ni}(2)$ - & $\mathrm{Si}$ & $2.345(2)$ & $\times 1$ \\
\hline & $\operatorname{Ti}(1)$ & $2.496(2)$ & $\times 1$ & & $\operatorname{Ti}(1)$ & $2.525(2)$ & $\times 1$ \\
\hline & $\mathrm{Ni}(2)$ & $2.551(3)$ & $\times 1$ & & $\mathrm{Ni}(1)$ & $2.551(3)$ & $\times 1$ \\
\hline & $\mathrm{Ni}(2)$ & $2.588(2)$ & $\times 2$ & & $\mathrm{Ni}(1)$ & $2.588(2)$ & $\times 2$ \\
\hline & $\operatorname{Zr}(2)$ & $2.698(2)$ & x 1 & & $\mathrm{Ni}(2)$ & $2.671(2)$ & $\times 2$ \\
\hline & $\operatorname{Zr}(1)$ & $2.784(2)$ & $\times 2$ & & $\operatorname{Zr}(2)$ & $2.754(2)$ & $\times 1$ \\
\hline & $\mathrm{Ni}(1)$ & $2.803(3)$ & $\times 2$ & & $\mathrm{Zr}(1)$ & $2.860(1)$ & $\times 2$ \\
\hline & $\mathrm{Zr}(2)$ & $2.891(2)$ & $\times 2$ & & $\mathrm{Zr}(1)$ & $2.871(2)$ & $\times 2$ \\
\hline & $\mathrm{O}(2)$ & $3.27(4)$ & x 1 & & & & \\
\hline & $O(1)$ & $3.386(1)$ & $\times 2$ & & & & \\
\hline \multirow[t]{2}{*}{$\operatorname{Ti}(1)-$} & $\mathrm{Ni}(1)$ & $2.496(2)$ & $\times 6$ & $\operatorname{Ti}(2)$ & $\mathrm{Ni}(1)$ & $2.436(2)$ & $\times 6$ \\
\hline & $\mathrm{Ni}(2)$ & $2.525(2)$ & $\times 6$ & & $\operatorname{Zr}(2)$ & $3.017(2)$ & $\times 6$ \\
\hline \multirow[t]{8}{*}{$\mathrm{Si} \quad-$} & $\mathrm{Ni}(2)$ & $2.345(2)$ & $\times 3$ & $O(1)=$ & $\operatorname{Zr}(2)$ & $2.2179(6)$ & $\times 4$ \\
\hline & $\operatorname{Zr}(2)$ & $2.903(6)$ & $\times 3$ & & $\operatorname{Zr}(1)$ & $2.340(1)$ & $\times 2$ \\
\hline & $\operatorname{Zr}(1)$ & $3.001(6)$ & $\times 3$ & & $\mathrm{O}(2)$ & $2.52(2)$ & $\times 2$ \\
\hline & $\operatorname{Zr}(1)$ & $3.011(2)$ & $\times 3$ & & $\mathrm{Ni}(1)$ & $3.386(1)$ & $\times 4$ \\
\hline & & & & $O(2)$ - & $\operatorname{Zr}(1)$ & $2.22(4)$ & $\times 3$ \\
\hline & & & & & $\operatorname{Zr}(2)$ & $2.35(4)$ & $\times 3$ \\
\hline & & & & & $O(1)$ & $2.52(2)$ & $\times 3$ \\
\hline & & & & & $\mathrm{Ni}(1)$ & $3.27(4)$ & $\times 3$ \\
\hline
\end{tabular}


are expected rather than strong nickel - nickel interactions, which were minimal in the results of the extended Hückel calculations of overlap populations for $\mathrm{Zr}_{4} \mathrm{Ni}_{2} \mathrm{O}$. The titanium - nickel interactions in this case are certainly more important than the nickel - nickel interactions.

The projection in Figure 6.3 shows a $\mathrm{Ni}_{12}$ icosahedron sharing six vertices with six very distorted silicon-centered icosahedra. The distortion is seen in the very short Si-Ni distances (2.34 $\AA)$, compared with the $\mathrm{Si}-\mathrm{Zr}$ distances (2.90-3.01 $\AA$ ). These silicon-centered icosahedra form a network of edge-sharing icosahedra. Figure 6.5 (b) shows how two of these icosahedra share edges. Figure 6.5 (a) shows the location of the silicon between the layers of zirconium antiprisms. The trigonal antiprisms and icosahedra share faces. Thus, the structure consists of a metal framework of zirconium trigonal antiprisms and nickel icosahedra which arrange in this three-dimensional network. Titanium and silicon fill the icosahedral sites, and oxygen occupies trigonal antiprismatic sites.

The crystal structure refinement yields the atomic ratios $\mathrm{Ni} / \mathrm{Zr} / \mathrm{Ti} / \mathrm{Si}$ of $6 / 5.4,1.7 / 0.9$, to be compared with the idealized atomic ratios of $6 / 6 / 1 / 1$. A small piece of the sample from which the crystal was extracted was studied by both EDS and XPS techniques. Surface analysis on a sample which was ion-beam etched in an argon atmosphere gave ratios of $6 / 5.8 / 1.6 / 0.5$. Semiquantitative elemental analysis by EDS on a rough surface also resulted in a $\mathrm{Ni} / \mathrm{Zr}$ ratio greater than one, with excess titanium, supporting the conclusion that titanium substitutes on the zirconium sites. The EDS experiment did not, however, indicate a deficiency in silicon. A bulk sample prepared with starting stoichiometry $\mathrm{Zr}_{6} \mathrm{Ni}_{6} \mathrm{TiSiO}_{2}$, and containing $\mathrm{ZrO}_{2}$ as a minor phase, had lattice parameters $\mathrm{a}=\mathrm{b}=$ 8.334(2) $\AA$ and $c=7.483(2) \AA$. This lattice expansion from that reported for the sample from which the single crystal was selected is expected if less titanium substitutes for zirconium on the $\operatorname{Zr}(2)$ site, and suggests that there is a homogeneity range for this phase. The structure was not observed when nickel was substituted by iron or cobalt. 
The sample was checked for superconductivity, but none was detected down to $6 \mathrm{~K}$. Magnetic measurements from 6-297 $\mathrm{K}$ show the sample is paramagnetic. A correction was applied for the diamagnetism of the core electrons, and an approximately $5 \%$ impurity phase of $\mathrm{ZrO}_{2}[111]$ (Figure 6.6). See also Figure 4.7.

\section{Discussion}

This new strucuure may usefully be compared to the kappa phases [94]. Kappa phases crystallize in the hexagonal space group $\mathrm{P}_{3} / \mathrm{mmc}$. This new phase crystallizes in the trigonal space group $P \overline{3} \mathrm{~m} 1$. Figure 6.7 compares the metal framework in the structures of these two phases, viewed perpendicular to the $[\overline{1} 10]$ direction. The oxygen atoms are omitted in this figure. Figure 6.7 (a) is similar to Figure 6.5, showing the icosahedral coordination of silicon (B) between the two layers of zirconium trigonal antiprisms (A). Figure 6.7 (b) is a view of the kappa phase which also contains parallel layers of trigonal antiprisms made up of metal atom $M$ at the top and bottom of the figure (A). A horizontal mirror plane contains the interstitial atom, $\mathrm{X}$, and one face of the trigonal antiprism. It can be noticed that the parallel layers are connected by a middle "antiparallel" layer ( $\left.\mathrm{A}^{\prime}\right)$. The interstitial atom has a tricapped trigonal-prismatic coordination. The new structure can be pictured as a modified kappa phase, where the distortion consists of expanding one trigonal face of the trigonal prism, as indicated by the arrows in Figure 6.7 (b), and moving the atoms to a position corresponding to the $\mathrm{Ni}$ atoms in Figure 6.7 (a). The interstitial atom then moves into this expanded region. A compression along the $c$-axis completes the distortion (a value of $c / a=0.97-0.99$ is typical for the kappa phases, compared to $c / a=0.90$ for the new structure).

The kappa phases are an intriguing class of compounds, in which the metal framework provides a host to many different interstitial elements. The general formula for the kappa-phase is $\mathrm{M}_{9} \mathrm{M}_{4} \mathrm{X}$, where $\mathrm{X}=\mathrm{B}, \mathrm{C}, \mathrm{Si}, \mathrm{Ge}, \mathrm{P}, \mathrm{As}, \mathrm{S}, \mathrm{Se}, \mathrm{Fe}, \mathrm{Co}$, or Ni. Apparently, the strength of the 


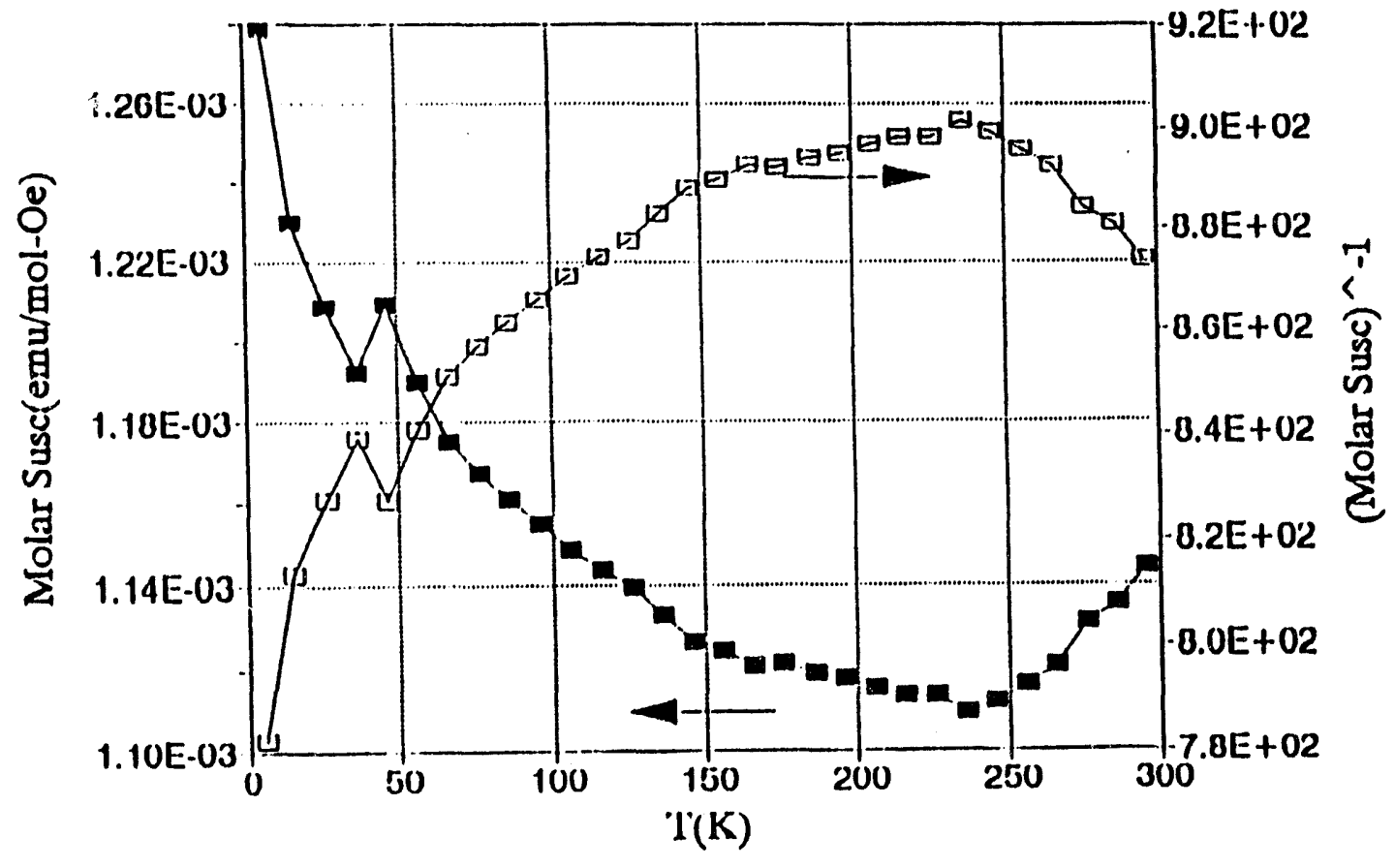

Figure 6.6 Magnetic susceptibility of $\mathrm{Zr}_{6} \mathrm{Ni}_{6} \mathrm{TiSiO}_{1.8}$. The bump below $50 \mathrm{~K}$ is attributed to atmospheric oxygen. 
(a) $\mathrm{A}$

[(0)I]

A

B

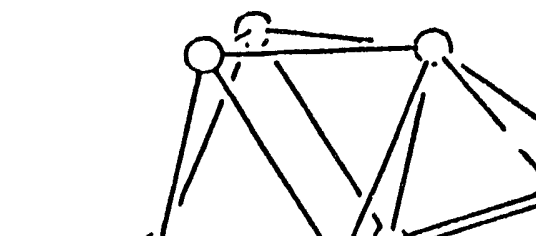

A

(b)

A

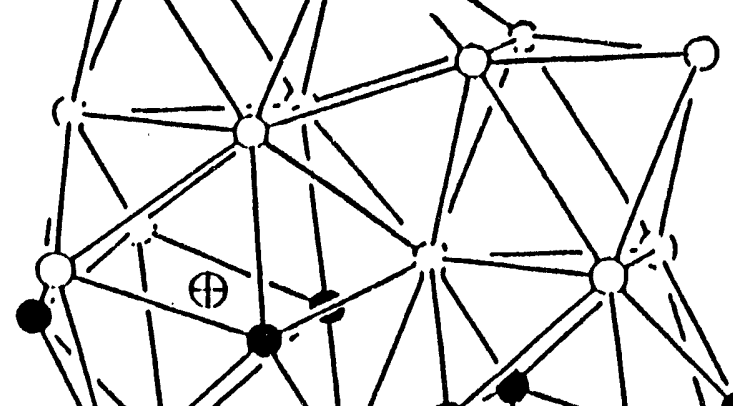

A

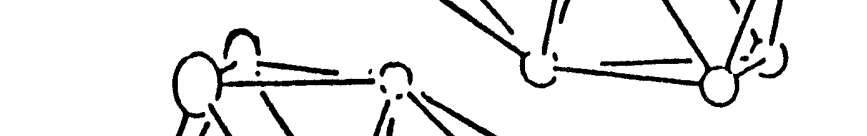

O M

$\oplus \mathrm{X}$

A

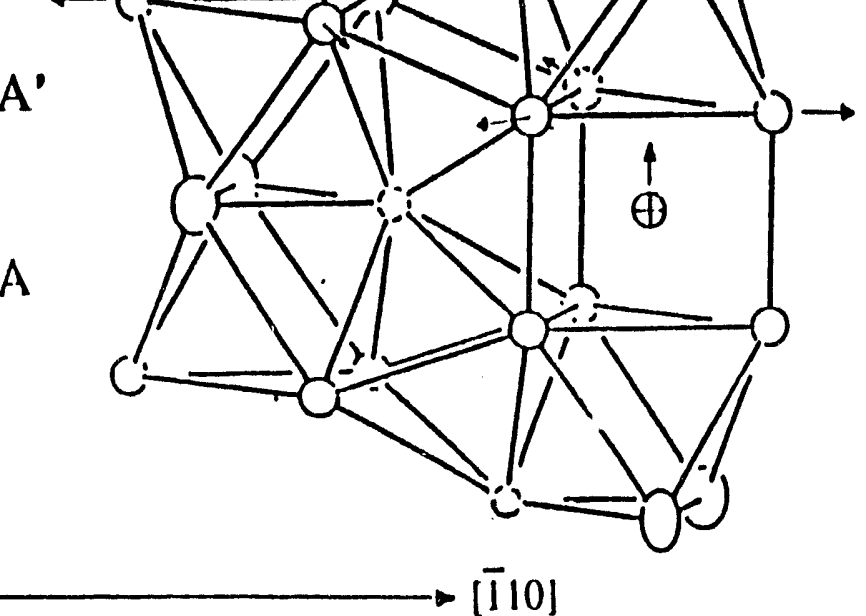

Figure 6.7 (a) $\mathrm{Zr}_{6} \mathrm{Ni}_{6} \mathrm{TiSiO}_{\mathrm{x}}$.

(b) Kappa-phase. Arrows show direction of distortion leading to the new structure. 
metal-metal interactions in the framework allows for the variability in X. A similar argument suggests that this new phase might also form with a variety of interstitial elements. The kappa phase and the new phase both have a metal/non-metal ratio of $13 / 1$, neglecting the oxygen. The difference between the two phases is the metal framework. The kappa phase contains two transition metals, while this new phase has a temary framework with two early transition metals and a late transition metal.

It is very likely that this new phase will also accomodate a variety of interstitial atoms in the icosahedral site occupied by silicon. A tabulation of preferred coordination number for main group, and iron group transition metal elements, based on the results of the structural determination of compounds in 324 structure types, indicates gallium and aluminum prefer a twelve coordinated site over a coordination number of nine [109]. Many of the elements which are found in the tricapped trigonal prismatic interstitial site of the kappa phase, including $\mathrm{B}, \mathrm{Ge}, \mathrm{As}, \mathrm{Si}$, and $\mathrm{P}$ prefer a coordination number of nine. While this does not preclude the possibility of these elements forming in this new structure type (as in the case of silicon), it certainly gives an indication of what might be expected in attempts to synthesize new compounds of this structure type. 


\section{IDEAS FOR FUTURE WORK}

\section{Cubic Laves Phase: $\mathrm{Zr} / \mathrm{Ni} / \mathrm{O}$}

Reference has been made throughout of the existence of an interstitially stabilized cubic Laves phase in the zirconium - nickel system. Very little is actually reported for this phase, and as these phases appeared in the course of this research, a few comments are appropriate. The Laves phase is not known in the binary system. It was initially reported as a cubic $\mathrm{ZrNi}_{2}$ [48], but was subsequently shown to form only when stabilized by an interstitial atom. Bsenko suggested it was stabilized by silicon [112]. Blažina and Ban report cubic $\mathrm{ZrNi}_{5}$ can substitute oxygen for nickel, forming $\mathrm{ZrNi}_{5-\mathrm{x}} \mathrm{O}_{\mathrm{x}}$, for $\mathrm{x}=0$ to 1 [113]. $\mathrm{ZrNi}_{5}$ crystallizes in the $\mathrm{AuBe}_{5}$ type structure, which is related to the $\mathrm{MgCu}_{2}$ structure by a group/subgroup relationship. The atoms in $\mathrm{MgCu}_{2}$ both occupy special positions, $8 a$ and $16 d$ in $\mathrm{Fd} \overline{3} \mathrm{~m}$. In the $\mathrm{AuBe}_{5}$ structure the eight fold site is split into two four fold sites, with a lowering in symmetry to $\bar{F} \overline{3} \mathrm{~m}$. In the Laves phase $\mathrm{AB}_{2}$, the larger $\mathrm{A}$ atoms are sixteen coordinated. The smaller B atoms are coordinated to twelve atoms. Because of the change in symmetry, the $\mathrm{AuBe}_{5}$ type structure splits the $\mathrm{A}$ atoms position of the Laves phase, and the large sixteen coordinated sites are occupied by both A and B atoms. The solution of Blažina and Ban places zirconium and oxygen on these large four fold sites. This is a very large site for an oxygen atom. Their work was based on powder diffraction data, without full profile refinement, and should be checked. A solution to this may also help to understand the structure of the Laves phase. The lattice parameter for $\mathrm{ZrNi}_{4} \mathrm{O}$ is $\mathrm{a}=6.680(5) \AA$. The lattice parameter of a cubic phase observed in the course of this work is $a=6.9158(4) \AA$.

The cubic phase was present in a sample also containing $\mathrm{Ni}_{10} \mathrm{Zr}_{7}$. This sample was examined by EDS, and identified as $\mathrm{Zr}_{26} \mathrm{Ni}_{70} \mathrm{O}_{4}$. This corresponds to a formula $\mathrm{ZrNi}_{3-\mathrm{x}} \mathrm{O}_{\mathrm{x}}$, with $x=0.3$. This is written assuming oxygen substitutes for nickel, not for zirconium. Clearly, the difference in lattice parameters between those reported by Blažina and Ban and those reported here 
indicate more than just a range of oxygen substitution. This $\mathrm{Zr} / \mathrm{Ni}$ ratio falls between the $1 / 2$ ratio for a Laves phase and the $1 / 4$ or $1 / 5$ ratio for the $A_{u B e}$ type. The Laves phases are tetrahedral close packed structures. The interstitial tetrahedral sites are too small for oxygen atoms, so substitution of oxygen on metal sites is assumed. No silicon was detected, so although it may also stabilize this cubic phase, it is not necessary. A single phase sample was prepared, and the magnetic measurements were taken (see Figure 4.7). A single crystal suitable for diffraction study was not found.

Hexagonal Laves Phase: $\mathrm{Zr} / \mathrm{Ti} / \mathrm{Ni}$

The reports for the $\mathrm{MgZn}_{2}$ type structure in the ternary $\mathrm{Zr} / \mathrm{Ti} / \mathrm{Ni}$ system are also incomplete. There are no Laves phases known in any of the binary systems, $\mathrm{Zr} / \mathrm{Ti}, \mathrm{Zr} / \mathrm{Ni}$, or $\mathrm{Ti} / \mathrm{Ni}$. It would be interesting to find this phase in a ternary system. There is indication that the hexagonal phase exists over a large region of homogeneity. One report gives the range of zirconium present as 21 to 30 atomic percent [106]. A $700^{\circ} \mathrm{C}$ isotherm of the $\mathrm{Zr} / \mathrm{Ti} / \mathrm{Ni}$ system shows the $\mathrm{MgZn}_{2}$ phase extending from 14-34 atomic \% $\mathrm{Zr}, 27-38$ atomic $\% \mathrm{Ni}$, and 33-59 atomic \% $\mathrm{Ti}$ [114].

This phase appeared in a sample which melted at $950^{\circ} \mathrm{C}$, and contained a mixture of the $\mathrm{MgZn}_{2}$ type phase and the filled $\mathrm{Ti}_{2} \mathrm{Ni}$ type phase. EDS measurements gave the stoichiometry of this hexagonal phase as $\mathrm{Zr}_{26} \mathrm{Ti}_{32} \mathrm{Ni}_{34} \mathrm{O}_{8}$. A single crystal was picked from this mixture. The results are given below. Structure factor amplitudes, including unobserved reflections, are included in the appendix. The stoichiometry from the refinement is much different from that given by EDS, and those given from previous studies.

It is interesting to observe titanium substituting for nickel, in light of the results given for new filled $\mathrm{Ti}_{2} \mathrm{Ni}$ phases, and $\mathrm{Zr}_{6} \mathrm{Ni}_{6} \mathrm{TiSiO}_{1.8}$, where titanium substituted for zirconium atoms. The two factors most frequently used in explaining the Laves phases are the relative sizes of the atoms, 
Table 7.1 Crystal data for hexagonal Laves phase

Formula

Space group

a $(\AA)$

c $(\AA)$

$\mathrm{V}\left(\AA^{3}\right)$

Z

$d_{\text {calc }}\left(\mathrm{g} / \mathrm{cm}^{3}\right)$

$\mu(\operatorname{MoK} \alpha)\left(\mathrm{cm}^{-1}\right)$

Data collection instrument

Radiation (monochromated in incident beam)

Octants measured

No. reflections measured

No. unique data, total with $\mathrm{F}_{\mathrm{o}}{ }^{2}>3 \sigma\left(\mathrm{F}_{\mathrm{o}}{ }^{2}\right)$

No. parameters refined

Trans. factors, $\max / \mathrm{min}$

$\mathbf{R}^{\mathrm{a}}, \mathbf{R}_{\mathbf{w}}{ }^{\mathrm{b}}, \mathrm{GOF}^{\mathrm{c}}$

Largest difference peak $\left(e / \AA^{3}\right)$

Largest negative peak $\left(e / \AA^{3}\right)$
$\mathrm{ZrNi}_{1.45} \mathrm{Ti}_{0.55}$

$\mathrm{P6}_{3} / \mathrm{mmc}$ (\#194)

5.154(2)

$8.376(3)$

192.7(1)

4

7.06

214.06

Rigaku AFC6R

$\operatorname{MoK} \alpha(\lambda=0.71069)$

$\pm h, \pm k, l$

1240

142

12

$1.00 / 0.88$

$0.028,0.034,1.03$

1.17

$-1.44$

${ }^{a} R=\Sigma\left\|F_{0}|-| F_{c}\right\| / \Sigma\left|F_{0}\right|$

${ }^{b} R_{w}=\left[\Sigma w\left(\left|F_{o}\right|-\left|F_{c}\right|\right)^{2} / \Sigma w\left|F_{o}\right|^{2}\right]^{1 / 2} ; w=1 / \sigma^{2}\left(\left|F_{o}\right|\right)$

${ }^{c}$ GOF $=\Sigma\left(\left(\left|F_{0}\right|-\left|F_{c}\right|\right) / \sigma_{i}\right) /\left(N_{\text {obs refl }}-N_{\text {parameters }}\right)$ 
Table 7.2 Atomic parameters for hexagonal Laves phase

\begin{tabular}{lccccc}
\hline Atom & $x$ & $y$ & $z$ & $\mathrm{~B}_{\mathrm{eq}}\left(\AA^{2}\right)^{\mathrm{a}}$ & $\%$ Occupancy \\
\hline $\mathrm{Zr}$ & 0.3333 & 0.6667 & $0.0670(2)$ & $0.99(5)$ & 100 \\
$\mathrm{Ni} 1$ & 0 & 0 & 0 & $1.0(1)$ & $55(5)$ \\
$\mathrm{Ti} 1$ & & & & & 45 \\
$\mathrm{Ni2}$ & $0.8288(3)$ & 0.6575 & $1 / 4$ & $0.9(1)$ & $80(5)$ \\
$\mathrm{Ti2}$ & & & & & 20 \\
\hline
\end{tabular}

${ }^{a} B_{e q}=8 \pi^{2} / 3 \Sigma_{1}^{3} \Sigma_{1}^{3} U_{i j} a_{i}^{*} a_{j}^{*} a_{i}^{*} \vec{a}_{j}^{*}$

Table 7.3 Anisotrupic thermal parameters for hexagonal Laves phase

\begin{tabular}{lcccccc}
\hline Atom & $\mathrm{U}_{11}$ & $\mathrm{U}_{22}$ & $\mathrm{U}_{33}$ & $\mathrm{U}_{12}$ & $\mathrm{U}_{13}$ & $\mathrm{U}_{23}$ \\
\hline $\mathrm{Zr}$ & $0.0134(7)$ & 0.0134 & $0.011(1)$ & 0.007 & 0 & 0 \\
$\mathrm{Ni1}$ & $0.012(1)$ & 0.012 & $0.014(2)$ & 0.006 & 0 & 0 \\
$\mathrm{Ti} 1$ & & & & & & \\
$\mathrm{Ni2}$ & $0.0112(9)$ & $0.013(1)$ & $0.012(1)$ & 0.007 & 0 & 0 \\
$\mathrm{Ti2}$ & & & & & & \\
\hline
\end{tabular}

Table 7.4 Interatomic distances less than $3.6 \AA$

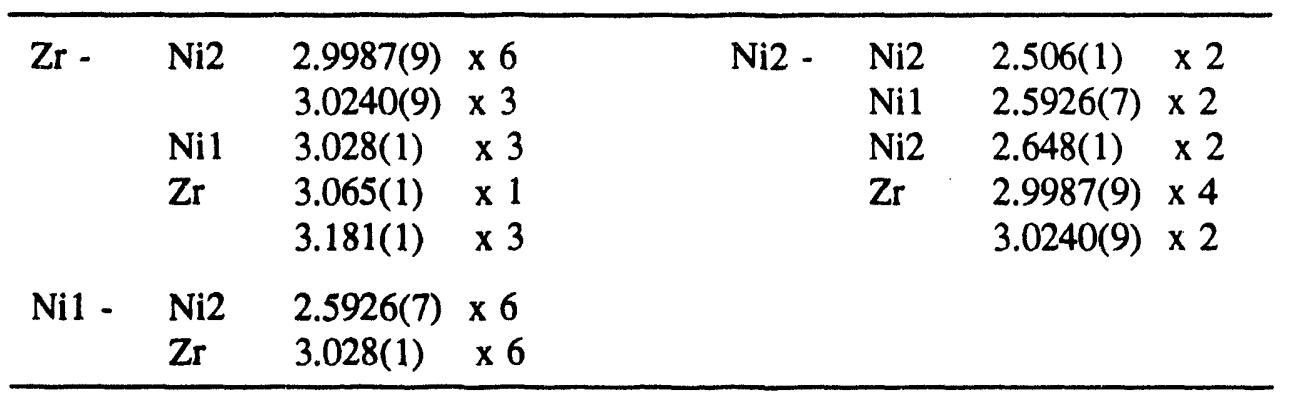


and the electron concentration. By size considerations, the titanium might be too small for the large sixteen coordinated site occupied by zirconium. The short titanium - nickel distances seen in this refinement are seen also in the filled $\mathrm{Ti}_{2} \mathrm{Ni}$ type phases and $\mathrm{Zr}_{6} \mathrm{Ni}_{6} \mathrm{TiSiO}_{1.8}$. Size considerationsfavor titanium substitution of nickel. By electron concentration considerations for transition metals which form the $\mathrm{MgZn}_{2}$ phase, $\mathrm{ZrNi}_{2-\mathrm{x}} \mathrm{Ti}_{\mathrm{x}}$ would be favored for $\mathrm{x}$ ranging from 0.67 to 1.56 [115], assuming there is no substitution on zirconium. Clearly, many details remain unknown.

\section{New Phase in $\mathrm{Zr} / \mathrm{W} / \mathrm{Ni} / \mathrm{O}$ System}

In trying to prepare a kappa phase of stoichiometry $\mathrm{Zr}_{9} \mathrm{~W}_{4} \mathrm{NiO}$, a sample was arc-melted and annealed at $1160^{\circ} \mathrm{C}$ for 10 hours. The powder pattem of the annealed sample contained lines identified as unreacted tungsten, and $\mathrm{W}_{2} \mathrm{Zr}$, and several more lines for another phase which has not been identified. The powder data is given below. The phase has a distinctive set of low angle lines not observed in any of the phases described previously. EDS measurements indicate titanium is present also.

\section{New Phase in $\mathrm{Zr} / \mathrm{Ni} / \mathrm{S}$ System}

Little work was actually performed in the sulfide system. Very likely, new and novel phases will be found in this ternary system. The results of this research show that even very small amounts of oxygen will favor formation of the new oxide phases. Therefore, work in the sulfide system will require great care in excluding all sources of oxygen throughout the synthetic process. As noted previously, the samples studied in this research were routinely handled in air. Thus, it may be necessary to eliminate steps like the arc-melting procedure, where the sample is momentarily exposed to air before and after melting, in favor of melting the samples in sealed metal tubes. 
Table 7.5 Powder data for $\mathrm{Zr} / \mathrm{W} / \mathrm{Ni} / \mathrm{O}$ sample

\begin{tabular}{clrllr}
\hline $2 \theta$ & $d$ & \multicolumn{1}{c}{$\mathrm{I} / \mathrm{I}_{\mathrm{o}}$} & $2 \theta$ & \multicolumn{1}{l}{$d$} & $\mathrm{I} / \mathrm{I}_{\mathrm{o}}$ \\
\hline 8.770 & 10.075 & 26.6 & 41.574 & 2.170 & 1.6 \\
8.950 & 9.872 & 15.4 & 42.224 & 2.139 & 6.2 \\
12.235 & 7.228 & 2.5 & 42.824 & 2.110 & 5.9 \\
12.655 & 6.990 & 11.2 & 43.980 & 2.057 & 1.3 \\
15.196 & 5.826 & 2.6 & 45.189 & 2.005 & 4.2 \\
15.526 & 5.703 & 2.7 & 45.489 & 1.992 & 1.1 \\
17.712 & 5.004 & 2.2 & 45.824 & 1.979 & 7.1 \\
19.496 & 4.550 & 2.4 & $47.742^{\mathrm{a}}$ & 1.904 & 18.1 \\
$20.188^{\mathrm{a}}$ & 4.395 & 25.6 & 48.220 & 1.886 & 3.6 \\
21.033 & 4.220 & 1.6 & 48.569 & 1.873 & 1.0 \\
23.774 & 3.740 & 3.4 & 50.240 & 1.814 & 0.7 \\
25.519 & 3.48 & 1.2 & 50.461 & 1.807 & 1.1 \\
29.905 & 2.986 & 0.8 & $52.390^{\mathrm{a}}$ & 1.745 & 12.6 \\
32.728 & 2.734 & 7.4 & 54.183 & 1.691 & 1.4 \\
32.936 & 2.717 & 3.0 & 54.869 & 1.672 & 2.2 \\
$33.268^{\mathrm{a}}$ & 2.691 & 11.1 & 56.578 & 1.625 & 1.8 \\
34.194 & 2.620 & 2.6 & 57.031 & 1.614 & 1.8 \\
35.195 & 2.548 & 17.3 & $58.239^{\mathrm{b}}$ & 1.583 & 22.1 \\
35.390 & 2.534 & 1.0 & 58.497 & 1.576 & 2.6 \\
35.771 & 2.508 & 2.7 & $59.417^{\mathrm{a}}$ & 1.554 & 3.6 \\
36.162 & 2.482 & 61.8 & 60.739 & 1.524 & 6.8 \\
36.724 & 2.445 & 58.0 & 60.964 & 1.518 & 1.9 \\
37.001 & 2.428 & 34.4 & 62.877 & 1.477 & 5.4 \\
37.205 & 2.415 & 20.1 & $63.441^{\mathrm{a}}$ & 1.465 & 44.5 \\
37.282 & 2.410 & 13.0 & 64.623 & 1.441 & 9.5 \\
37.447 & 2.400 & 11.0 & 66.037 & 1.414 & 48.2 \\
37.787 & 2.379 & 15.2 & 66.918 & 1.397 & 3.7 \\
38.674 & 2.326 & 36.0 & 67.343 & 1.389 & 11.2 \\
38.909 & 2.313 & 39.6 & 67.583 & 1.385 & 3.6 \\
$39.223^{\mathrm{a}}$ & 2.295 & 72.7 & 69.845 & 1.363 & 1.3 \\
39.671 & 2.270 & 81.7 & & 1.346 & 32.5 \\
$40.275^{\mathrm{b}}$ & 2.238 & 100.0 & & & \\
$41.042^{\mathrm{a}}$ & 2.197 & 41.5 & & & \\
\hline & & & & & \\
\hline
\end{tabular}

${ }^{\mathrm{a}} \mathrm{W}_{2} \mathrm{Zr}$
${ }_{\mathrm{W}}$ 


\section{Vaporization Study of $\mathrm{Nb}_{4} \mathrm{Ni}_{2} \mathrm{O}$}

A sample of $\mathrm{Nb}_{4} \mathrm{Ni}_{2} \mathrm{O}$ was annealed at $1350^{\circ} \mathrm{C}$ for 8 hours, then $1100^{\circ} \mathrm{C}$ for 1 hour, and quenched. The sample showed the two phases $\mathrm{Nb}_{4} \mathrm{Ni}_{2} \mathrm{O}(\mathrm{a}=11.5917(5) \AA)$ and $\mathrm{Nb}_{6} \mathrm{Ni}_{6} \mathrm{O}(\mathrm{a}=$ $11.2344(7) \AA$ ), as well as $\mathrm{NbO}$, which was also present as a minor phase in the initial sample. The quartz jacket had black vapor deposited film, probably nickel. It would be worthwhile to study the thermodynamics of the decomposition of $\mathrm{Nb}_{4} \mathrm{Ni}_{2} \mathrm{O}$ at high temperatures. The relation between these two phases may reveal much more about the filled $\mathrm{Ti}_{2} \mathrm{Ni}$ structures in general. 


\section{REFERENCES}

1. Moody, G.J.; Thomas, J.D.R. J. Chem. Soc. 1964, $1964,1417$.

2. Owens, J.P.; Conard, B.R.; Franzen, H.F. Acta Cryst. 1967, 23, 77.

3. Kapustinskii, A.F. Quart. Rev. Chem. Soc. 1956, 10, 283.

4. Pauling, L. The Nature of the Chemical Bond. 3rd ed. Comell University Press, Ithaca, 1960.

5. Owens, J.P.; Franzen, H.F. Acta Cryst. 1974, B30, 427.

6. Conard, B.R.; Franzen, H.F. High Temp. Sci. 1971, 3, 49.

7. Chen, H.-Y.; Franzen, H.F. Acta Cryst. 1972, B28, 1399.

8. Franzen, H.F.; Graham, J. Z. Kristallogr. 1966, 123, 133.

9. Franzen, H.F.; Beineke, T.A.; Conard, B.R. Acta Cryst. 1968, B24, 412.

10. Chen, H.-Y.; Tuenge, R.T.; Franzen, H.F. Inorg. Chem. 1973, 12, 552.

11. Franzen, H.F.; Smeggil, J.G. Acta Cryst. 1969, B25, 1736.

12. Franzen, H.F.; Smeggil, J.G. Acta Cryst. 1970, B26, 125.

13. Harbrecht, B. J. Less-Common Met. 1988, 138, 225.

14. Wada. H.; Onoda, M. Mat. Res. Bull. 1989, 24, 191.

15. Kim, S.-J.; Nanjundaswamy, K.S.; Hughbanks, T. Inorg. Chem. 1991, 30, 159.

16. Yao, X.; Franzen, H.F. J. Solid State Chem. 1991, 86, 88.

17. Yao, X.; Franzen, H.F. J. Amer. Chem. Soc. 1991, 113, 1426.

18. Yao, X.; Franzen, H.F. Z. Anorg. Allg. Chem. 1991, 598/599, 353.

19. Yao, X.; Miller, G.J.; Franzen, H.F. J. Alloys Compd. 1992, 183, 7.

20. Yao, X.; Marking, G.; Franzen, H.F. Ber. Bunsenges. Phys. Chem. 1992, 96, 1552.

21. Marking, G.A. Ph.D. Dissertation, Iowa State University, 1993.

22. Nanjundaswamy, K.S.; Hughbanks, T. J. Solid State Chem. 1992, 98, 278. 
23. Franzen, H.F. Prog. Solid St. Chem. 1978, 12, 1.

24. Harbrecht, B.; Franzen, H.F. J. Less-Common Met. 1986, 115, 177.

25. Harbrecht, B. J. Less-Common Met. 1986, 124, 125.

26. Calhorda, M.J.; Hoffmann, R. Inorg. Chem. 1988, 27, 4679.

27. Harbrecht, B. Z. Kristallogr. 1988, 182, 118.

28. Harbrecht, B. J. Less-Common Met. 1988, $141,59$.

29. Conard, B.R. Ph.D. Dissertation, Iowa State University, 1969.

30. Franzen, H.F. Anales de Fisica 1990, B86, 39.

31. Smeggil, J.G. Ph.D. Dissertation, Iowa State University, 1969.

32. Binary Alloy Phase Diagrams, 2nd Ed.; T.B. Massalski, Ed.; ASM International, Materials Park, 1970.

33. Laves, F. In Theory of Alloy Phases, Amer. Soc. Met., Cleveland, Ohio, 1956.

34. a)Slater, J.C. J. Chem. Phys. 1964, 41, 3199. b)Slater, J.C. Quantum Theory of Molecules and Solids, Vol. 2, McGraw-Hill Book Co., Inc., New York, 1963.

35. Goldschmidt, V.M. Trans. Faraday Soc. 1929, $25,253$.

36. Zachariasen, W.H. Z. Kristallogr. 1932, 81, 1.

37. Pauling, L. Proc. Roy Soc. A. 1927, 114, 181.

38. a)Shannon, R.D.; Prewitt, C.T. Acta Cryst. 1969, B25, 928. b)Shannon, R.D. Acta Cryst. 1976, A32, 752.

39. Nevitt, M.V.; Downey, J.W. Trans. Met. Soc. AIME, 1961, 221, 1014.

40. Cima. M.; Brewer, L. Met. Trans. B 1988, 19B, 893.

41. Brewer, L; Wengert, P.R. Met. Trans. 1973, 4, 83.

42. Brewer, L In Alloying, J.L. Walter, M.R. Jackson; C.T. Sims, Eds.; ASM Intemational, Metals Park, 1988.

43. Hume-Rothery, W. Prog. Mat. Sci. 1968, 13, 229.

44. Johnston, R.L.; Hoffmann, R. Z. Anorg. All. Chem. 1992, 616, 105. 
45. Hoistad, L.M.; Lee, S. J. Am. Chem. Soc. 1991, 113, 8216.

46. Leonard, S.R.; Snyder, B.S.; Brewer, L.; Stacy, A.M. J. Solid State Chem. 1991, 92, 39.

47. Bsenko, L. J. Less-Common Met. 1979, 63, 171.

48. Petkov, V.V.; Markiv, V.Ya.; Gorskiy, V.V. Russ. Metallurgy, 1972, 2, 188.

49. McGlynn, S.P.; Vanquickenbome, L.G.; Kinoshita, M.; Carroli, D.G. Introduction to Applied Quantum Chemistry, Holt, Rinehart and Winston, Inc., New York, 1972.

50. Basch, H.; Viste, A.; Gray, H.B. Theoret. Chim. Acta 1965, 3, 458.

51. Miller, G.J., Department of Chemistry, Iowa State University, Ames, IA, unpublished research, 1991.

52. Hoffmann,R. J. Chem. Phys. 1963, 39, 1397.

53. Ammeter, J.H.; Bürgi, H.-B.; Thibeault, J.C.; Hoffmann, R. J. Am. Chem. Soc. 1978, 100, 3686.

54. Whangbo, M.-H.; Hoffmann, R. J. Chem. Phys. 1978, 68, 5498.

55. Takusagowa, F., Ames Laboratory, Iowa State University, Ames, IA, unpublished research, 1981.

56. Ziebarth, R.P., Ames Laboratory, Iowa State University, Ames, IA, unpublished research, 1984.

57. Clark, C.M.; Smith, D.K.; Johnson, G.J. "A Fortran IV Program for Calculating X-Ray Powder diffraction Pattem-Version5," Department of Geosciences, Pennsylvania State University, University Park, 1973.

58. Johnson, C.K. "ORTEP-II, A Fortran Thermal-Ellipsoid Plot Program," Report ORNL-5138, Oak Ridge National Laboratory, Oak Ridge, 1976.

59. Werner, P.-E. "SCANPI Version 8 for IBM PC/AT," Arrhenius Laboratory, University of Stockholm, Sweden, 1990.

60. Malmros, G.; Wemer, P.-E. Acta Chem. Scand. 1973, 27, 493.

61. Johansson, K.E.; Palm, T.; Werner, P.-E. J. Phys. E.Sci. Instrum. 1980, 13, 1289.

62. Sheldrick, G.M. In Crystallographic Computing 3, G.M. Sheldrick; C. Krüger; R. Goddard, Eds.; Oxford University Press, 1985.

63. TEXSAN: Single Crystal Structure Analysis Software, Version 5.0, Molecular Structure 
Corporation, The Woodlands, 1989.

64. Krypyakevich, P.I.; Markiv, V.Ya; Bumashova, V.V. Dopov. Akad. Nauk Ukr. RSR, Ser A, 1970, 32(6), 551.

65. Boller, H. Monatsh für Chem 1973, 104, 545.

66. Mackay, R.; Franzen, H.F. J. Alloys Compd. 1992, 186, L7.

67. Pearson's Handbook of Crystallographic Data for Intermetallic : $h a s e s$ 2nd ed.. P. Villars and L.D.Calvert. Eds., Amer. Soc. Metals, Materials Park, 1991.

68. Westgren, A.; Phragmén. G. Trans. Amer. Soc. Steel Treating, 1928, 13, 539.

69. Nevitt, M.V. In Intermetallic Compounds, J.H. Westbrook, Ed.; John Wiley \& Sons, Inc. $1967,220-224$.

70. Kuo, K. Acta Met. 1953, 1, 301.

71. Jeitschko, W.; Holleck, H.; Nowotny, H.; Benesovsky, F. Monatsh. Chem. 1964, 95, 1004.

72. Newsam, J.M.; Jacobson, A.J.; McCandlish, L.E.; Polizzotti, R.S. J. Solid State Chem. 1988 , 75, 296.

73. Kotyk. M.: Stadeimaier, H.H. Metallurgical Trans. 1970, $1,889$.

74. Holleck, H.; Thümmler, F. Monatsh. Chem. 1967, 98, 133.

75. Nevitt, M.V.; Downey, J.W.; Morris, R.A.Trans. Met. Soc. AlME 1960, 218, 1019.

76. Karlsson, N. Nature, 1951, 168, 558.

77. Bonhomme, F.; Selvam, P.; Yoshida, M.; Yvon, K.; Fischer, P. J. Alloys Comps. 1992, 178, 167.

78. Rupp, B.; Fischer, P. J. Less-Commun Met. 1988, 144, 275.

79. Mueller, M.H..; Knott. H.W. Trans. Met. Soc. AIME 1963, 227, 674.

80. Mackay, R.; Franzen, H.F. Z. Anorg. Allg. Chem. 1992, úl6, 154.

81. Mackay, R.; Franzen, H.F. Chem. Mater. accepted for publication.

82. Hamilton, W.C. Acta Cryst. 1965, 18, 502.

83. Stadelmaier, H.H.; Fiedler, M.-L. Z. Metallkde. 1975, 66, 224. 
84. Hyde, B.G.; Andersson, S. Inorganic Crystal Structures, John Wiley \& Sons, Inc. N.Y. 1989.

85. Basch, H.; Gray, H.B.; Theor. Chim. Acta 1966, 4, 367.

86. Richardson, J.W.; Nieuwport, W.C.; Powell, R.R.; Edgell, W.F. J. Chem. Phys. 1962, 36. 1057.

87. Hoffmann, R. J. Chem. Phys. 1963, 39, 1397.

88. Baranovskii, V.I.; Nikolskii, A.B. Teor. Eksp. Khim. 1967, 3, 527.

89. Herman, F.; Sillman, S. Atomic Structure Calculations, Prentice Hall, Englewood Cliffs, 1963.

90. Rogl, P.;Nowotny, H.Monatsh. Chem. 1976, 108, 1167.

91. Andersson, S.; Hyde, S.T.; von Schnering, H.G. Z. Kristallogr. 1984, 168, 1.

92. von Schnering, H.G.; Nesper, R. Angew. Chem. (Int. Ed. Eng.) 1987, 27, 1059.

93. Rautala, P.; Norton, J.T. Trans. AIME, 1952, 194, 1045.

94. Hârsta, A.; Rundqvist, S. J. Solid State Chem. 1987, 70, 210 and references therein.

95. Schewe-Miller, I. unpublished results, Ames Laboratory, Iowa State University, Ames, Iowa, 1993.

96. Hårsta. A.; Joilansson, T.; Rundqvist, S.; Thomas, J.O. Acta Chem. Scand. Ser. A, 1977, 31 , 260.

97. Rogl, P.; Nowotny, H.; Benesovsky, F. Monatsh. Chem. 1973, 104, 182.

98. Hârsta, A. J. Solid State Chem. 1985, 57, 362.

99. Hârsta. A. J. Solid State Chem. 1985, 57, 373.

100. Hårsta, A. Acta Chem. Scand. Ser.A 1981, 35, 43.

101. Hârsta, A. Acta Chem. Scand. Ser.A 1982, 36, 535.

102. Rogl, P.; Rupp, B.; Wiesinger, G.; Schefer, J.; Fischer, P. J. Less-Common Met. 1985, 113 , 103.

103. Hårsta. A.; Rundqvist, S.; Thomas, J.O. J. Solid State Chem. 1983, 49, 118.

104. Kirkpatrick, M.E.; Larsen, W.L. Trans. Amer. Soc. Metals, 1961, 54, 580. 
105. Semenenko, K.N.; Verbetskii, V.N.; Mitrokhin, S.V.; Burnasheva, V.V. Russ. J. Inorg. Chem., 1980, 25, 961.

106. Molokanov, V.V.;Chebotnikov, V.N.;Kovneristyi, Yu.K. Inorg. Mat., 1989, 25, 46.

107. van Vucht, J.H.N. J. Less-Common Met., 1966, 11, 308.

108. Glimois, J.L.; Forey, R.; Guillen, R. J.L. Feron, J. Less-Common Met., 1987, 134, 221.

109. Zhao, J.T. Ph.D. Dissertation, Universite de Geneve, 1991.

110. Rabe, K.M.; Phillips, J.C.; Villars, P.; Brown, I.D. Phys. Rev. B 1992, 45, 7650.

111. Selwood, P.W. Magnetochemistry, 2nd ed. Interscience Publishers, New York, 1956.

112. Bsenko, L. J. Less-Common Met. 1979, 63, 171.

113. Blažina, Ž.; Ban, Z. J. Less-Common Met. 1973, 33, 321.

114. Eremenko, V.N.; Semenova, E.L.; Tretyachenko, L.A. Dopo. Akad. Nauk Ukr. RSR, Ser. A 1988, $50,76$.

115. Haydock, R.; Johannes, R.L. J. Phys. F: Metal Phys. 1975, 5, 2055. 


\section{ACKNOWLEDGEMENTS}

It has been a privilege working under the direction of Professor Hugo F. Franzen, and a pleasure working with the group members.

J.W. Anderegg was responsible for the ESCA studies. Dr. G.J. Miller was very helpful with the band calculations. Dr. J. Ostenson performed the magnetic measurements. Quantitative EDS was done by Dr. W. Straszheim. Qualitative EDS was done by G.L. Schimek. Shirley Standley provided secretarial assistance.

This work was performed at Ames Laboratory under contract no. W-7405-eng-82 with the U.S. Department of Energy. The United States govermment has assigned the DOE Report number IS-T 1647 to this thesis. 
APPENDIX:

OBSER VED AND CALCULATED STRUCTURE FACTOR AMPLITUDES 
Olsserved and calculated structure factor annplitudes $(x 10)$ for $\mathrm{Zr}_{3} \mathrm{NiO}$

\begin{tabular}{|c|c|c|c|c|c|c|c|c|c|c|c|c|c|c|}
\hline k & 1 & Fo & FC & sigf & $k$ & 1 & Fo & FC & $\operatorname{sigF}$ & k & 1 & Fo & FC & $8 i g F$ \\
\hline 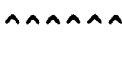 & $\wedge \wedge$ & $1=$ & $0 \wedge \wedge \wedge$ & ค^n & $\begin{array}{l}-9 \\
-9\end{array}$ & $\begin{array}{r}-3 \\
0\end{array}$ & $\begin{array}{r}2006 \\
618\end{array}$ & $\begin{array}{r}1949 \\
627\end{array}$ & $\begin{array}{l}36 \\
2.1\end{array}$ & $\begin{array}{l}-4 \\
-2\end{array}$ & $\begin{array}{r}0 \\
-3\end{array}$ & $\begin{array}{r}993 \\
2046\end{array}$ & $\begin{array}{r}978 \\
2044\end{array}$ & $\begin{array}{l}13 \\
35\end{array}$ \\
\hline 0 & 2 & 275 & 116 & 2.1 & -7 & -8 & 534 & 497 & 30 & 0 & -6 & 1835 & 1877 & 32 \\
\hline 0 & 4 & 2117 & 2191 & 36 & -7 & -6 & 1475 & 1496 & 30 & 0 & 0 & 3571 & 3572. & 55 \\
\hline 0 & 6 & 2363 & 2.391 & 11) & -7 & -1 & 762 & 711 & 2.4 & 0 & 4 & 152 & 1550 & 28 \\
\hline 0 & 10 & 1617 & $1631)$ & 39 & -7 & -1 & 572 & $5 \%$ & 20 & 0 & 10 & & 1378 & 2 \\
\hline 2 & 1 & 2.2 .1 & 11 & 2.4 & -7 & 1) & 2.329 & 2.339 & 38 & 2 & 5 & 8 & 826 & 12 \\
\hline ?. & 3 & $2811 \%$ & 2189 & 11 & -5 & -9 & 296 & 337 & $4 \%$ & 2 & $\%$ & 102 & 992 & 27 \\
\hline 2 & 5 & 11114 & 10131 & 2.1 & $-!$ & -8 & 6,67 & 611 & 2 & 2 & 9 & 518 & 591 & 39 \\
\hline 2 & 6 & 311 & $3: 14$ & 30 & -5 & -1 & 617 & 635 & 1 & 1 & 1 & 1054 & 1011 & 18 \\
\hline 2 & 7 & 1185 & 1188 & 37 & -5 & -5 & 1173 & 1181 & 2.6 & 4 & 4 & & 430 & \\
\hline 2 & 9 & 72.7 & 681 & 31 & $-!$ & -3 & 150 & 1540. & 28 & 4 & 8 & & & i. \\
\hline 2 & 11 & 191 & 410 & 38 & -5 & -1 & 51 & 525 & 18 & 6 & 2 & & & \\
\hline 4 & 0 & 1266 & 1209 & 26 & -3 & -10 & 723 & 702 & 2 & 6 & 6 & & 581 & \\
\hline 4 & 1 & 1418 & 1418 & 27 & -3 & -9 & 719 & 731 & 6 & 6 & 8 & & 9 & \\
\hline 4 & 2 & 2068 & 2019 & 35 & -3 & -4 & 452 & 167 & 1 & 8 & 0 & & 9 & \\
\hline$i$ & 3 & $5 \%$ & $59 i$ & 23 & -3 & -2 & 1195 & 1183 & 2 & 8 & 3 & & 537 & \\
\hline 4 & 1 & 638 & 669 & $3 \%$ & -3 & -1 & $2 \% 6$ & 2300 & 5 & 8 & 5 & & 562 & 24 \\
\hline 1 & 5 & 1267 & 1290 & 30 & -1 & -11 & $4 \%$ & 147 & 3 & 10 & 0 & & 1219 & 70 \\
\hline 1 & 6 & 569 & $51 B$ & 29 & -1 & -7 & 118 & 120 & 27 & 10 & 5 & 118 & 1214 & \\
\hline 1 & 7 & 500 & 511 & 2.1 & -1 & -1 & 950 & 981 & 22 & 12 & 2 & & 825 & \\
\hline 4 & 8 & 1619 & 1633 & 36 & $-j$ & -2 & 1911 & 1903 & 31 & 12 & 3 & & 938 & \\
\hline$i$ & 9 & 501 & 169 & 31 & 1 & 3 & 1790 & 1795 & 29 & & & & & \\
\hline 4 & 10 & 555 & 539 & 31 & 1 & 5 & 964 & $\begin{array}{r}922 \\
\end{array}$ & $\begin{array}{l}23 \\
36\end{array}$ & ^^^ & $\wedge 1$ & $11=$ & naAn & \\
\hline 6 & 0 & 595 & 573 & $\begin{array}{l}26 \\
29\end{array}$ & 1 & 8 & 1451 & $\begin{array}{l}1473 \\
2340\end{array}$ & $\begin{array}{l}36 \\
55\end{array}$ & & & & & \\
\hline 6 & 1 & $10 \%$ & 1100 & 29 & 3 & 0 & 212 & 2340 & 5 & -9 & -3 & 1384 & 1349 & 32 \\
\hline 6 & 2. & 2028 & 2070 & 36 & 3 & 3 & 71 & 693 & 2 & -9 & 0 & & 490 & 3 \\
\hline 6 & 3 & 1041 & 1040 & 2.9 & 3 & 5 & 2191 & 22.49 & 3 & -7 & 0 & $158 B$ & 160 & 3 \\
\hline 6 & 4 & 1061 & 1100 & 30 & 3 & 6 & 88 & 8B2 & 2 & -5 & -7 & & 549 & 7 \\
\hline 6 & 5 & 1706 & 1671 & 31 & 3 & 7 & 73 & 748 & 3 & -5 & -5 & & 710 & 26 \\
\hline 6 & 6 & 711 & 755 & 35 & 3 & 8 & 738 & 7.56 & 2 & -5 & -3 & 11 & 1135 & \\
\hline 6 & 8 & 12.03 & 1189 & 31 & 5 & 0 & 658 & 611 & 3 & -5 & -2 & & 715 & 24 \\
\hline 6 & 10 & 53 & 443 & 34 & 5 & 2 & 1.108 & 1110 & 2 & -3 & -7 & 456 & 478 & 53 \\
\hline 8 & 0 & 1300 & 1331 & 32 & 7 & 3 & 1100 & 1142 & 2 & -3 & -2 & & 663 & 46 \\
\hline 8 & 1 & 324 & 333 & 40 & 7 & 7 & 715 & 711 & 5 & -3 & -1 & 12 & & 28 \\
\hline 8 & 2 & 1312 & 1273 & 33 & 9 & 1 & 36 & 332 & 2 & -3 & 0 & 13 & & 21 \\
\hline 8 & 3 & 652 & 671 & 30 & 9 & 2 & 30 & 31 & 28 & -1 & -8 & 10 & 1081 & 34 \\
\hline 8 & 5 & 656 & 656 & 31. & 9 & 6 & 49 & 518 & 27 & -1 & -7 & 3 & & 3 \\
\hline 8 & 6 & 399 & 429 & 38 & 9 & 7 & 105 & 1046 & 42 & -1 & -5 & & & 4 \\
\hline 8 & 8 & 923 & 961 & 43 & 11 & 0 & & 1079 & 3 & -1 & -3 & 10 & & 2 \\
\hline 10 & 0 & 1516 & 1532 & 36 & 13 & 1 & & 988 & 32 & 1 & 1 & & & 33 \\
\hline 10 & 1 & 1025 & 1036 & 36 & & & & & & $\overline{1}$ & 2 & 11 & 11 & 28 \\
\hline 10 & 3 & 397 & 305 & 39 & ^^^ & & $h=$ & $\wedge \wedge \wedge$ & คค^^ & 1 & 4 & 60 & & 25 \\
\hline 10 & 1 & 658 & 637 & 31 & & & & & & 3 & 3 & & & 29 \\
\hline 10 & 5 & 136 & 1420 & 38 & -10 & -6 & 922. & 915 & 5 & 3 & 5 & & & 94 \\
\hline 10 & 6 & 109 & 109 & 10 & -10 & -4 & 53 & 51 & 2 & 3 & 6 & & & 7 \\
\hline 12 & 2 & 95 & & 43 & -10 & -1 & 88 & 86 & 4 & 7 & 3 & & & 2 \\
\hline 12 & 3 & 99 & 1070 & 42 & -8 & -6 & & 31 & 5 & 7 & 4 & & & 32 \\
\hline 12 & 1 & & 416 & 5 & -8 & -2 & 108 & 1097 & 5 & $\gamma$ & 6 & & & 57 \\
\hline 14 & 0 & 92. & 92.0 & 46 & -6 & -5 & 138 & $138 \%$ & 66 & & & & & \\
\hline 11 & 2 & 48 & 469 & 43 & -6 & $\begin{array}{l}-1 \\
-3\end{array}$ & & $\begin{array}{l}850 \\
802\end{array}$ & 2.8 & & & $\mathbf{l}$ & 4 & \\
\hline ค ^^^ & $\wedge$ । & $\mathbf{n}=$ & $1 \wedge \wedge \wedge$ & คค^ヘ & -6 & -1 & 86 & 867 & 26 & -4 & & 332 & 295 & 10 \\
\hline & & & & & & & & & & -4 & -2 & 784 & 773 & 27 \\
\hline $\begin{array}{l}-13 \\
-11\end{array}$ & $\begin{array}{l}-3 \\
-6\end{array}$ & $\begin{array}{l}319 \\
383\end{array}$ & 284 & $\begin{array}{l}41 \\
42\end{array}$ & $\begin{array}{l}-4 \\
-1\end{array}$ & $\begin{array}{l}-7 \\
-6\end{array}$ & $\begin{array}{l}510 \\
499\end{array}$ & $\begin{array}{l}486 \\
496\end{array}$ & $\begin{array}{l}2.4 \\
23\end{array}$ & $\begin{array}{l}-4 \\
-2\end{array}$ & $\begin{array}{l}-1 \\
-3\end{array}$ & $\begin{array}{r}675 \\
1186\end{array}$ & $\begin{array}{r}627 \\
1215\end{array}$ & $\begin{array}{l}25 \\
64\end{array}$ \\
\hline-11 & -7 & 1073 & 1078 & 30 & -4 & -5 & 103 & 1038 & 27 & 0 & 0 & 184 & 1859 & 35 \\
\hline-9 & -5 & 378 & 402 & 37 & -1 & -3 & & 457 & 25 & 0 & 4 & & & 28 \\
\hline-9 & -4 & 381 & 366 & 29 & -1 & -2 & & 1477 & 60 & 4 & 0 & 705 & 690 & \\
\hline
\end{tabular}


Observed and calculated structure factor amplitudes (X5) for $\mathrm{Zr}_{4} \mathrm{Ni}_{2} \mathrm{O}$

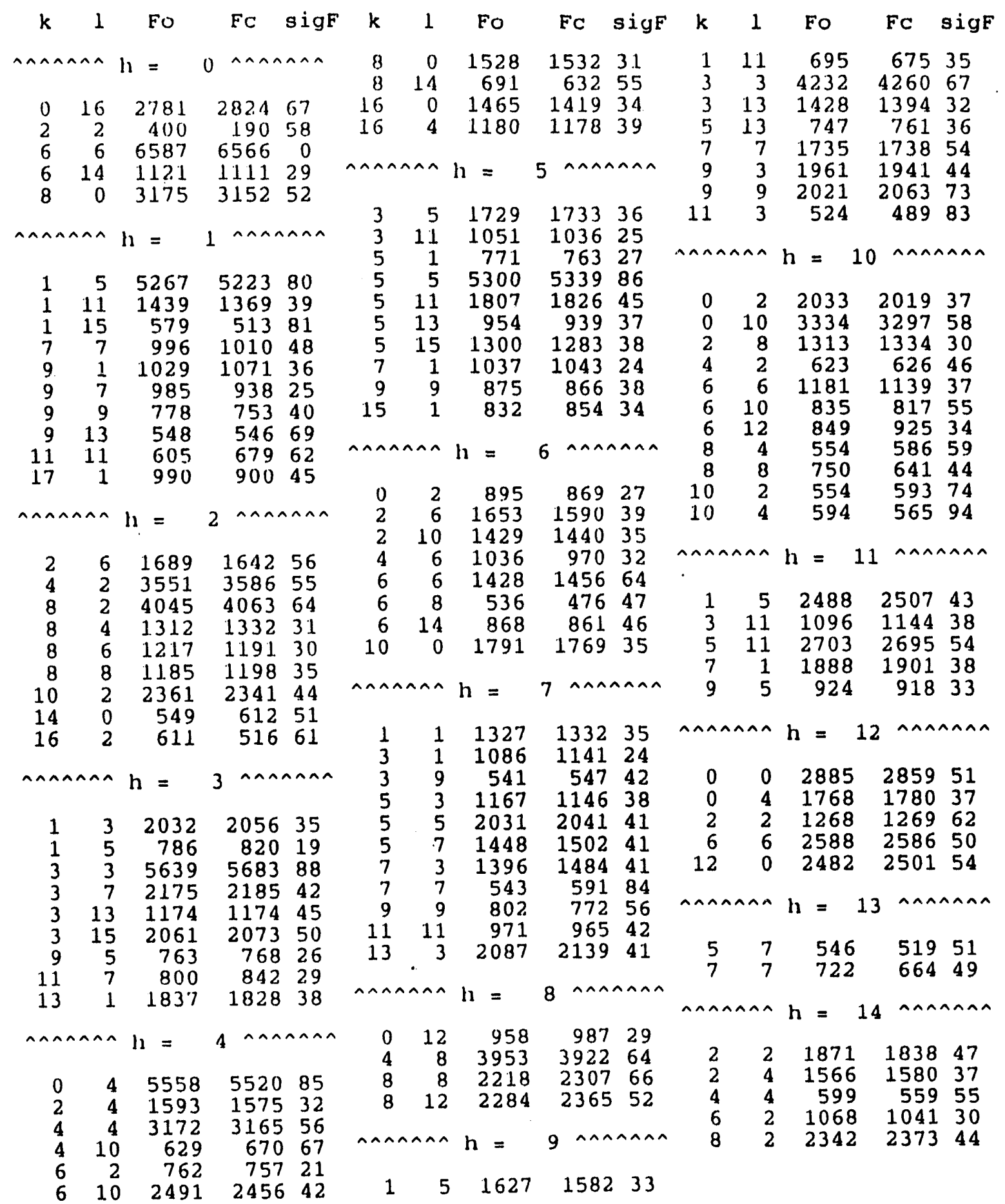


Observed and calculated structure factor amplitudes (X3) for $\mathrm{Zr}_{6} \mathrm{Ni}_{4} \mathrm{Ti}_{2} \mathrm{O}_{0.6}$

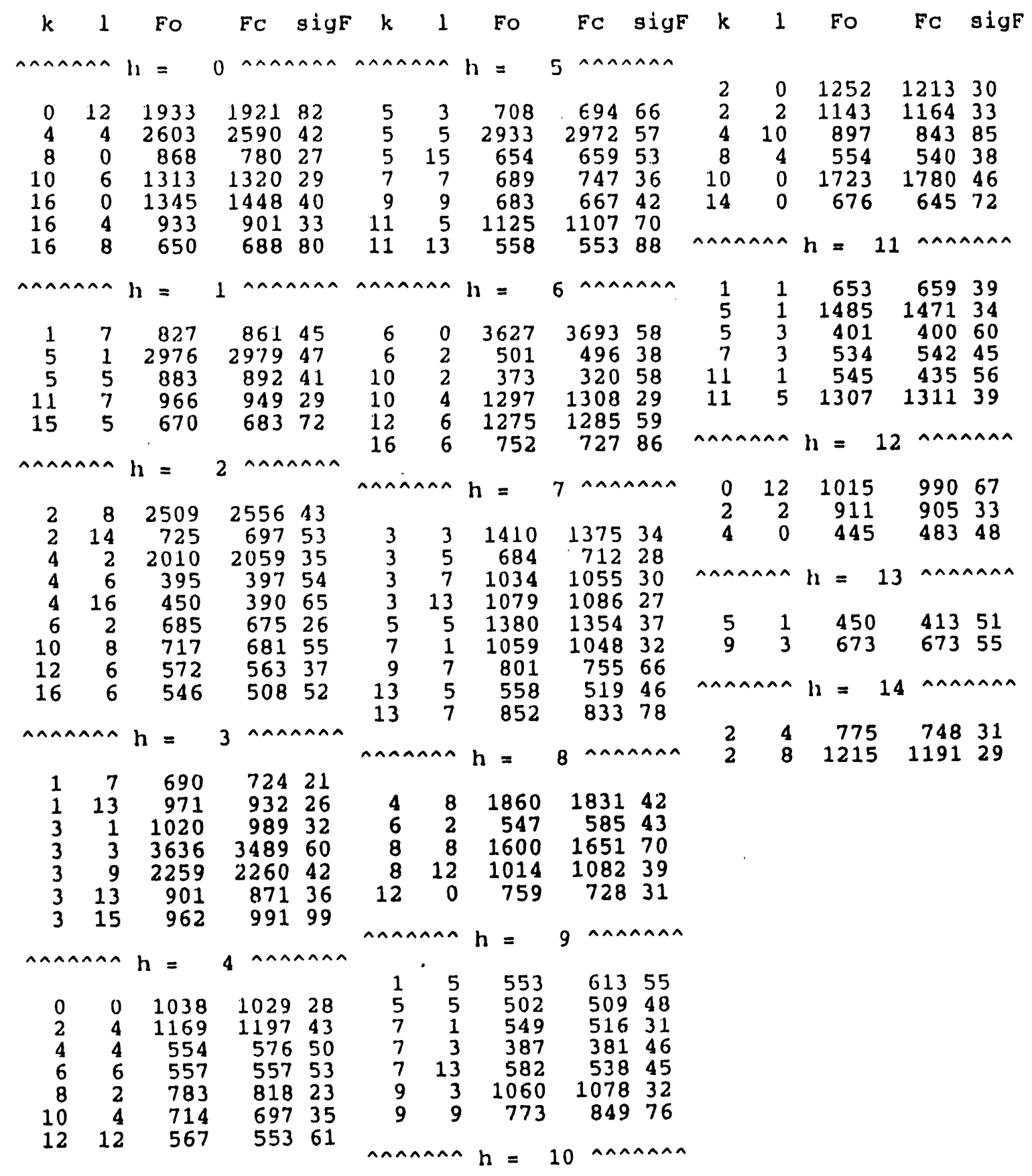


Observed and calculated structure factor amplitudes $(\mathrm{X} 5)$ for $\mathrm{Nb}_{6} \mathrm{Ni}_{6} \mathrm{O}$

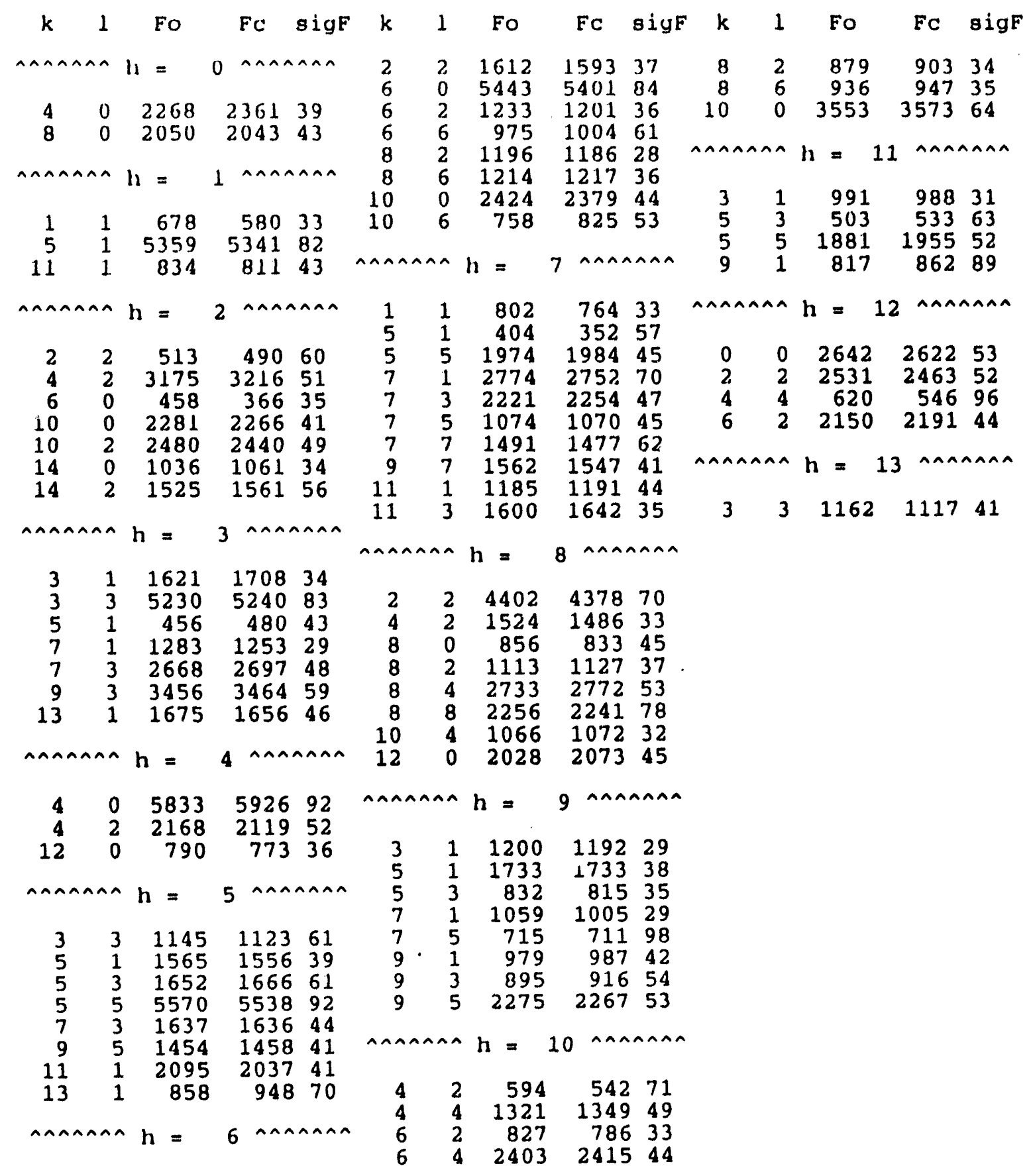


Observed and calculaled structure factor amplitudes $(X 1)$ for $\mathrm{Nb}_{6} \mathrm{Ni}_{4} \mathrm{Ta}_{2} \mathrm{O}_{2}$

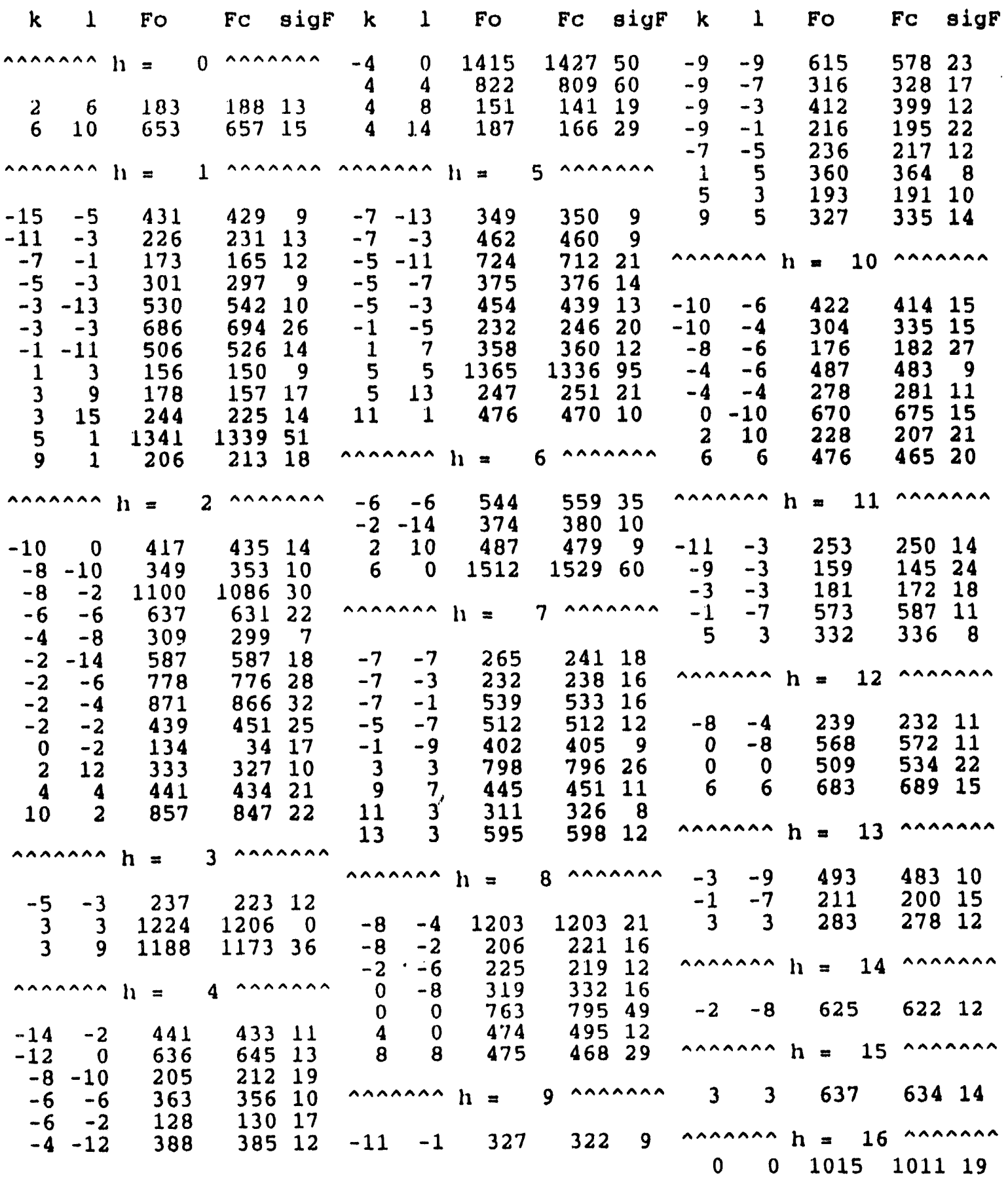


Observed and calculaled siructure factor anplitudes $(x 10)$ for $\mathrm{Zr}_{9} \mathrm{~W}_{4}(\mathrm{~S} / \mathrm{Ni}) \mathrm{O}_{3}$

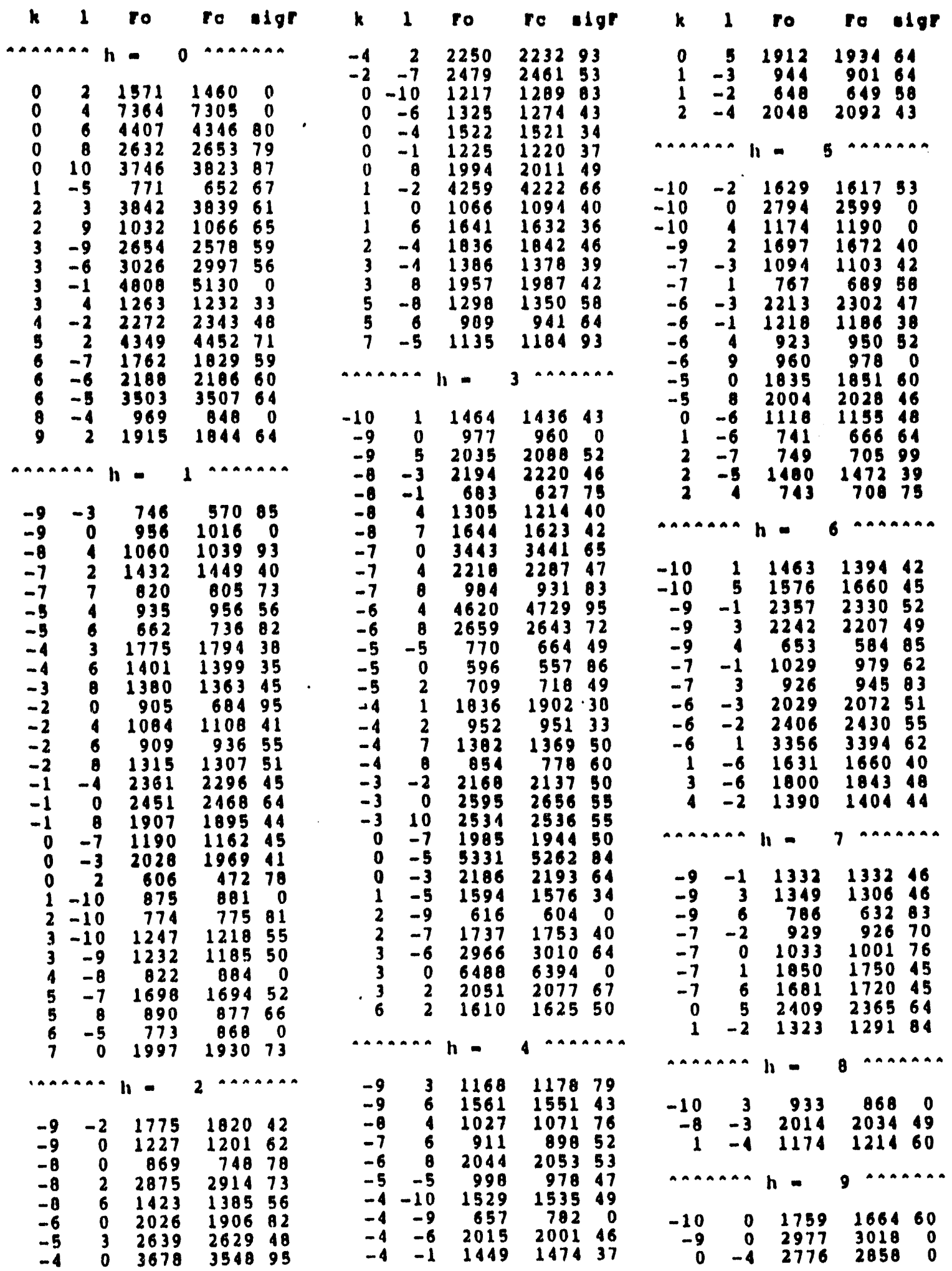


Observed and calculaled siructure factor amplitudes $(\times 5)$ for $\mathrm{Zr}_{6} \mathrm{Ni}_{6} \mathrm{TiSiO}_{1.8}$

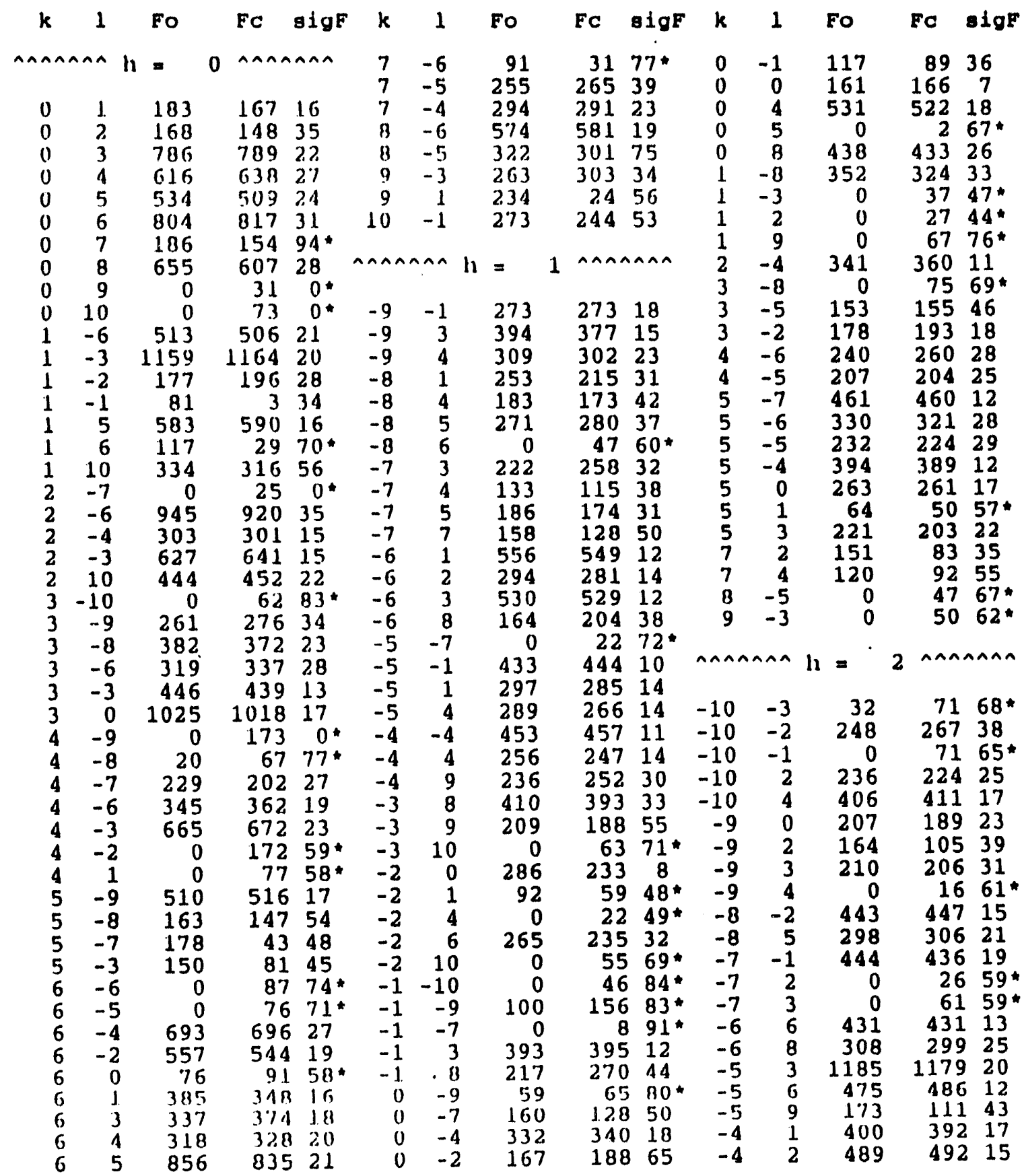




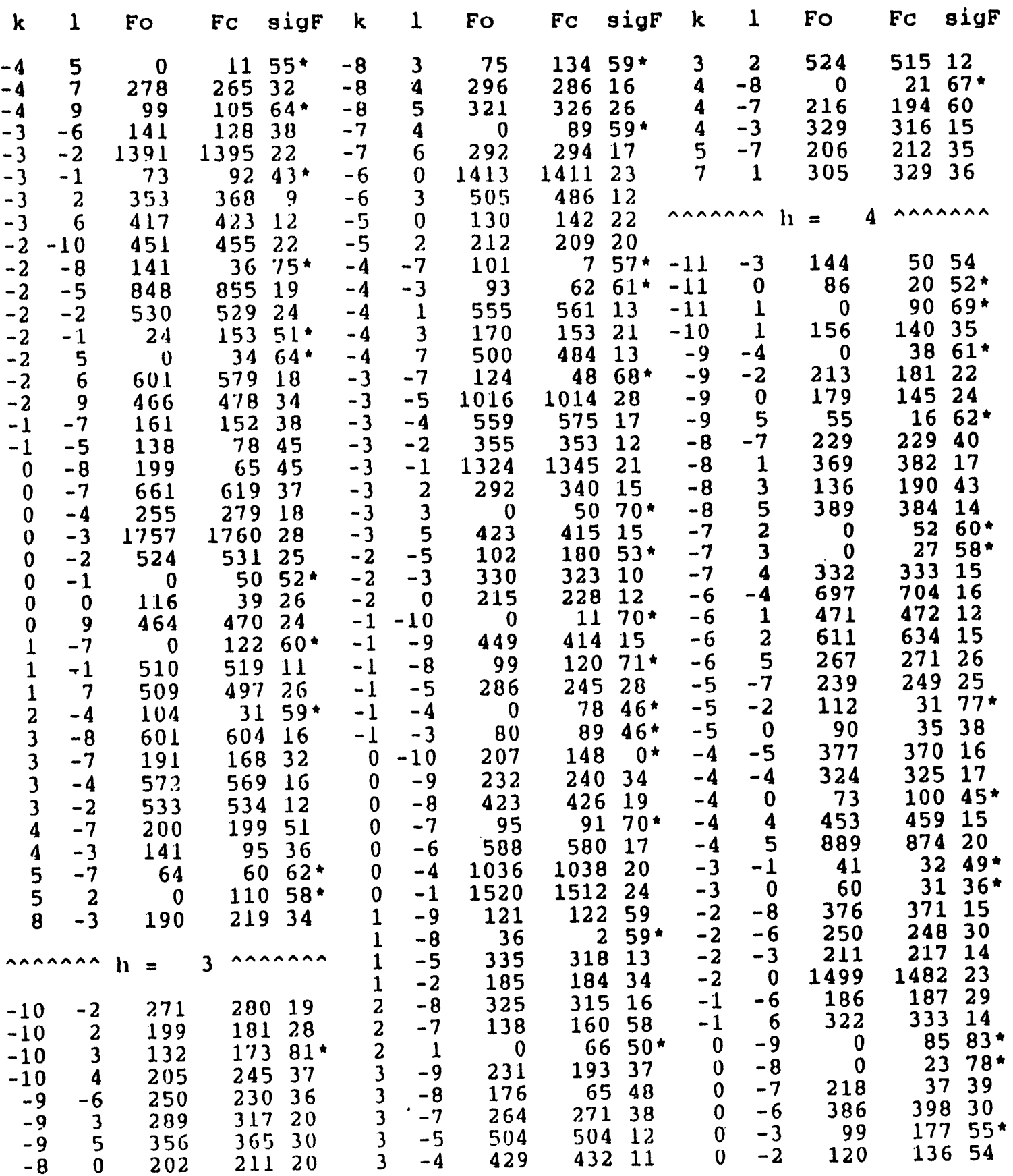




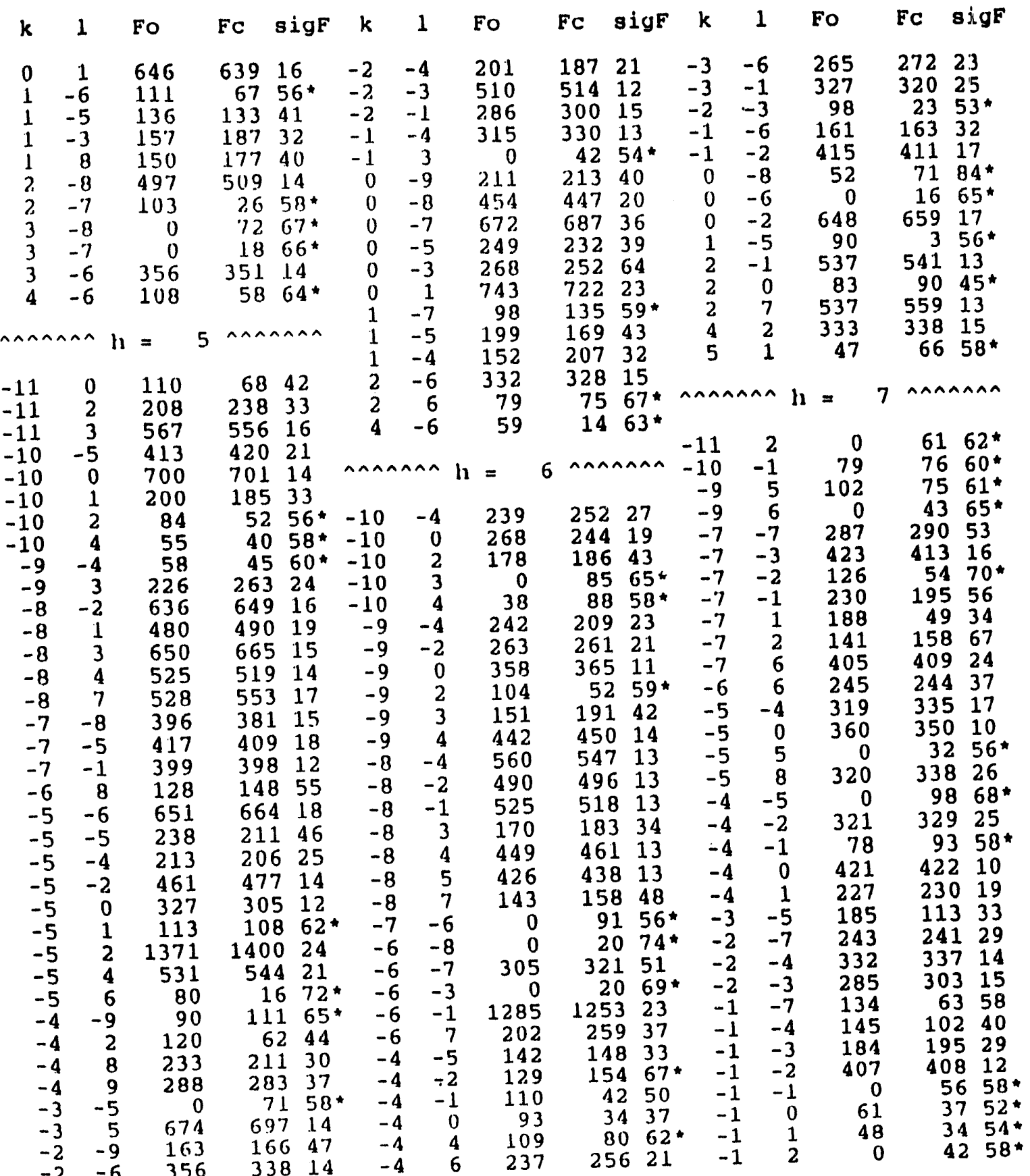




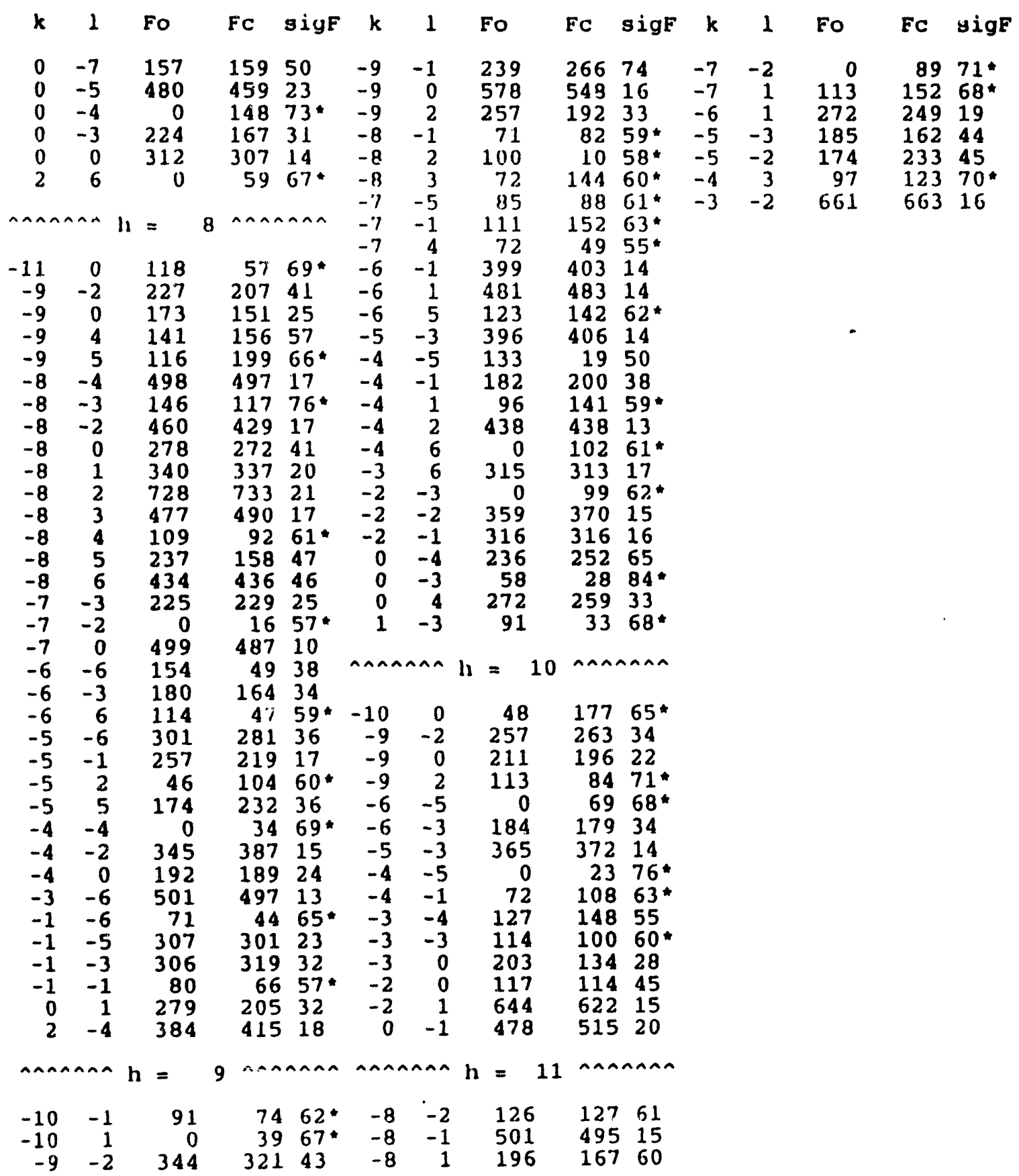

* indicates unobserved reflection 
Observed and calculated structure factor amplitudes $(x 10)$ for $\mathrm{ZrNi}_{1.5} \mathrm{Ti}_{0.5}$

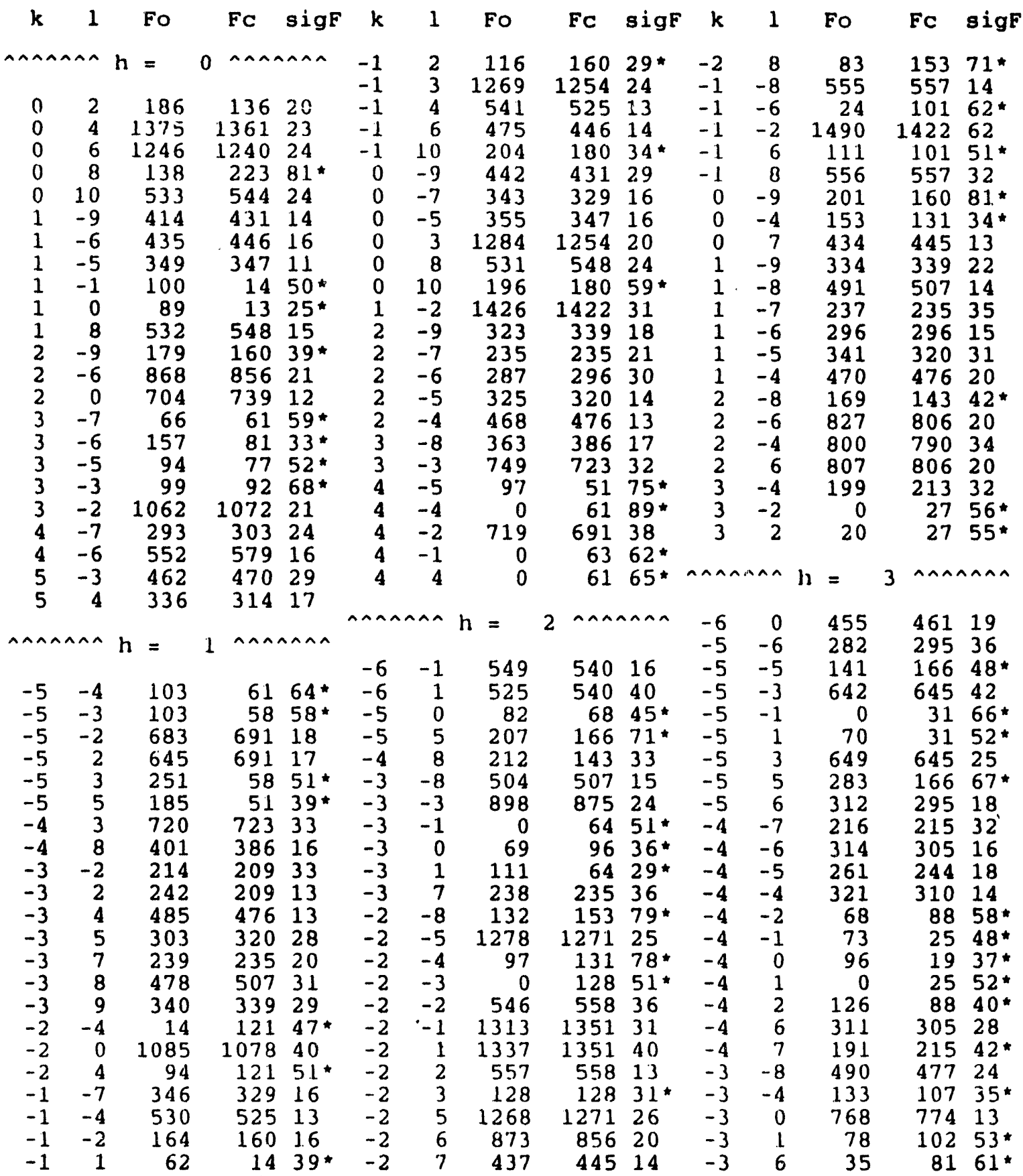




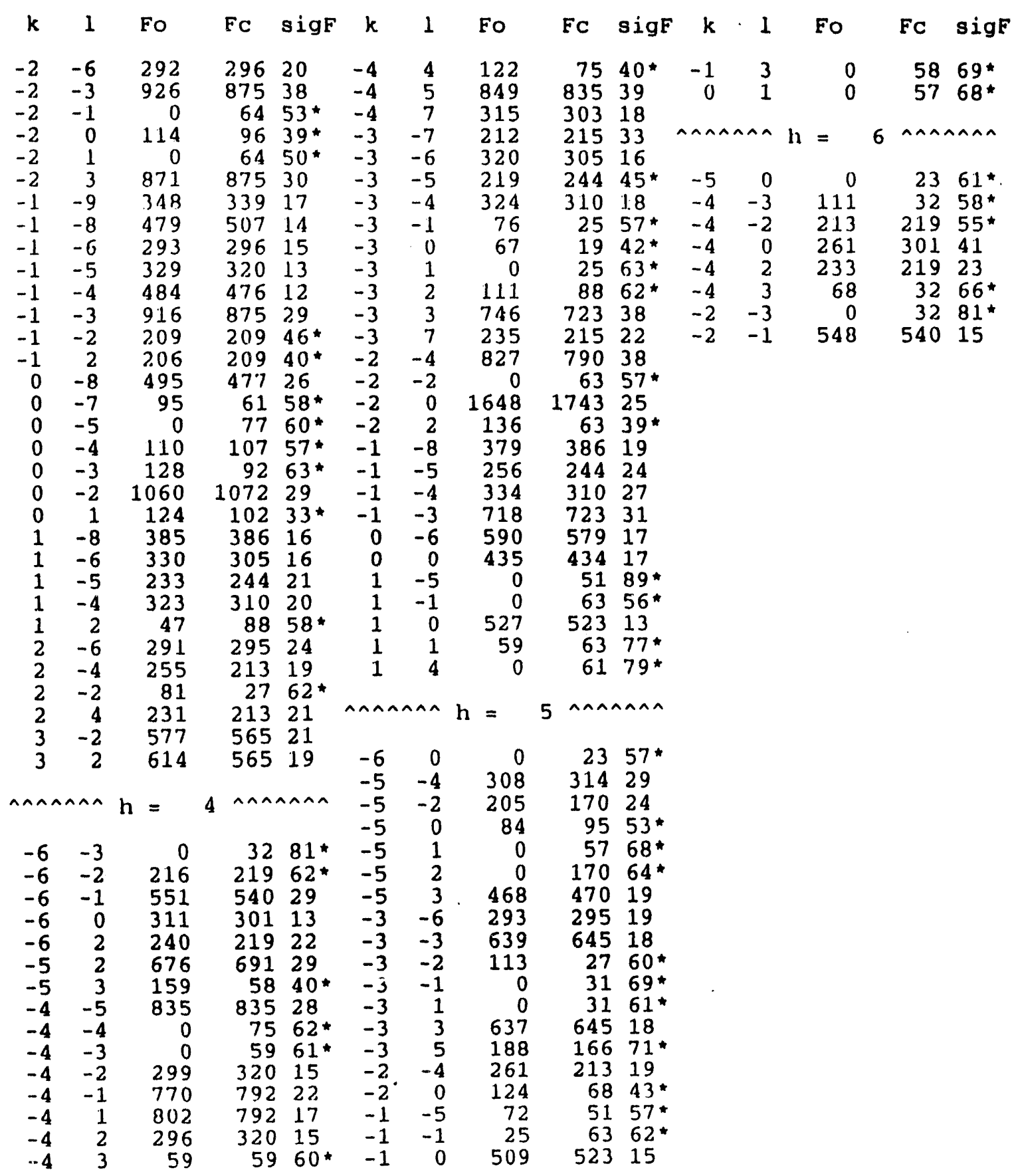

* indicales unubserved reflection 

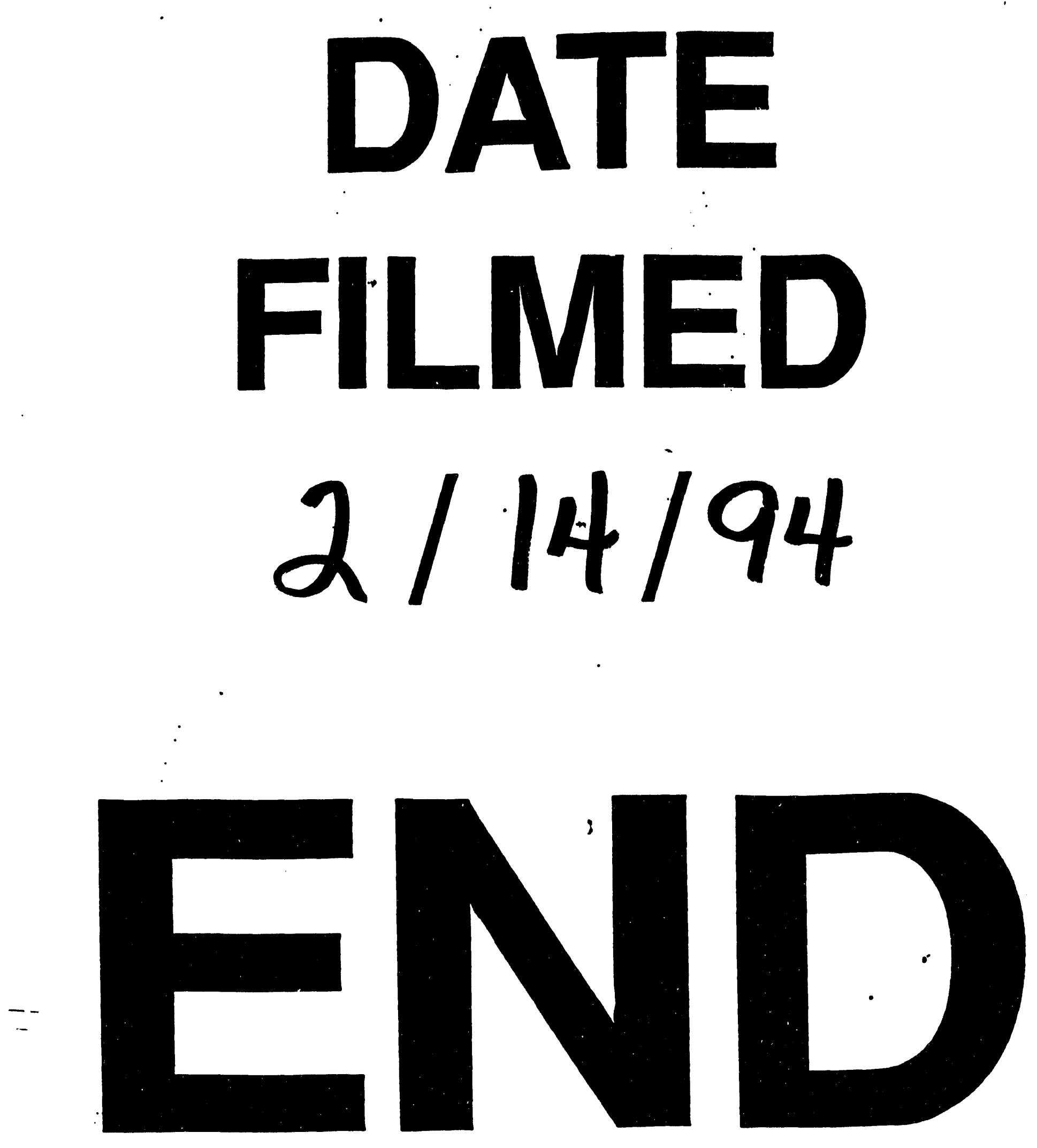
